
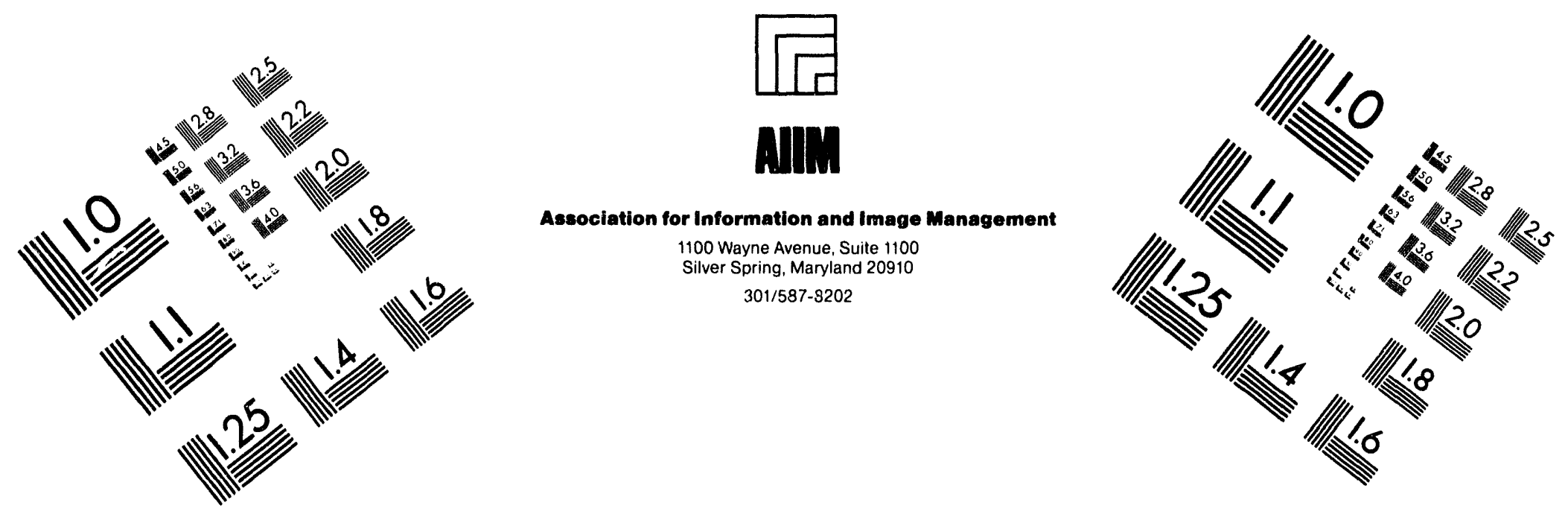

\title{
Centimeter
}

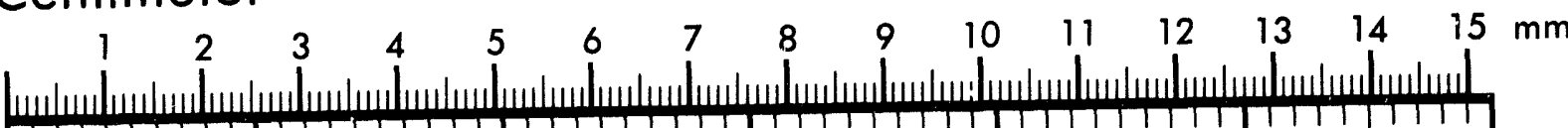
|ய1 Inches
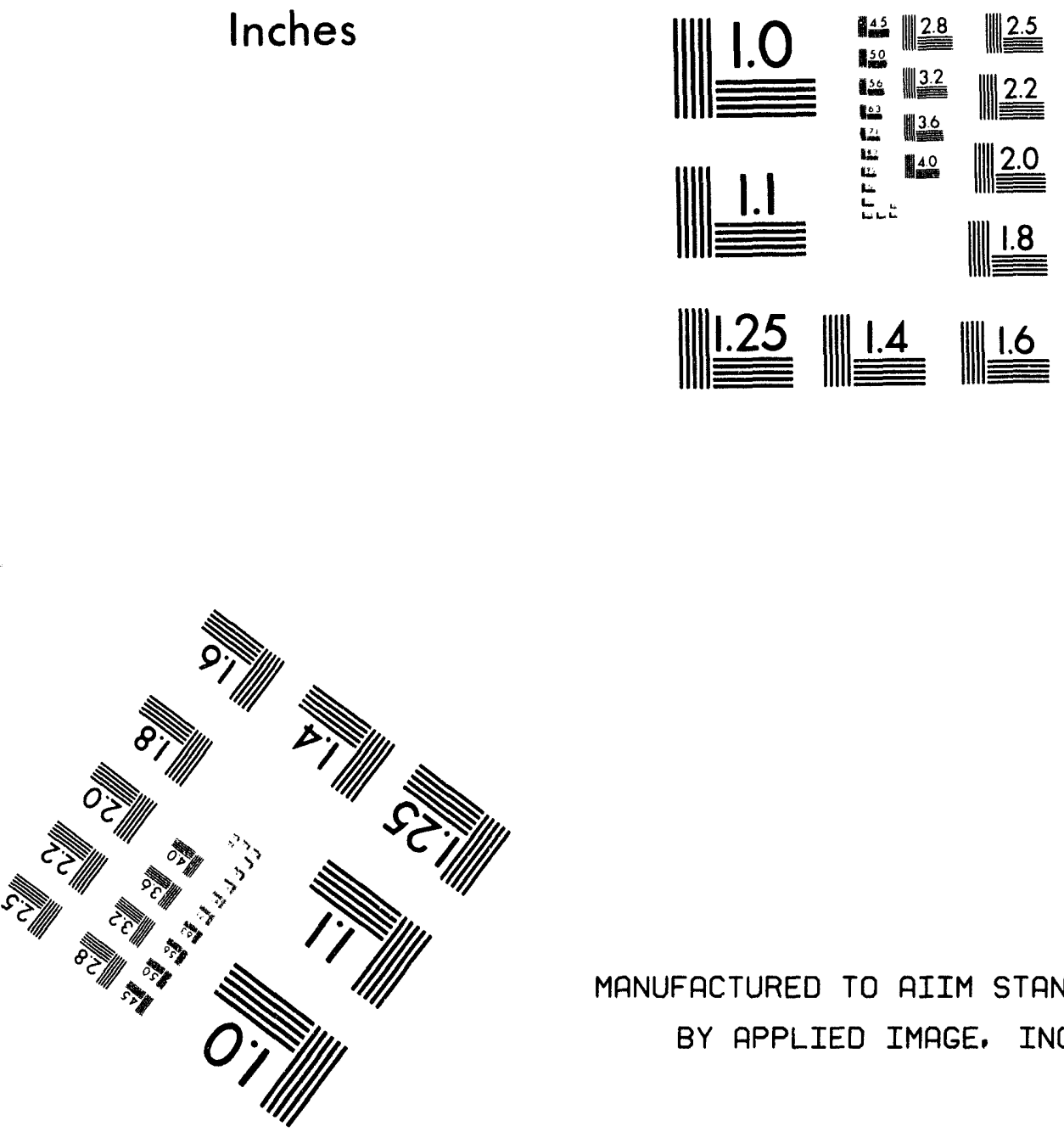

MANUFACTURED TO AIIM STANDARDS

BY APPLIED IMAGE. INC.

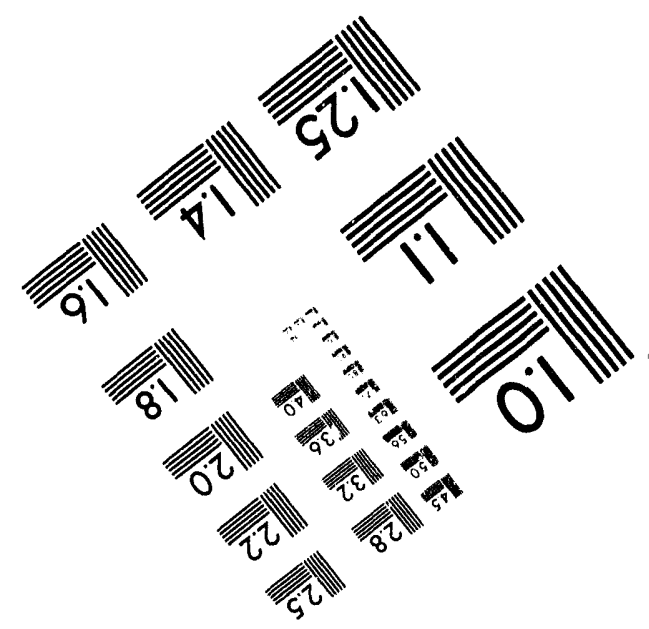



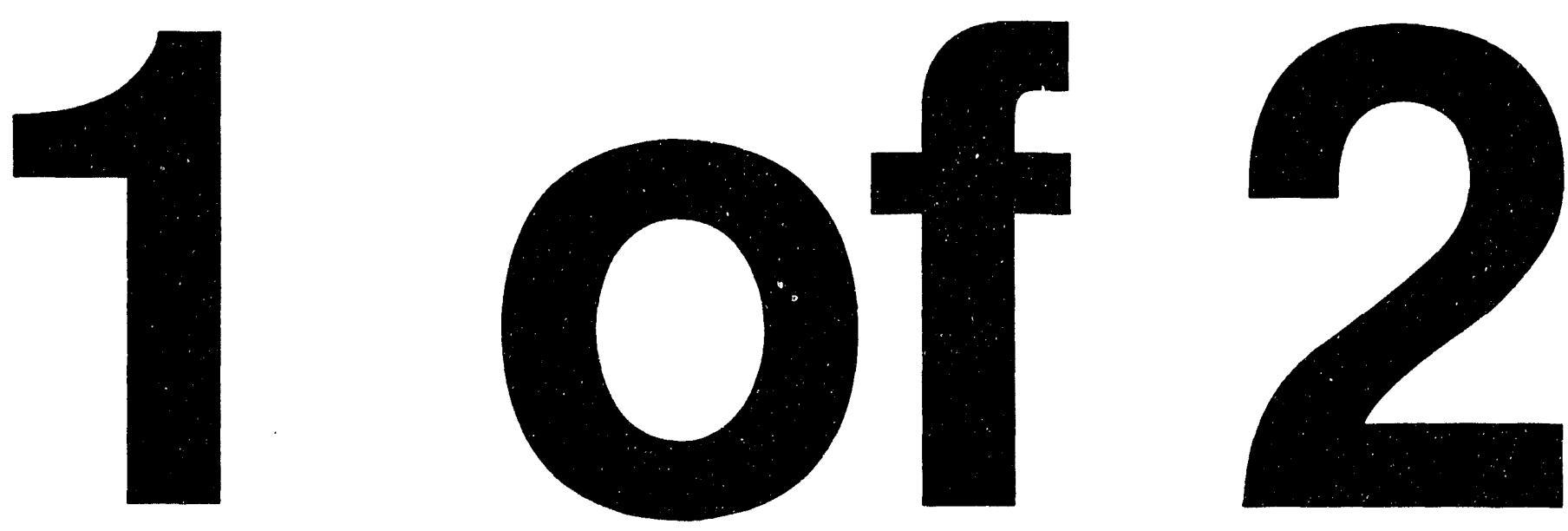
WSRC-TR-94-0328

\section{COMMERCIAL INTEGRATION AND PARTNERING AT SAVANNAH RIVER SITE}

by

Steole, J.R.

Westinghouse Savannah River Company

Savannah River Site

Aiken, South Carolina 29808

Babione, R.A.

SCIENTECH, Inc., ID, USA

Shikashio, L.A.

SCIENTECH, Inc., ID, USA

Wacaster, A.J.

SCIENTECH, InC., ID, USA

Paterson, A.D.

SCIENTECH, Inc., ID, USA

This paper was prepared in connection with work done under the above contract number with the U.S. Department of Energy. By acceptance of this paper, the publisher and/or recipient acknowledges the U. S. Government's right to retain a nonexclusive, royalty-free license in and to any copyright covering this paper, along with the right to reproduce and to authorize others to reproduce all or part of the copyrighted paper. 


\section{DISCLAIMER}

This report was prepared as an account of work sponsored by an agency of the United States Government. Neither the United States Government nor any agency thereof, nor any of their employees, makes any warranty, express or implied, or assumes any legal liability or responsibility for the accuracy, completeness, or usefulness of any information, apparatus, product, or process disclosed, or represents that its use would not infringe privately owned rights. Reference herein to any specific commercial product, process, or service by trade name, trademark, manufacturer, or otherwise does not necessarily. constitute or imply its endorsement, recommendation, or favoring by the United States Government or any agency thereof. The views and opinions of authors expressed herein do not necessarily state or reflect those of the United States Government or any agency thereof.

This repon has been reproduced directly from the best available copy.

Available to DOE and DOE contractors from the Office of Scientific and Technical Information, P. O. Box 62, Oak Ridge, TN 37831; prices available from (615) $576-8401$.

Available to the public from the National Technical Information Service, U. S. Department of Commerce, 5285 Port Royal Rd., Springfield, VA 22161 


\title{
COMMERCIAL INTEGRATION AND PARTNERING AT SAVANNAH RIVER SITE
}

\author{
Prepared for: \\ Westinghouse Savannah River Company \\ Waste and Environmental Remediation Programs \\ Savannah River Technology Center
}

John L. Steele

Robert A. Babione*

Andrew D. Paterson*

Laura A. Shikashio*

Arthur J. Wacaster*

i. ne 1994

This work was supported by the U.S. Department of Energy, Environmental Management Office of Technology Development.

* SCIENTECH, Inc. 
John L. Steele

Robert A. Babione*

Andrew D. Paterson*

Laura A. Shikashio*

and Arthur J. Wacaster*

Savannah River Technology Center

Publication Date: June 1994

Westinghouse Savannah River Company Savannah River Site

Aiken, SC 29808

* SCIENTECH, Inc., 1585 N. Skyline Drive, Idaho Falls, ID 83402 


\section{TABLE OF CONTENTS}

Page

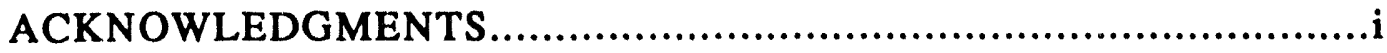

EXECUTIVE SUMMARY ............................................ ii

1. CURRENT SITUATION AT SAVANNAH RIVER SITE
A. Technology Development Program ..................................1-1
B. Review of SRTC Technology Development Program ..................1-8
Overall Recommendation .........................................1-8
Recommendations for SRTC.....................................1-8
C. Key Consideration at SRS ......................................... 1-11
Regional Strengths and Weaknesses ........................... 1-11
Critical Issues for Improving Industry Involvement.................... 1-11
Suggested Short Term Commercialization Project Criteria .......... 1-11
Possible Multi-track Funding Categories for Industry Projects ...... 1-12
Scenario....................................................... 1-12

2. COMMERCIAL INTEGRATION

A. Overview .........................................................2-2

B. Evaluation/Screening Processes ......................................2-3

C. Commercial Success Criteria and Evaluation Methodology ...............2-8

Qualitative Commercialization Success Factor Assessment ..............2-8

Quantitative Commercial Success Constraint Analysis

Criteria and Methodology ...................................... 2-10

3. PARTNERSHIPS

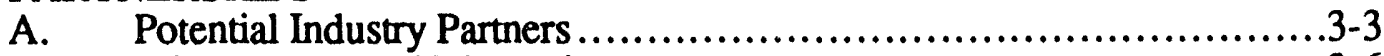

B. Private Investors' Viewpoints .......................................

Types of Investors - The Current Environment ......................3-6

Interest in Funding Development of Technology .....................3-7

Perceptions of DOE Interest in Cost-Shared Development ............3-8

Venture Capital Ratings of Industry Segments.......................3-8

Examples of Acquisitions in Environmental Industry ...............3-9

C. Regional (South Carolina, Georgia) Associations........................ 3-11

Introduction...................................................... 3-11

Samples of Existing Organizations ............................... 3-11

Discussion of Organizational Alternatives ....................... 3-13

4. INDUSTRY PERSPECTIVE

Introduction ..........................................................4-2

A. DOE Industry Roundtables...........................................

Major Issues Raised/Past Problems ..............................4-3

What an M\&O/National Lab Can Do ................................4-5

Successful Commercialization Is........................................4-7

Summary Points .............................................4 


\section{TABLE OF CONTENTS (Continued)}

B. Perspective from Another Region (WGA) ........................ 4-10

Major Recommendations to DOE ................................... 4-10

Poll and Analysis .............................................. 4-11

What is Successful Commercialization................................ 4-12

Barriers/Incentives from Company/Investor Perspective ........... 4-13

5. SAMPLE IMPLEMENTATION PILOT PROGRAM

A. Piloc Programs Concept ..........................................5-2

B. Example: Water Resources Technology Center.........................5-3

APPENDICES

APPENDIX 1. SUCCESS FACTORS IN TECHNOLOGY DEVELOPMENT

APPENDIX 2. CONSTRAINT ANALYSIS FOR ASSESSMENT OF BUSINESS RISKS

APPENDIX 3. PROTECH OVERVIEW

APPENDIX 4. VALLEY OF DEATH

APPENDIX 5. PUBLISHED EXCERPTS 


\section{ACKNOWLEDGMENTS}

The authors wish to express their appreciation to the Office of Techno'ogy Development, U.S. Department of Energy, for their sponsorship of this work, and specifically Dr. Clyde Frank, for his vision and leadership in bridging the gap from technology research to technology commercialization. But most of all, for his persistent encouragement to keep reaching for implementation--the true measure of success.

The development of our criteria in Section 2 was partially based on the earlier work of Dr. Bruce Merrifield, Wharton Business School; and he graciously consulted with us on our new developments.

Appreciation is also due to Ms. Cherie Miskin-Dees, Ms. Patti Rupert, and Ms. Beth Burgoyne of SCIENTECH for their diligent and courageous efforts in preparing the text and graphics for this report and for their editing proficiency that made this report more accessible to the reader. 


\section{EXECUTIVE SUMMARY}

"In the current global war for competitive advantage, size and weight will no longer get you into the winner's circle. Fast-moving, customer-driven entrepreneurship will. We've got to learn to do less, not more; keep it small, personal, and simple." --Larry Farrell, Searching for the Spirit of Enterprise: Dismantling the Twentieth-Century Corporation.

Savannah River Site (SRS), particularly the Savannah River Technology Center (SRTC) with the experience from the first successful Integrated Technology Demonstration, can provide an excellent foundation for meeting DOE-EM's objectives with the new DOE-EM five focus area approach. With this in mind, SRTC established an activity to pursue full commercialization of environmental technologies. This resulted in forming a small "virtual corporation" of specialists that cut across organizational boundaries. This team collectively understands the gamut of commercialization issues for DOE, i.e., the small business and industry viewpoint, investor interests, DOE processes, commercialization barriers, and DOE and regional environmental and waste processing needs.

This report is an assessment of the status of commercialization at SRS and provides recommendations for enhancement as well as some tools critical to implementation. In Chapter 1, a review was made of the current situation at SRS with regards to taking technology development to commercial fruition. This was done from the perspective of comparing it to known commercialization models and processes. It was found that SRTC already works through many of the steps in these processes. With integration and action-oriented efforts of the inclusion of business and market (i.e., commercial) factors, SRTC could become an aggressive, successful developer of commercialized technologies.

Commercial success criteria tools were developed with regards to integrating them with SRTC selection criteria to ensure that all critical factors are covered in technology commercialization project evaluations. This is found in Chapter 2, with the reference materials in the appendices. Use of the criteria not only identifies those projects with the greatest chance of success, but also provides a basis for prioritization of projects.

Private investors are very clear that their interest lies in funding commercial enterprises (actual businesses). not merely technologies. Mobilizing private capital is critical to real job growth and long-term economic development. Discussion of this is found in Chapter 3, along with the perspective from the investor community on the environmental market. Also, potential industry partners (technology-developer type companies) were identified that are willing to be involved with SRS' technology applications and regional development efforts. As another important component to success, regional support organizations were reviewed and evaluated. It was determined that there are numerous such organizations in the SRS two-state region, but they are, for the most part, policy, research, or education oriented. Actual commercial development of technologies is not a common occurrence, and, in some cases, not even intended. Small and minority business is an important aspect of regional growth and technology commercial success. It is well-known that enterprise and new jobs creation are overwhelmingly found in small businesses, not large corporations.

Industry's view of government required cost-sharing (e.g., CRADAs) is considered a "reverse subsidy"-- existing cost-sharing concepts give the impression that industry is expected to subsidize government programs. Also, the laws and regulations do not 
facilitate transfer and commercialization of techiologies from National Laboratories.

For a practical commercial perspective and recommendation, the input from the DOE-

EM and the Western Governors Association (WGA) industry roundtables are presented in summary in Section 4. The participants are president/CEO/vice-president levels representing a cross-section of categories in the environmental industry, and their experience and insights are noteworthy and relevant to technology commercialization implementation success. For instance, industry participants gave many suggestions and recommendations for the National Laboratories and M\&Os that could be constructive immediately, e.g., develop "reference" sites, give industry process benchmarks, provide opportunity assessments, help get public acceptance of technologies, etc.

A concept described in Section 5 is one option, in a field of possibilities, for true industry partnership, leveraging resources, and making the most of each participant's capabilities and involvement; SRS can establish a pilot program that would focus on a technical/environmental/waste need of not only DOE, but also the industrial/geographic region, such as the regional pulp and paper industry. A "Water Resources Technology Network" pilot is described as an example of what and how to implement and the roles for the participants. The objective is to provide a supporting market-pull regional network from industry and academia that would ensure the greatest chance of commercial success of technologies relevant to the region and technical focus. The overall objective is to achieve specific goals and actions for SRS without more planning or building of large-scale, time-consuming, and costly programs/organizations.

The excerpt material in the Appendices is representative of the direction of this Administration and of the thinking of the industry-investor world, as well as some comments from books, such as "Reinventing the Government". It is worth the time to understand implementation of the 10 steps in "Reinventing the Government", such as "concentrate on earning, not spending" and "fund outcomes, not inputs." The Appendices also provide reference and research material for further details of the basis, mechanics, and formulae for the commercial success criteria.

By including the additional principles of business and markets in its ongoing programs, the Savannah River Site can show the way to effective collaborative programs for research and engineering applications. It will help DOE-EM to more directly achieve its major cleanup priorities. SRS can become the leader in the DOE Complex for commercialization of internally or externally developed technologies that also support regional economic growth, i.e., specific results with actual spin-off businesses, expanded businesses, and new jobs. 
SECTION 1

CURRENT SITUATION AT SAVANNAH RIVER SITE 


\section{A. TECHNOLOGY DEVELOPMENT PROGRAM}

The Technology Development Program at Savannah River Site is very aggressive for the Department of Energy', having a successfully developed and implemented DOE Integrated Demonstration (for groundwater and soils remediation) to its credit. In fact, it was the first one of its kind for the Department of Energy. The current direction continues in this thrust:

- Technology commercialization and economic development is a high SRS priority;

- SRS resources have been enhanced and realigned to assure a focused site-wide initiative; and

- Acknowledgment of the DOE's Office of Technology Development's Regional Technology Initiatives as critical to success.

External organizations are being formed at SRS to integrate all activities affecting the future of SRS, and to establish a single focal point with outside stakeholders interested in SRS' future and in the economic development of the region.

SRS has a strategic vision to be recognized by its public and industrial customers, as an important contributing partner for innovative technologies which enhance regional and industrial competitiveness. Its strategic goal is to achieve, within three years, greater than $25 \%$ of SRS' R\&D program dedicated to dual-use technologies, technology development partnerships, and work for others. SRS hopes to achieve its vision by creating an enhancing culture, organizing for success, focusing on dual-use technologies, developing effective processes, enhancing privatization and regional economic development, and creating a network of alliances. SRS has some regional technology resources it established, such as the Savannah River Regional Diversification Initiative, Savannah River Research Campus and Southeastern Technology Center; and some proposed, such as the Southeastern Environmental Resource Alliance. These are intended to complement and augment the technology commercialization efforts at Savannah River Site. SRS has good partnerships with regional universities, most notably the South Carolina Universities Research and Education Foundation, with its focus on waste management and environmental restoration and member schools, such as the University of South Carolina, Clemson University, and the Medical University of South Carolina. SRS also has a link with ERDA (Education, Research and Development Association of Georgia Universities) and its focus on health and safety, and its member schools, such as the Georgia Institute of Technology, Clark Atlanta University, Georgia State University, University of Georgia, and Emory University.

The Savannah River Technology Center recognizes that it must continually adjust to changing needs, that flexibility, resourcefulness, and innovation in conducting its programs is the order of the day. SRTC has accomplished so far, besides developing the first DOE Integrated Technologies Demonstration, establishment of an active technology transfer program, with more than 500 disclosures in the pipeline and a dozen licenses granted, and it has established productive working relationships and meaningful projects with the regional universities. SRTC is working on expanded efforts in technology exchange, especially increased licensing efforts, and on more entrepreneurial efforts, such as partnering with industry, networking, and leveraging its resources.

The following three figures illustrate SRS' current structure and processes. 


\section{SRS Technology Utilization}

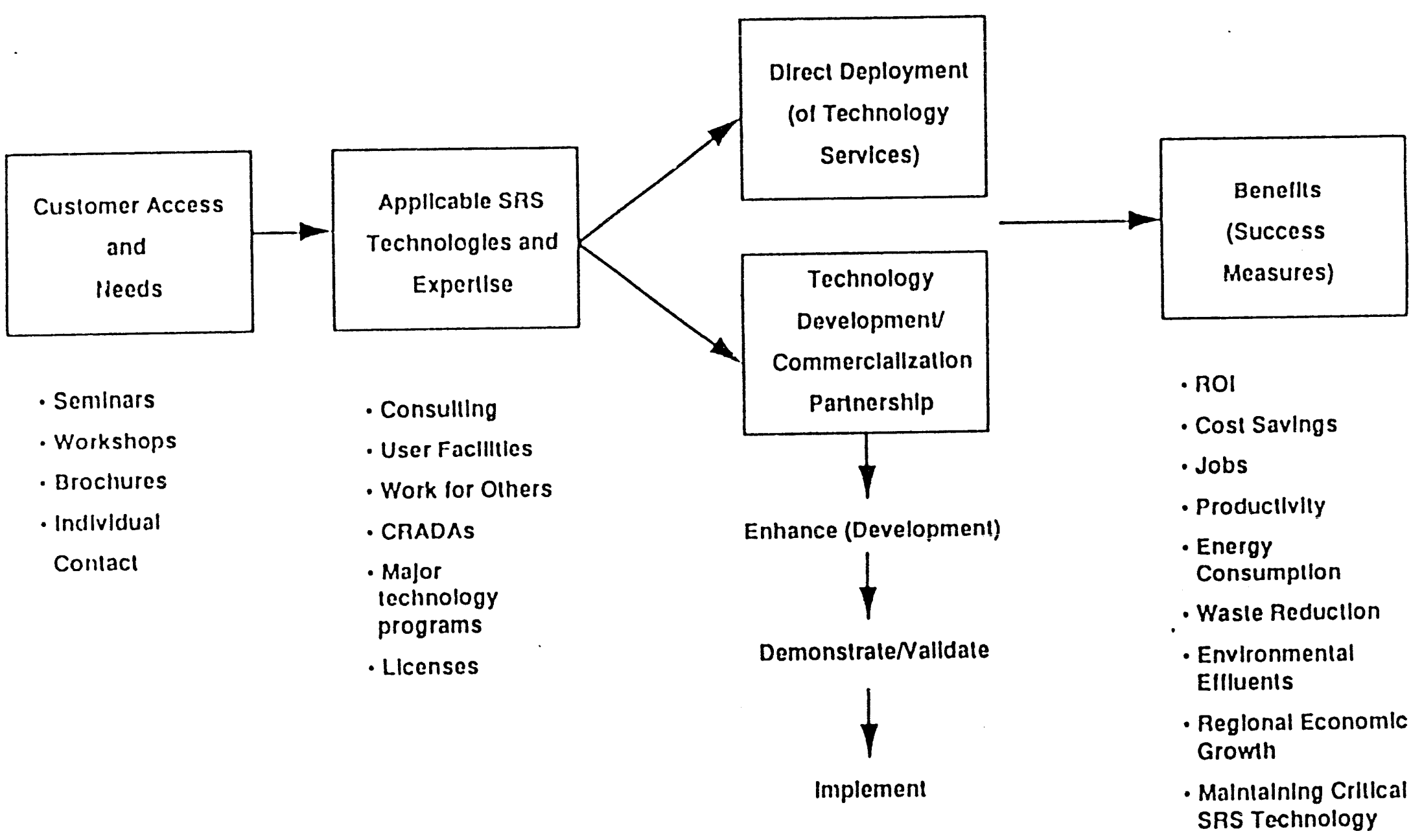


Stage 1: Funding Decision

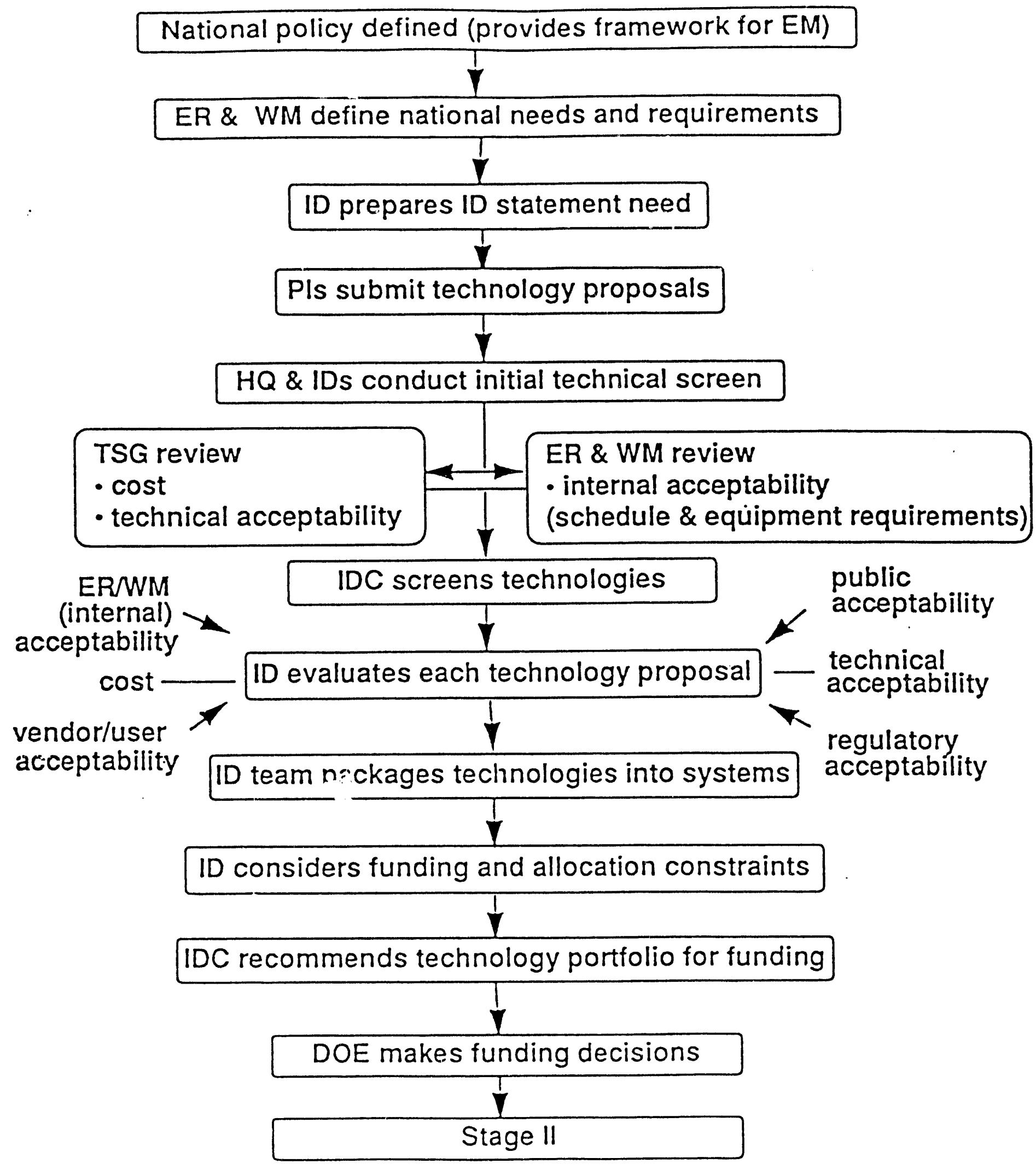


Slage 11: Preparation for Demonstration

0
กิ
0
0
3
$\overline{8}$
$\vdots$
$\dot{0}$

DOE makes funding decisions

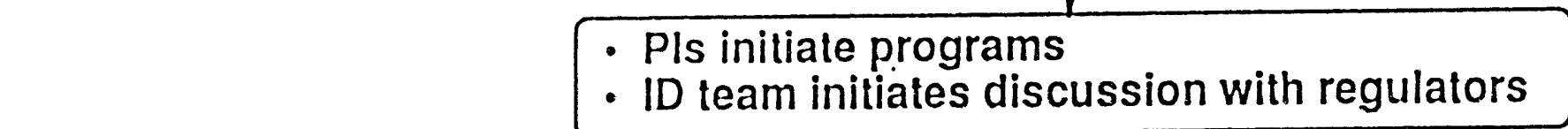

- ID team initiates discussion with regulators

Stakeholder review

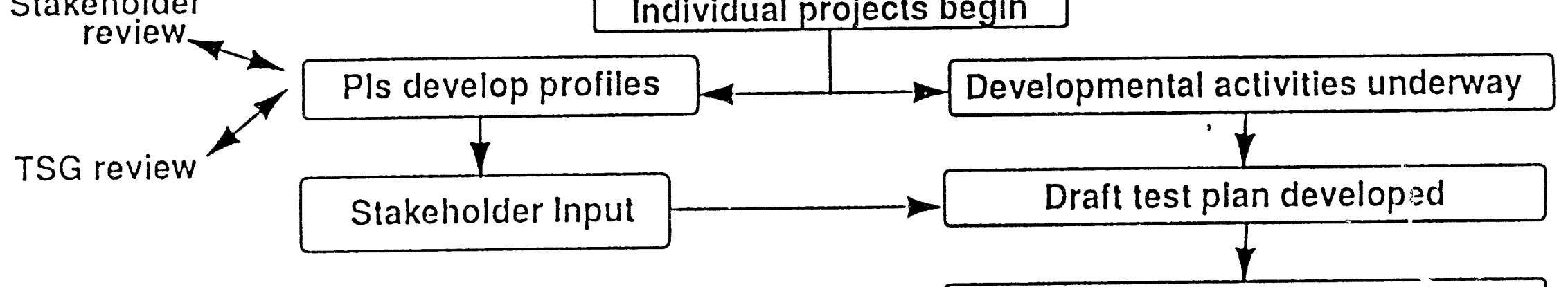

is

TSG/Demo operations revie: $v$

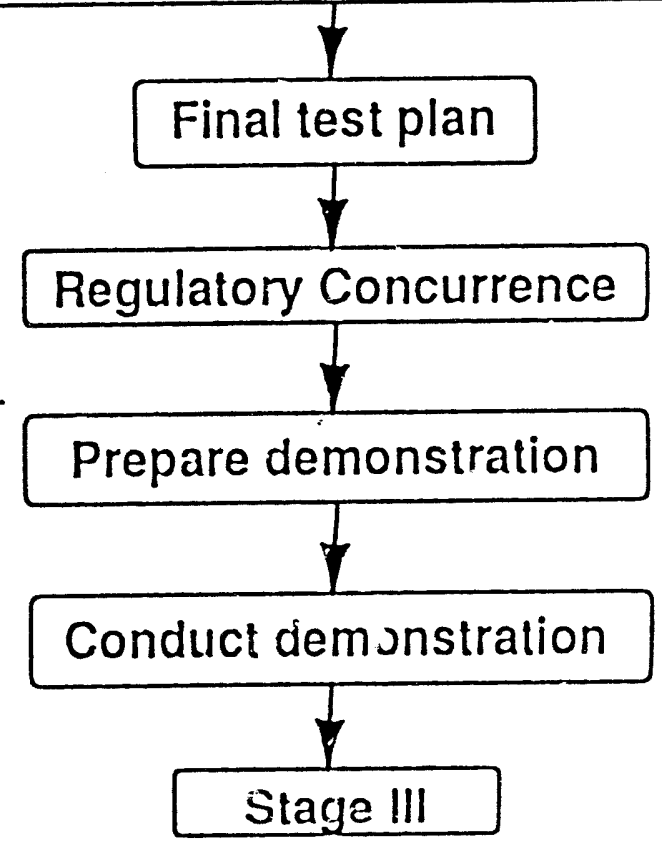


Stage III: Demonstration and Evaluation

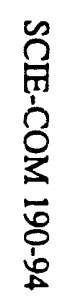

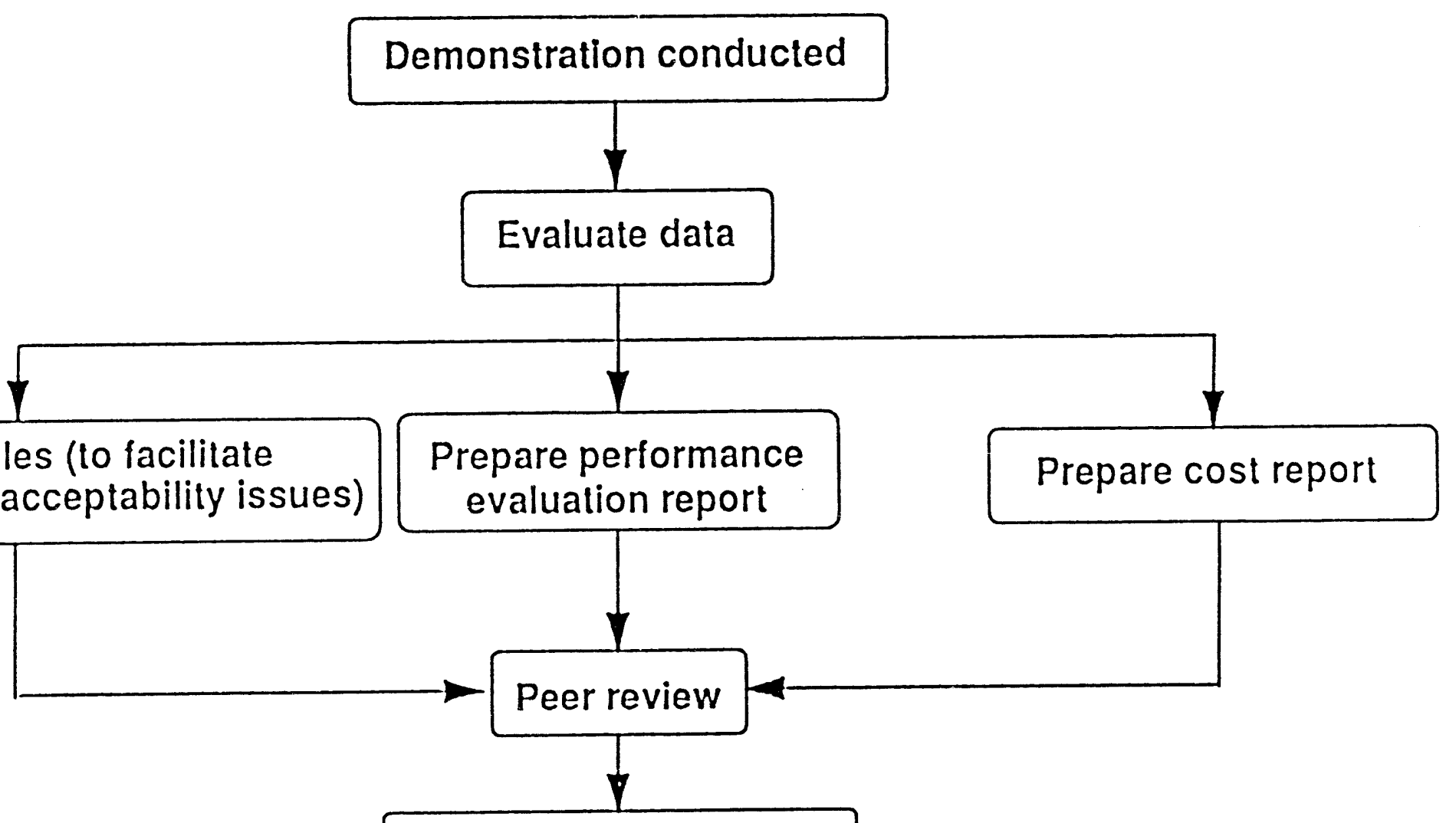

Update profiles (to facilitate assessment of acceptability issues)

র́

ID conducts evaluation

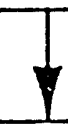

IDC makes recommendation on deployment

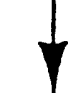

Technology implemented as appropriate 


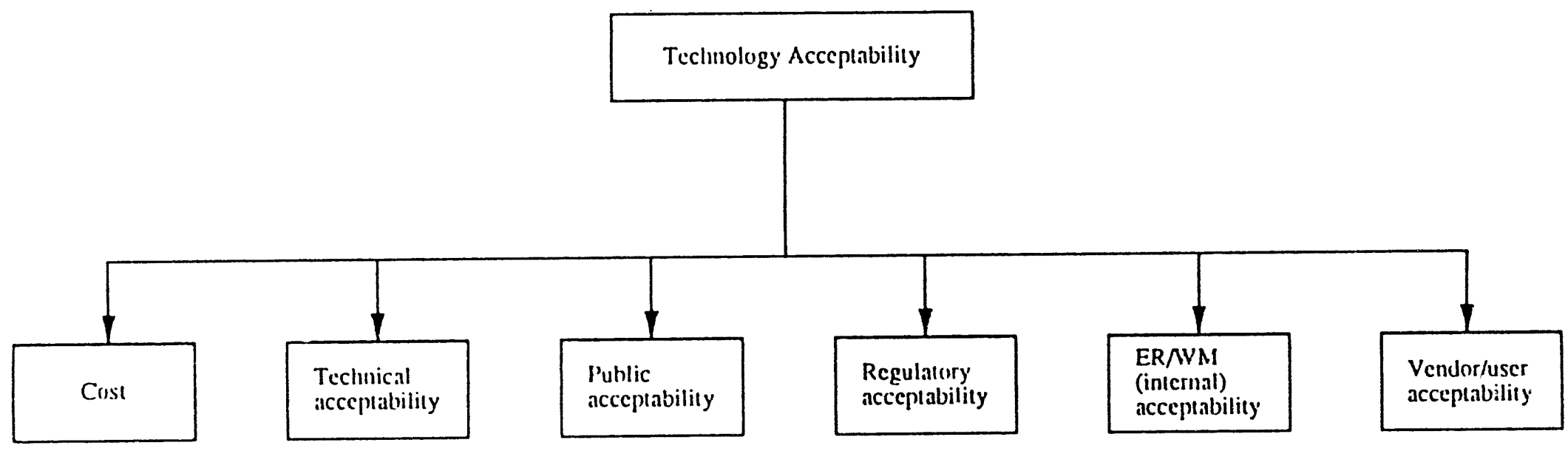




\title{
B. REVIEW OF SRT : TECHNOLOGY DEVELOPMENT PROGRAM
}

\author{
Based on Kickoff Session at SR Site and DOE-OTD Meeting Nov. 11/12, 1993
}

\begin{abstract}
A good foundation exists for commercialization; but an overall understanding of critical industry issues is lacking, notably knowledge of commercial markets and critical success factors for competing in them. This is understandable given the nature of a DOE M\&O contract, but to fully engage in commercialization effectively, an integration of commercial issues is vital.
\end{abstract}

\section{Qverall Recommendation}

The quickest route for SRS program managers to climb the learning curve on commercial issues is to experience them through case studies or actual implementation. Moving some actual projects through SRS programs in the next 6 months is crucial to demonstrate real payback on the $\$ 30$ million economic development funding and amplify technology commercial applications' mechanisms. In an era of "smart weaponry", program mechanisms can be finetuned after launch, based on experience and issues raised in real projects. Using the tools described in Section 2 will help SRS meet regulatory priorities, while attracting private sector cost-share on projects. Some portion of the $\$ 30$ million should flow to industry -- as an initial benchmark, DOE-OTD suggested $28 \%-30 \%$, or $\$ 8-\$ 10$ million over the next 12 months. These tools build on the existing WSRC program processes. SRS is a recognized site for running the first successful Integrated Demonstration. It covered technology development and regulatory issues and only needs to include business/market issues for full commercialization. Overall, the idea is to build on what is in existence; cover the mandatory and necessary, but do not "reinvent the wheel" or build another bureaucracy.

\section{Recommendations for SRTC Technology Development Program Mechanisms}

- Multi-Party Organizations

The multi-program foundation is well described, but it depends on overly large staffing and long ramp-up requirements, e.g., SERA, before projects with industry get started. The new federal budget realities dictate a more "entrepreneurial" approach where projects are developed from the outset and then staffing is built in support of projects, rather than in anticipation of commercialization projects. Avoiding a high staff up mode is especially important because the $\$ 30$ million is one-time funding, not ongoing support. The consolidated solicitation proved that if bids are offered, industry will come to SRS, rather than primarily adding staff at SRS to go out and chase industry.

- Small Business Outreach

This program is excellently led, and perhaps could augment the consolidated solicitation, and SBIR-type opportunities as vehicles for funding commercialization projects, particularly involving small and disadvantaged businesses. It also needs to ensure that its system includes high technology-based companies and potential technology developers.

- Industrial Partners

This program could be expanded to include user facilities in essence as a "fast-track CRADA" with local approval and less paperwork and delays. It could better define "industrial partners" to include consortia, associations, investors, and other private entities. 
- User Facilities

This needs to be better defined and correlated with the core competency study and tied in with the industrial partners program. If this can be coupled with regulatory priorities and onsite permitting, then it could be more valuable to industry.

- Consolidated Solicitation - Vendor Forum

This is a fairly novel procurement strategy, and judging by the response of over 1,000 proposals, one that elicited significant response from industry. However, it may be useful to augment the SRS technical merit analysis by looking at industry cost-share ("cost-share" is used in the full sense that if demonstrations are cost-shared, equipment capitalized, and investment made in the technology, then a successful demonstration should merit a performance contract, that industry can expect a return on investment through real sales), business potential regulatory priorities, and community acceptance to sort out proposals as follows:

(1) SRS could group each of the 85 abstracts into three categories of regulatory priority.

(2) An amendment to the solicitation in the highest priority categories could be issued to proposers asking for a one or two page response outlining cost-share and market potential. The response should also indicate whether a small/disadvantaged business is involved in the pre-proposal.

(3) The responses with the greatest cost share, market potential, and SB/DB involvement that also rank high technically, should represent very worthwhile projects that merit funding. Evidence of cost-share should also improve SRS competition for DOE funds. This process supports the achievement of the SRS Strategic Plan for Technology Transfer and Commercialization by offering some "quick. wins".

- Regional Technology Initiatives, Including University Consortia

A meeting with longstanding regional organizations should be arranged as soon as possible to discuss possible joint ventures such as SERA, specifically, the Southern States Energy Board and the Southern Governors Policy Group. These organizations could add considerable leverage to SRS initiatives. 


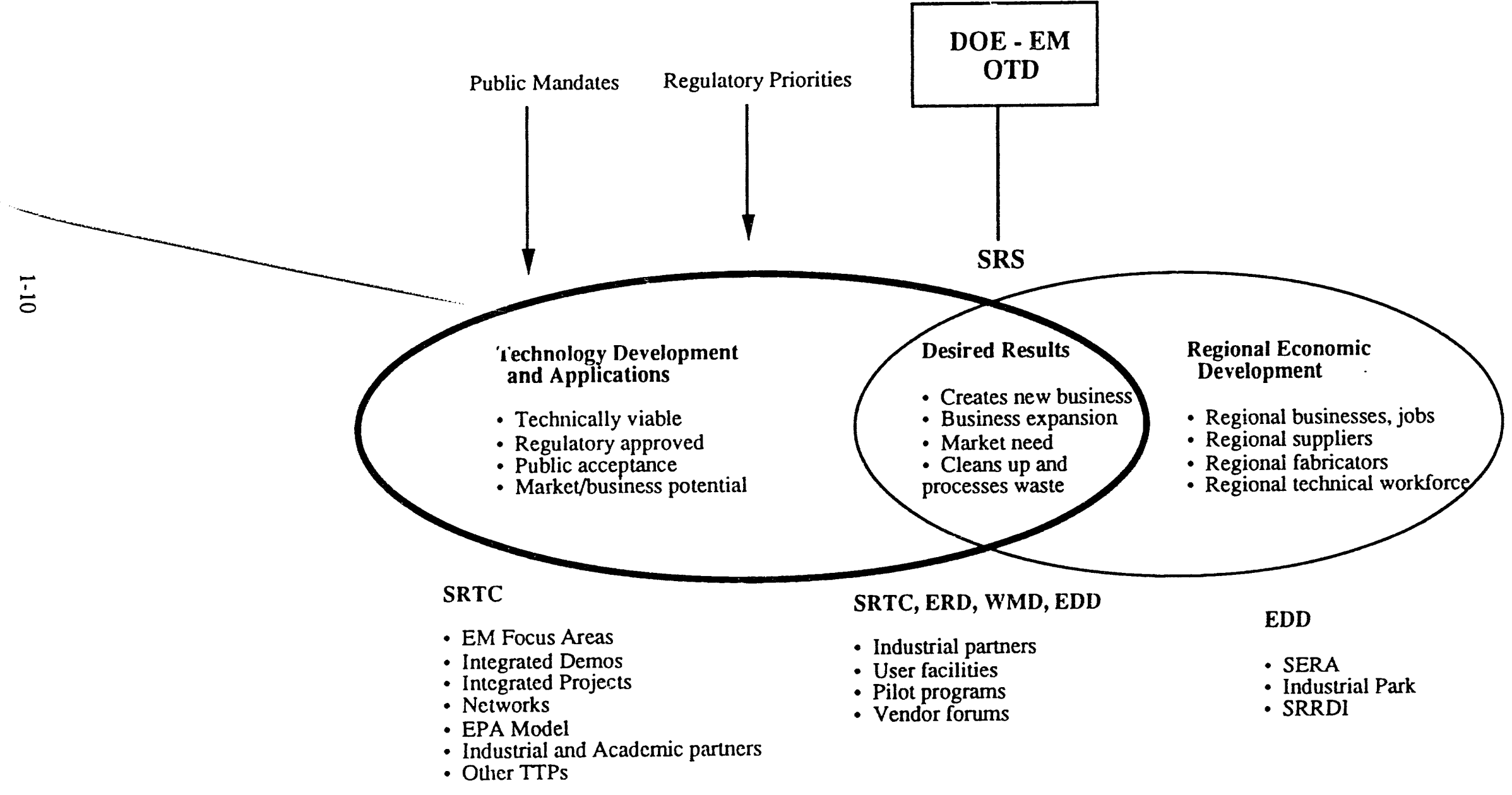


Figure 1.5. SRS and Technology Developrisent (Enhanced) Implementation of Advanced Environmental ER/WM Technologies

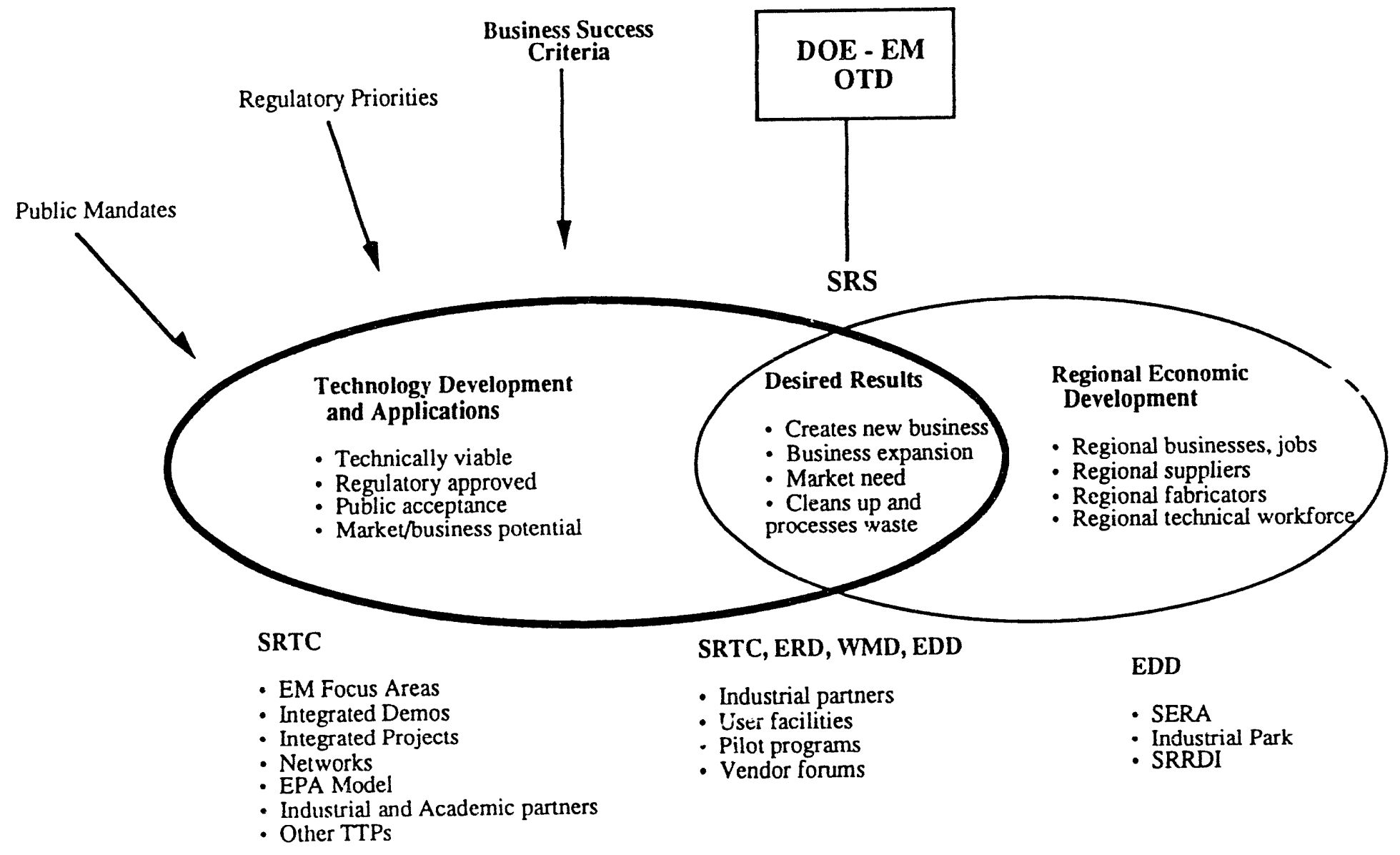




\section{KEY CONSIDERATIONS FOR TECHNOLOGY APPLICATION PROJECTS AT SRS}

\section{Regional Strengths and Weaknesses}

Commercialization mechanisms and projects should take into account SRS regional strengths and weaknesses.

Strengths

- Powerful, cohesive political clout

- Substantial annual DOE funding

- University programs already in place

- Lower operating costs in region

- Pro-business local/state attitudes

- Common environmental problems

- Attractive climate/place to live
Weaknesses.

- Lacks critical mass of high tech industry

- Budgets facing cutbacks, uncertainty

- Cumbersome procurement

- High cost to engage in SRS contracts

- Small local commercial markets

- Not-invented-at-SRS" syndrome

- Remote site for industry; hard to get to

Critical Issues for Improving Industry Involvement

- Fast response -- quick time to market with a quality product is crucial.

- Identified streamlined procurement pathway based on successful demonstration.

- Clear regulatory buy-in for streamlined permitting and larger regional market.

- Interfaces with other DOE sites as well as DoD projects.

- Recognition of private sector investment as cost-share from industry.

- Avoid technology-driven pet projects that do not meet the objective commercialization criteria.

- Start with what's already commercially available.

- Ownership of technology and protection of intellectual property rights.

Suggested Short-term Commercialization Project Criteria (not exhaustive):

- Technology meets a high environmental priority for SRS.

- The market applications for the technology are broader than SRS, and preferably are high needs for both DoD and industry (e.g., subsurface characterization, portable instruments, in-situ treatment). The SRS Core Competency study is a useful guide for this.

- Potential for successful demonstration is relatively high, i.e., the technology is at fullscale already and possibly has some units already in the field.

- Private sector funding has been invested already as evidence that the product represents a business, not just a technology. This would be a particularly good screen for SRS technologies; without industry interest, it may just be another "sandbox" project.

- Projects utilize local resources and small and disadvantaged businesses (SDBs).

- Use of regional suppliers/fabricators. 


\section{Possible Multi-track Funding Categories for Industry Projects}

A multi-track process can be applied to the recent SRS Vendor Forum to provide flexibility to attract various industrial partners and efficiency in reaching programmatic results. Types of multi-track funding are as follows.

A) No Cash: Company provides equipment to SRS on its own funding as costshare. SRS conducts tests and provides a prompt analysis of the results.

B) Some Cash: SRS pays company for prototype equipment on cost-share basis. SRS conducts tests and provides a prompt analysis of the results.

C) All Cash: Company is a small or disadvantaged business, and SRS provides an SDB set-aside contract to cover company costs of demonstration. SRS conducts tests and provides a prompt analysis of the results. Look to tap local project support such as SBICs, incubators, state programs, ARPA-RTAs.

D) Data Sharing: The company gets site performance data which is shared with ER and WM actual clean-up contracts.

\section{$\underline{\text { Scenario }}$}

SRS could take the following actions that would facilitate remediating the Site, attract industry's help, develop local economy, and be a model for other DOE sites:

- Separate out, and package remediation and non-high level waste processing work, from the work for which there are no answers right now, e.g., high level waste, and put it out on bids for the industry with existing technologies.

- With the contractor on site, as work progresses, there may be unanswerable questions related to the technology/process effectiveness; or questions of application beyond what it had performed before, differing site/environmental/waste conditions, etc. These questions of engineering or science would be separated from the remediation or waste processing work and turned over to SRTC to deal with, as a research/development effort. The ER/WM contractor continues with its job through completion or is stopped if there is a critical question to solve.

- If it is a critical problem, then that would take priority attention at SRS.

- If it is a side issue that needs technology development, it goes through the standard SRTC project selection process, such as TTPs.

This separates out the remediation and waste processing work that industry can take care of from the work that DOE and WSRC would be best equipped to solve, e.g., handling high-level radioactive waste. This would be the best use of all parties; each party has a specific nonduplicative role.

Remediation gets done; waste gets processed; and continuing research and development is meaningful to the DOE Environmental Restoration/Waste Management needs. 
SECTION 2

COMMERCIAL INTEGRATION 


\section{A . OVERVIEW}

This section describes the integration of commercial success evaluation and screening processes into the existing technology project evaluation process for the technology development/demonstration projects at the Savannah River Site (SRS). While processes for evaluating technology projects in areas such as technical performance and regulatory compliance are well established at SRS, mechanisms for evaluating project merit on the basis of probable commercial success are lacking. The incorporation of these commercial success evaluation processes will result in a more complete commercialization program at SRS.

Commercial success criteria and evaluation methods, resulting in numerous technology commercialization business start-ups, were adapted for incorporation into the SRS technology programs. Commercial success evaluations, using the criteria in this report, can be applied at various stages of new technology development to help in funding and continuation decisions, as well as providing guidance on specific commercialization projects for improving the likelihood of success. The actual success criteria used will depend on the stage of development of both the technology and the private sector company that intends to commercially market the technology.

Part B of this section describes the different evaluation and screening processes and how they relate to the overall technology development and commercialization process.

Part $\mathrm{C}$ of this section provides commercial success evaluation criteria and methodology. 


\section{B . EVALUATION/SCREENING PROCESSES}

Figure 2-1 shows the recommended decision making framework for the SRS technology development and commercialization process. Technology project acceptability is dependent on acceptability in three areas: technical, stakeholder (regulatory and socio-political), and industrial (commercial success). Accordingly, it is recommended that SRS technology development/commercialization projects be evaluated at appropriate stages of conception and completion in these three areas, as amplified below:

- Technical Performance -- Is the technology expected to perform as required at an acceptable cost? How does it compare with other technologies in performance and cost?

\section{- Stakeholder Acceptability}

- Regulatory Priorities and Issues -- Will the proposed technology allow SRS and regional clean-up schedules to be met? Can technology specific regulatory requirements such as permitting, be met in a cost effective manner for SRS, as well as, external market applications?

- Socio-Political -- Are program specific economic development objectives (i.e., growth of private industry in surrounding community/region) expected to be met if commercial success is achieved? Is the project consistent with public interests and is there a positive public perception?

\section{- Industrial}

- Commercial Success -- Is the private sector technology company expected to be successful in commercial marketing of the technology?

Figure 2-2 shows how these evaluations and screening activities fit into the technology development and commercialization process.

This process is fairly generic and applies to the desired environmental technology development and commercialization process at SRS. Critical points for performing these evaluations are Steps 4, 5, 8, and 9 as indicated in Figure 2-2. In Step 4, candidate technologies are evaluated in all three areas to determine appropriateness for on-site implementation and commercialization support. In Step 5, stakeholder (regulatory and socio-political) issues associated with the specific environmental need are evaluated to identify barriers in these areas that need to be addressed before continuing with problem solution. In Step 8, technology demonstration proposals (which may include internal SRS developed technologies or technologies from external sources, and, by definition, include participation by a private sector company) are evaluated in all three areas as part of the basis for proposal acceptance. In Step 9, the final results (and interim results if appropriate) of the on-site demonstration projects are evaluated in all three areas to determine appropriateness for continued funding, as well as, to identify weaknesses that can be corrected.

Table 2-3 provides information on criteria, resources, and application tools for each of the three evaluation areas. Interdependency of the different evaluations requires a partially iterative process (e.g., stakeholder and industrial cross-feed each other, industrial is dependent on the results of the other evaluations, etc.). Commercial success evaluation tools are described in Part $\mathrm{C}$ of this section.

There are various sources of information for supporting the application of these tools. For example, ProTech, as described in Appendix 3, is a DOE data system that focuses on technologies 
from the Integrated Demonstrations. ProTech includes detailed information profiles on many innovative and existing "baseline" technologies associated with the Integrated Demonstrations. These profiles are organized in accordance with criteria that support technical performance and stakeholder acceptability evaluations. 
Figure 2-1.

Recommended Decision Making Framework for the SRS

Technology Development/Commercialization Process

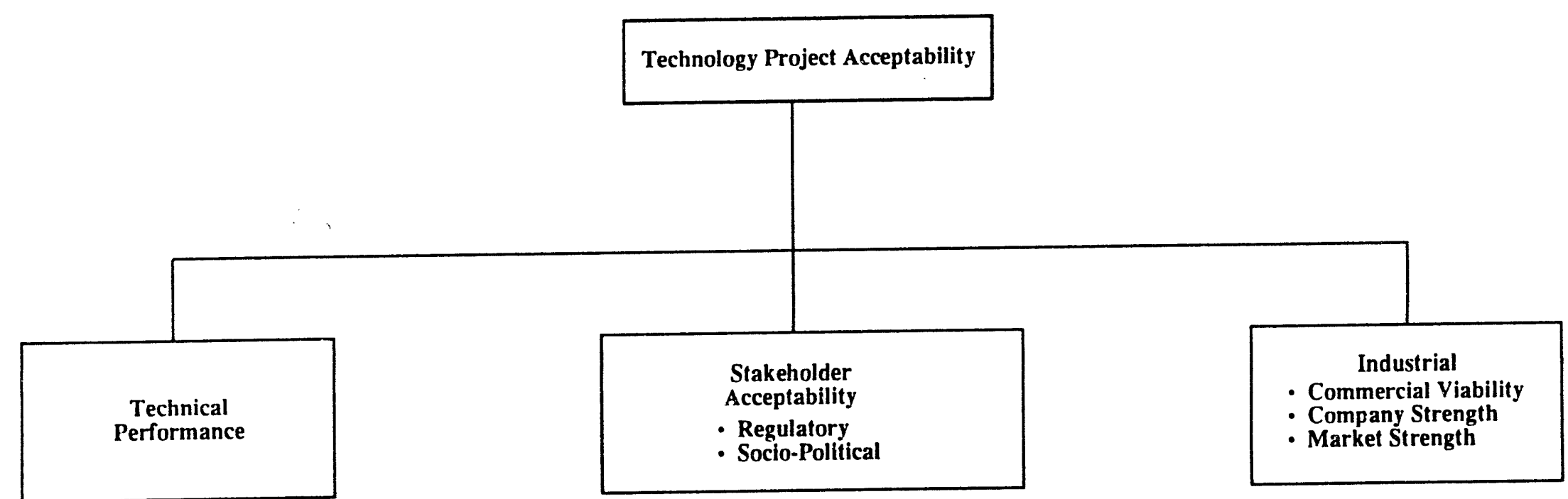


Figure 2-2.

Technology Development/Commercialization

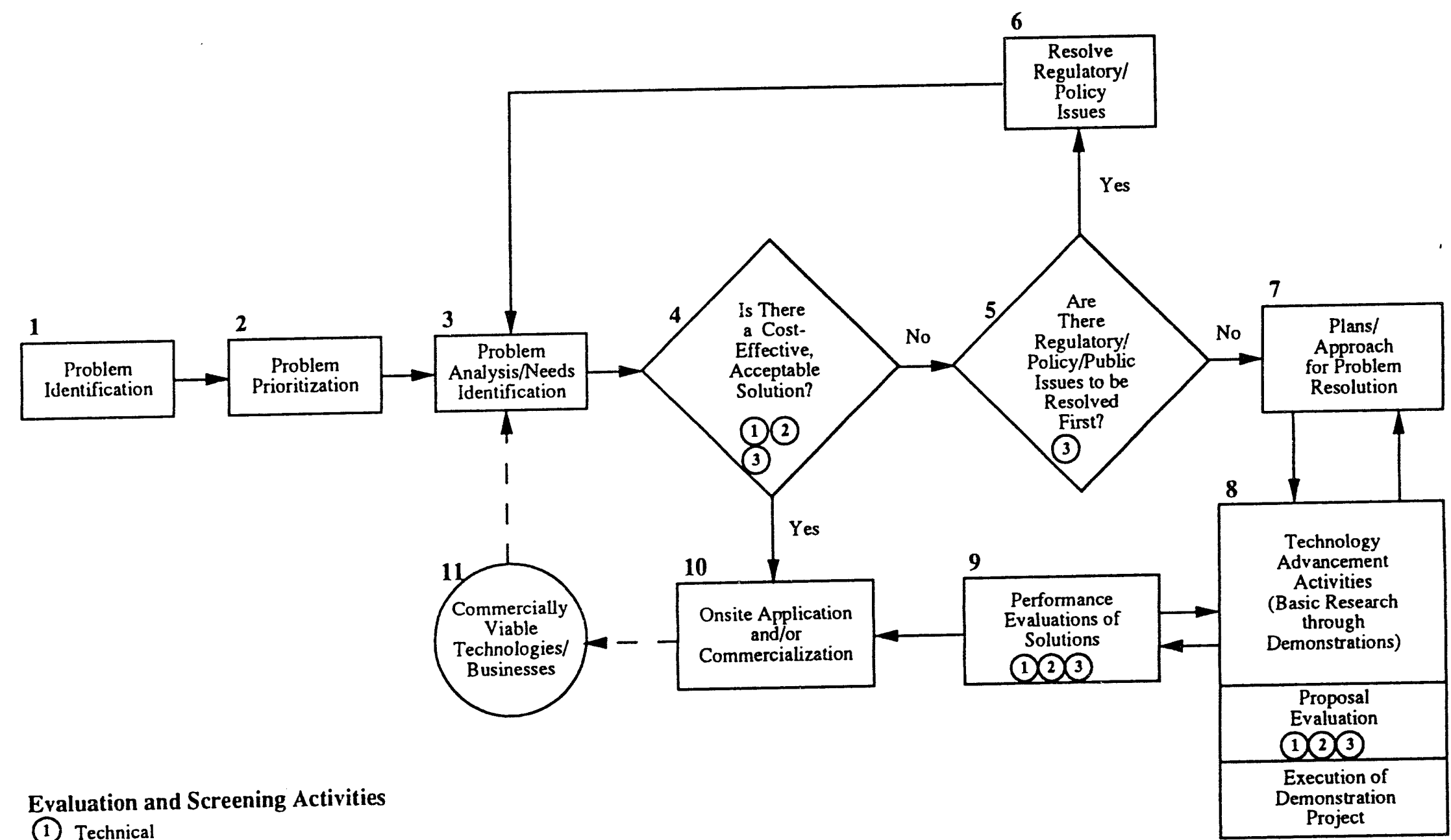

(1) Technical

Based on DOE-EM Action

(2) Industrial

(3) Stakeholders

Plan, January 25, 1994 
Table 2-3.

Screening Criteria and Resources

\begin{tabular}{|c|c|c|}
\hline Evaluation & Criteria & $\begin{array}{l}\text { Resources/Tools } \\
\text { (Not all-inclusive) }\end{array}$ \\
\hline $\begin{array}{l}\text { Technical } \\
\text { (Evaluation processes in } \\
\text { place at SRS) }\end{array}$ & $\begin{array}{l}\text { Performance } \\
\text { requirements defined in } \\
\text { Step } 3 \text { of Figure } 2-2 \\
\text { process. }\end{array}$ & $\begin{array}{l}\text { ProTech (technology } \\
\text { comparison data system } \\
\text { for DOE technologies } \\
\text { from ID's) } \\
\text { EnviroTRADE } \\
\text { (environmental } \\
\text { technology information } \\
\text { system under } \\
\text { development at Sandia } \\
\text { National Laboratories) } \\
\text { VISITT (EPA } \\
\text { Environmental } \\
\text { Technology Database -- } \\
\text { Report 542-R-93-001) } \\
\text { ATTIC (EPA on-line } \\
\text { information service) } \\
\end{array}$ \\
\hline $\begin{array}{l}\text { Stakeholder } \\
\text { - Regulatory } \\
\text { - Socio-Political } \\
\text { (Evaluation processes in } \\
\text { place at SRS) }\end{array}$ & \begin{tabular}{|l|} 
Regulatory priorities \\
defined in Step 2 of \\
Figure $2-2$ process. \\
Need specific and \\
project specific \\
regulatory issues may be \\
defined at various stages \\
including Steps $3,4,5$, \\
8 (based on proposal \\
information), and 9 \\
(based on information \\
gained during the on-site \\
demonstration project \\
execution) of the \\
Figure $2-2$ process. \\
Socio-Political \\
requirements defined in \\
Steps 3 and 5 of \\
Figure $2-2$ process. \\
\end{tabular} & $\begin{array}{ll}- & \text { ProTech } \\
\text { - Results of Commercial } \\
\text { Success Evaluation }\end{array}$ \\
\hline $\begin{array}{l}\text { Industrial } \\
\text { - Commercial Success } \\
\text { (Evaluation methodology } \\
\text { provided in Part C of this } \\
\text { section) }\end{array}$ & $\begin{array}{l}\text { Criteria have been } \\
\text { generically defined } \\
\text { external to specific SRS } \\
\text { requirements and } \\
\text { specific project } \\
\text { characteristics. See } \\
\text { description of } \\
\text { commercial success } \\
\text { evaluation tools in } \\
\text { Part C of this section. }\end{array}$ & \begin{tabular}{|l} 
See description of \\
commercial success \\
evaluation tools in \\
Part C of this section. \\
Results of technical, \\
regulatory, and \\
economic development \\
evaluations. \\
ProTech (limited \\
correlation) \\
\end{tabular} \\
\hline
\end{tabular}




\section{Commercial Success Criteria and Evaluation Methodology}

It is recommended that the commercial success evaluation of SRS technology application projects, to be performed as indicated in Figure 2-2, be conducted in a two step process:

Step 1. The completion of a qualitative commercialization success factor assessment as described in part (A).

Step 2. If acceptable results are determined, the commercial success evaluation should continue with the more comprehensive quantitative commercial success constraint analysis described in part (B).

\section{(A) Qualitative Commercialization Success Factor Assessment}

The Massachusetts Institute of Technology's extensive experience in creating successful commercial companies based on technologies developed at MIT has resulted in the identification of critical principles that relate to the probability of success. These principles are presented in a technical paper by John T. Preston, MIT (Appendix 1). One of the most important points is that the probability of commercial success is dependent of seven critical factors and is described by the following equation:

$$
\mathrm{Ps}=(\mathrm{Pt})(\mathrm{Qt}) \times(\mathrm{Pm})(\mathrm{Qm}) \times(\mathrm{Pinv})(\mathrm{Qinv}) \times \mathrm{I}
$$

where:

$\begin{array}{ll}\mathrm{Ps}= & \text { Probability of success } \\ \mathrm{Pt}= & \text { Passion of technologists } \\ \mathrm{Qt}= & \text { Quality of technology } \\ \mathrm{Pm}= & \text { Passion of company managers } \\ \mathrm{Qm}= & \text { Quality of company management } \\ \mathrm{Pinv}= & \text { Passion of investor(s) } \\ \mathrm{Qinv}= & \text { Quality of the private sector investment } \\ \mathrm{I}= & \text { Image of company }\end{array}$

Each factor in the equation can have a value of zero to one. Since the factors are multiplicative, a failure of any factor (resulting in a value of zero) would mean the probability of success is zero as well. These seven factors are qualitatively defined in the following pages. For additional guidarice refer to Appendix 1.

It is recommended that this qualitative assessment be performed by a management team from appropriate SRS organizations. This evaluation should consist of a top level qualitative assessment of strengths and weaknesses associated with each success factor based on the judgment of the evaluation team. The identification of a significant uncorrectable weakness associated with any single factor indicates the need to consider terminating the project. The assessment of each factor should be documented with adequate justification for determination of acceptability or unacceptability. Necessary corrective actions should also be defined, and should be identified as conditional requirements for continuing the project. The completion of this top level assessment for a technology application project should result in a recommendation from the following choices:

- Continue with the project based on the acceptable assessment of all seven success factors,

- Continue with the project on the condition that the identified required corrective actions are properly implemented, or

- Terminate the project. 


\section{Top Level Success Factors and Assessment Criteria}

\section{Success Factor 1: Quality of Technology}

Criteria to consider:

- Strong potential for creating new products ("strong product pipeline")

- Strong copyright position

- Strong market potential

- Ability of the industry to accept and protect new technologies

- Appropriate timing (relative to factors such as development status of related technologies)

\section{Success Factor 2: Ouality of Proposed Technology Company Management}

Criteria to consider:

- Healthy balance sheet

- Clearly focused development/commercialization strategy

- Realistic assessment of market

\begin{tabular}{|l|}
\hline Success Factor 3: Ouality of Private Sector Investment \\
Criteria to consider: \\
- Strong business development track record \\
- Good network of connections with potential partners or customers \\
- Adequate level of personal involvement willing to devote to the business \\
- Loquate access to money \\
- Optimum level of investment funding (sufficient for appropriate progress in technology and \\
business development, but not extravagant)
\end{tabular}

\section{Success Factor 4: Passion of Technologists \\ Success Factor 5: Passion of Company Managers \\ Success Factor 6: Passion of Investors}

"Passion" = strength, determination, commitment

Criteria to consider:

- Appropriate distribution of equity

- Appropriate economic incentives

- Sufficient probability of financial reward

- Appropriate recognition of good performance

- Absence of over zealous watchdog/oversight functions

- Equitable, "non-hostile" licenser/licensee agreements 
Success Factor 7: Image of the Technology Company

Criteria to consider:

- Recognized experts in technology field included in commercial technology company management team

- Commercial venture company teamed or affiliated with known industry corporate leaders in technology field

- Commercial venture company obtains technology from a highly credible research and development institution

\section{(B) Quantitative Commercial Success Constraint Analysis Criteria and Methodology}

The Commercial Success Constraint Analysis approach presented below was developed by Dr. Bruce Merrifield, Wharton Business School. This approach provides a quantitative guide for assessing the probable success of a new technology commercialization business venture. The following is a summary of Dr. Merrifield's model presented in a form easy to apply to SRS technology application projects. Appendix 2 should be referred to as necessary for additional information and understanding. It is strongly recommended that individuals experienced in new technology market analysis techniques be used to perform these analyses at SRS. Consultants could be used on a case by case basis if these skills are not available within the current staff.

\section{Guidance for Evaluating Proposed New Businesses}

The constraint model identifies 12 commercial success criteria (or "factors") grouped into two categories as listed below:

\section{Business Attractiveness Factors}

01. Sales/Profit Potential

02. Growth Potential

03. Competitor Reactivity

04. Risk Distribution

05. Potential for Industry Restructure

06. Political and Social Constraints

\section{Business Fit Factors}

07. Capital Availability

08. Marketing and Distribution

09. Manufacturing Competence

10. Technical Support Capability

11. Access to Critical Materials and Components

12. Management

The intrinsic Business Attractiveness Factors are not easily changed; however, the Business Fit Factors can be strengthened by taking appropriate actions. Each of the 12 factors are scored from 
zero to ten using charts and descriptive information provided below. Two conditions are necessary to indicate a high probability of success (i.e., an 80 to $90 \%$ success to failure ratio):

(1) the total of the scores for the six Business Attractiveness Factors should be 35 or higher, and (2) the total of the scores of all 12 factors should be 80 or higher. Lesser total values indicate a low probability of success and a decision to terminate the project is warranted. Since some effort is required to collect and evaluate the information needed to develop the score for each factor, such as performing comprehensive market analyses, it is recommended that the constraint analysis be completed in two parts, with the Business Attractiveness Factors being evaluated first to determine if it is appropriate to continue. Guidance for determining the score of each factor is provided on the following pages. 


\section{Guidance for Evaluating Existing Businesses}

These same criteria can also be used by commercial businesses that will have resulted from SRS technology application projects to assist in periodic business strategy decisions. Growth/divest decisions can be made based on the following:

A total score of 80 or higher for all 12 factors -- a growth strategy is suggested

A total score of 60 or lower for all 12 factors -- a divestment strategy is suggested 


\section{Success Criterion 1. Sales/Profit Potential}

This criterion addresses both sales and profit potential for the technology commercialization venture. The total score for the criterion (maximum of 10 ) is based on the sum of the two individual scores for (1) sales potential (maximum of 5 for expected sales of $\$ 1$ billion or greater) and (2) return on investment using discounted cash flow method (maximum of 5 for ROI of $20 \%$ or higher).

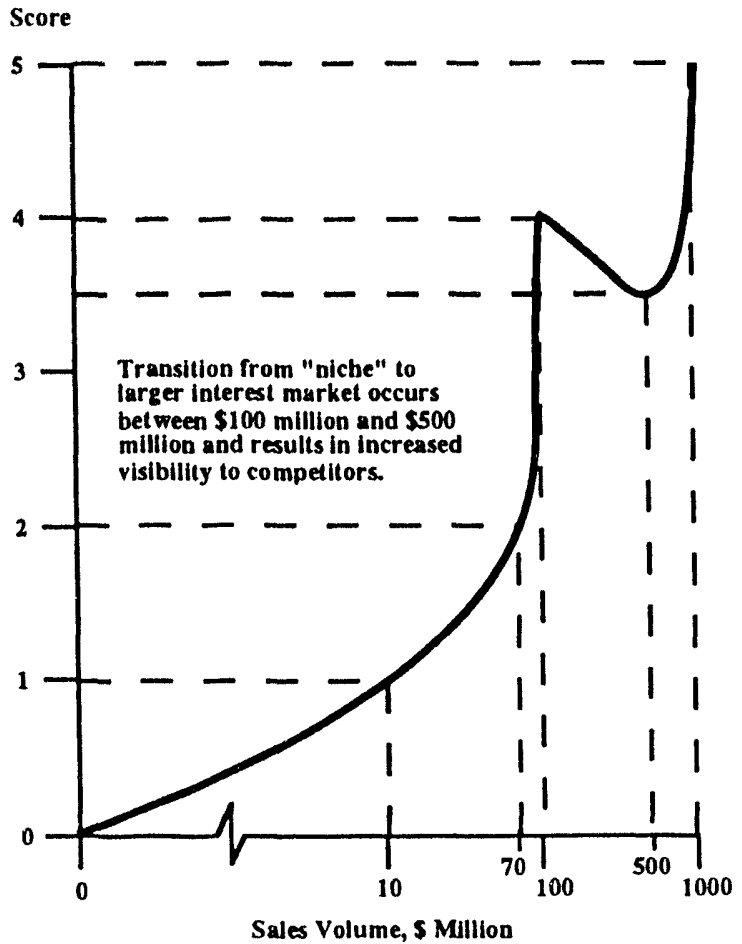

Part 1 - Measurement of Sales Potential

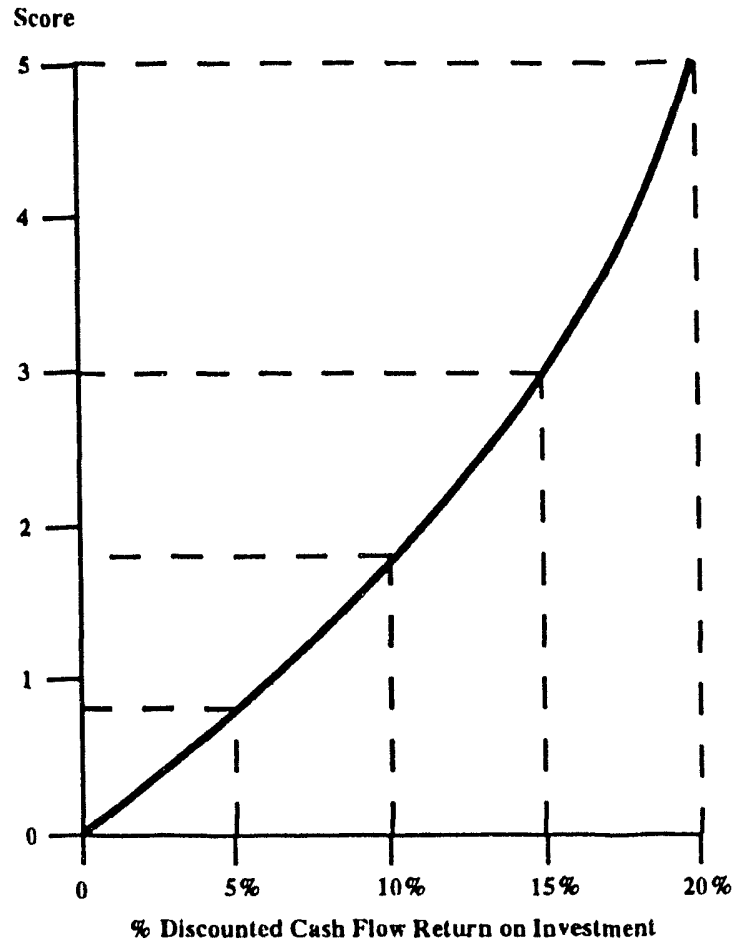

Part 2 - Profit Potential

Success Criterion 1. Sales/Profit Potential

(Score is total of two parts) 


\section{Success Criterion 2. Growth Potential}

This criterion addresses the expected growth rate of the new commercial venture. The maximum score for the criterion is 10 for an expected market growth rate of $20 \%$ per year or greater.

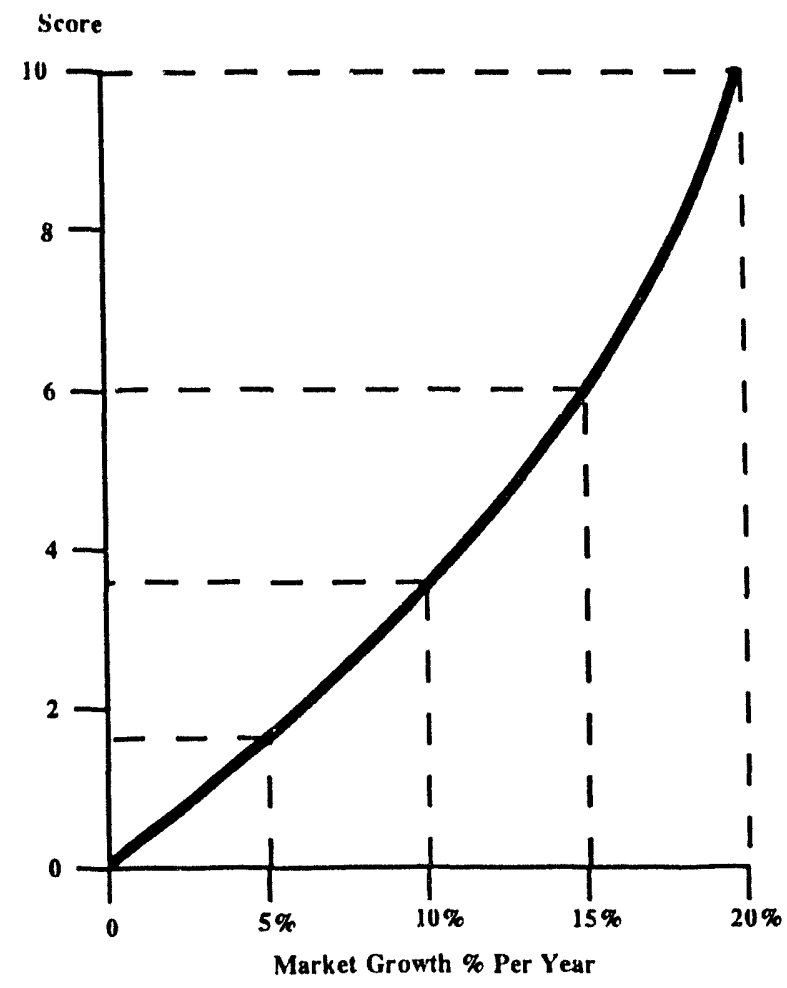

Success Criterion 2. Growth Potential 


\section{Success Criterion 3. Competitor Reactivity}

This criterion is scored in three parts: (1) the current market share of the dominant competitor (maximum score of 4 with a minimum competitor market share); (2) the type of combined patent or copyright protection available for the proposed venture (score ranges from zero to 3; and (3) expected market life for venture product (years until obsolete) (maximum score of 3 for 8 or more years expected life). The overall score for this criterion (maximum of 10 ) is the sum of the three parts.

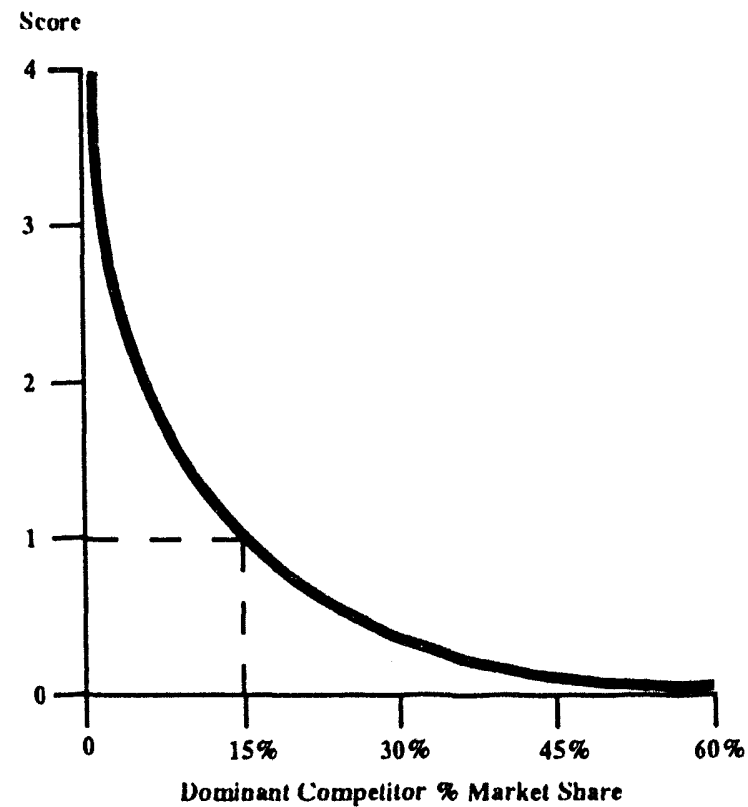

Part 1 - Dominant Competitive Reactivity

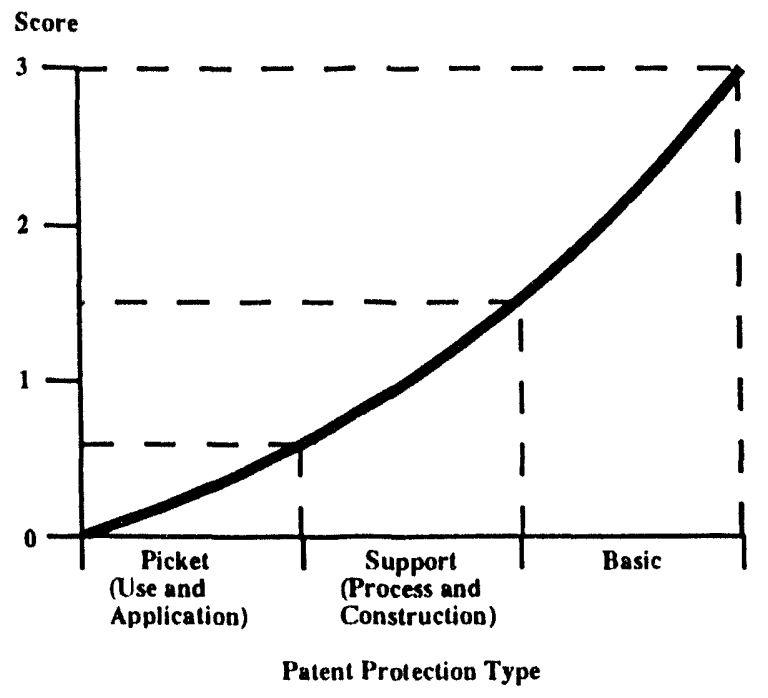

Part 2 .. Proprietary Character of the Operation

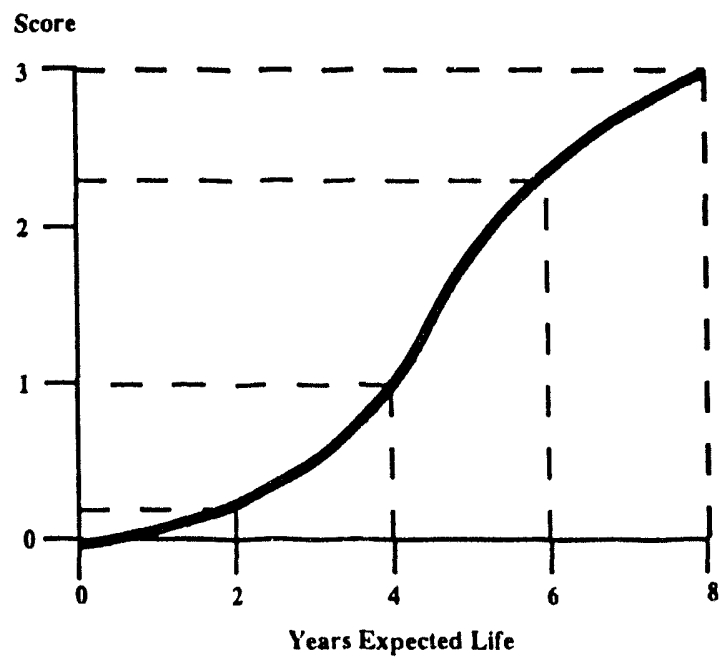

Part 3 .- Rate of Technical Obsolesce

Success Criterion 3. Competitor Reactivity

(Score is total of three parts) 


\section{Success Criterion 4. Risk Distribution}

This criterion addresses the number of separate markets that the venture will serve. Multiple markets (differentiated businesses) are important to reduce risk so that the failure of a single market will not result in the failure of the entire venture. A maximum score of 10 is provided for a scenario with 4 or more differentiated businesses.

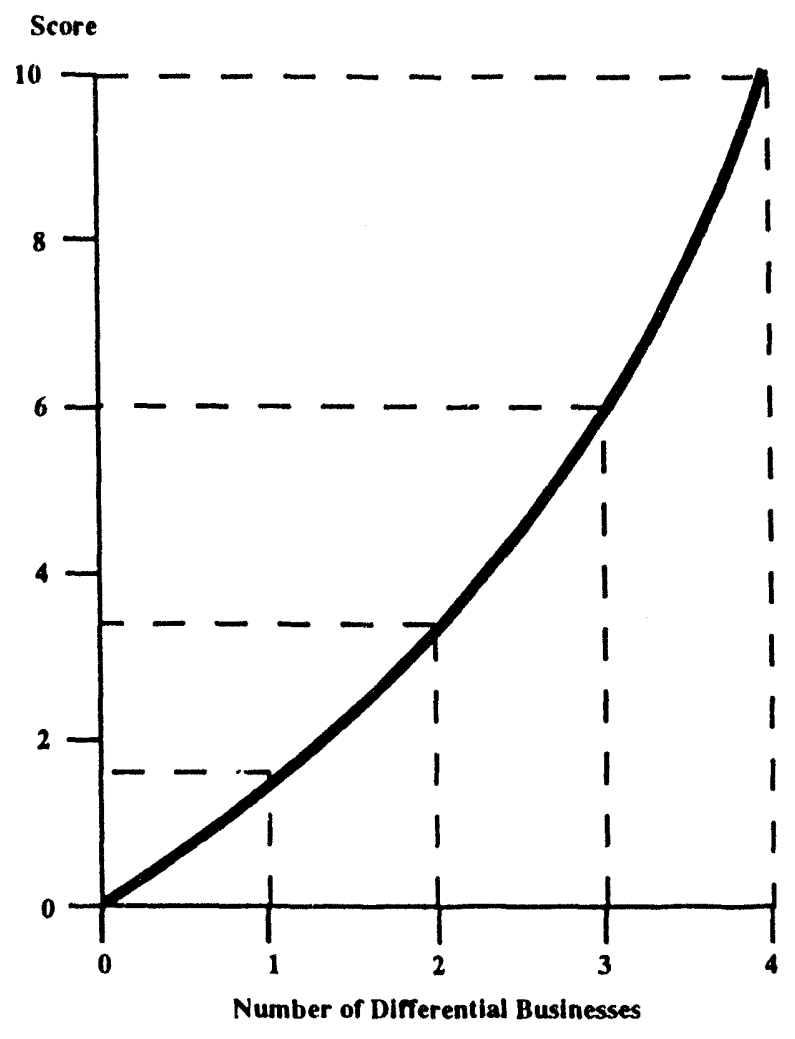

Success Criterion 4. Risk Distribution 


\section{Success Criterion 5. Potential for Industry Restructure}

This criterion addresses the potential for the new technology to significantly impact critical segments of an industry or even entire industries. The ability of a new technology to restructure multiple industries in their entirety leads to the highest scores, ranging from about 4 to a maximum of 10 depending on the judgment of significance.

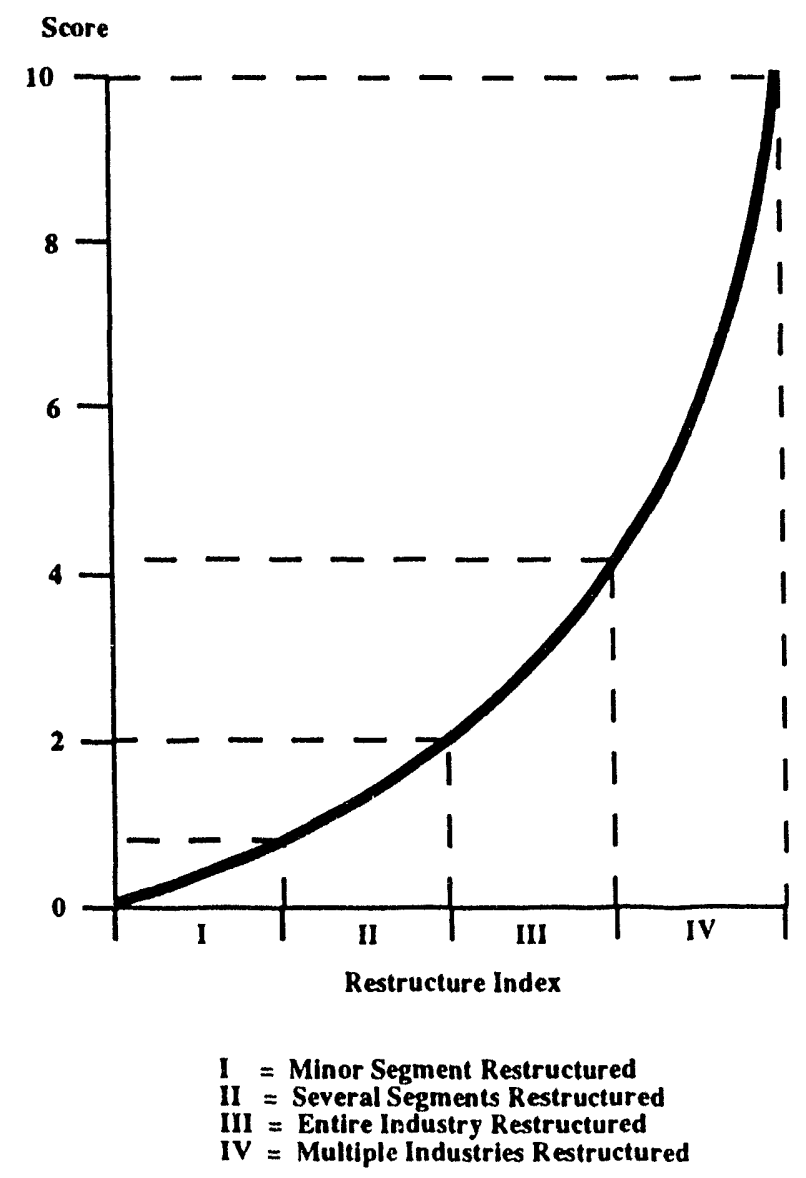

Success Criterion 5. Potential for Industry Restructure 


\section{Success Criterion 6. Political and Social Constraints}

This criterion considers the assessment of the net impact of political and social disincentives and incentives. Disincentives may include item', such as regulatory constraints and unfavorable local public opinion of the industry. Incentives may include items such as special tax incentives, special provisions for support infrastructure services (roads, utilities, etc.), and strong local public support of the industry. The score for this criterion ranges from zero for a net assessment of strong disincentives to 10 for a net assessment of strong incentives, with a score of 5 provided for a neutral assessment.

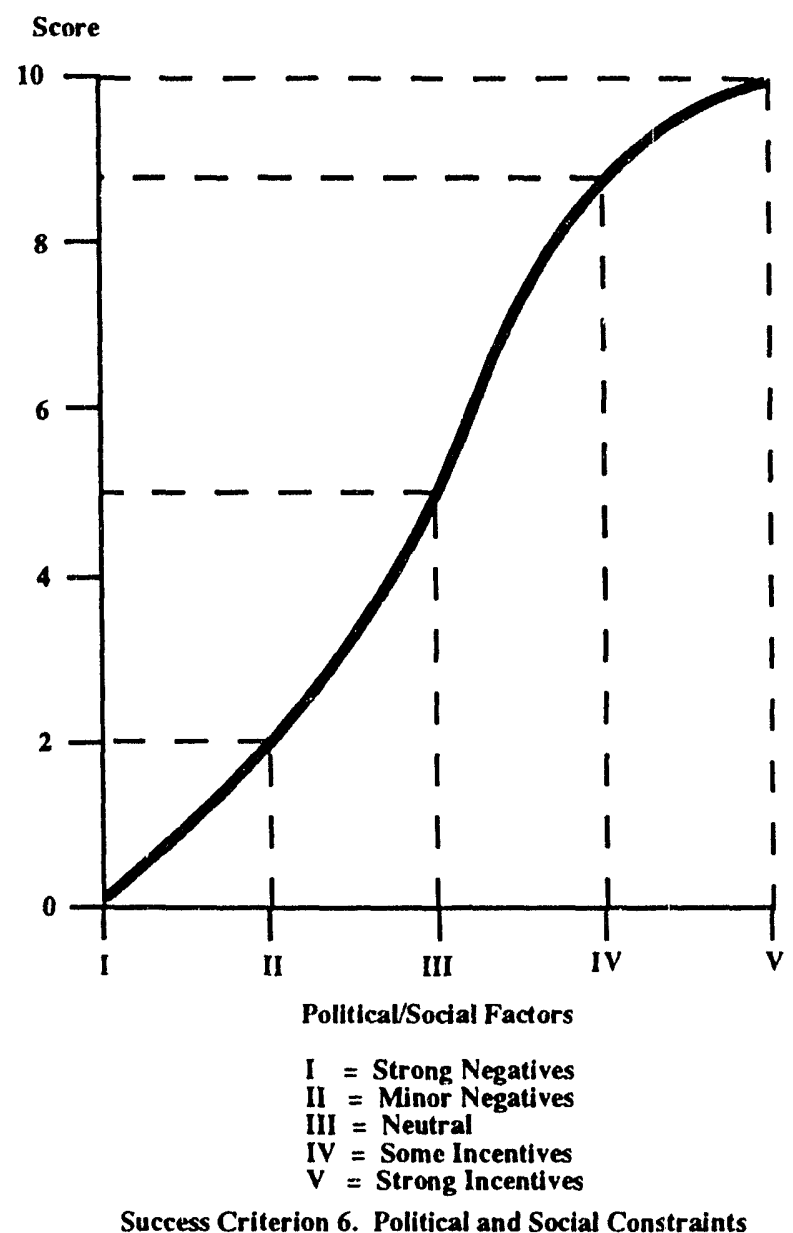




\section{Success Criterion 7. Capital Availability}

This criterion addresses the availability of capital to sustain business development at a 20\% return on investment (discounted cash flow method). This criterion is scored from zerc to 10 based on a judgment of availability of adequate capital ranging from "low" to "high".

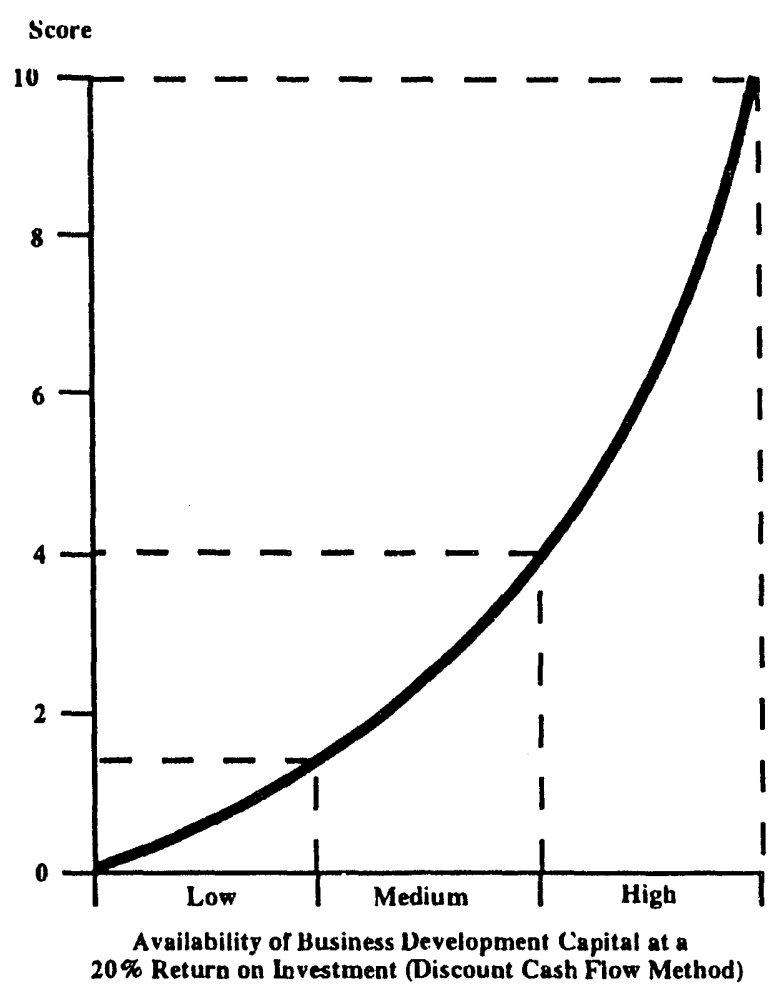

Success Criterion 7. Capital A vailability 


\section{Success Criterion 8. Marketing and Distribution}

This criterion addresses marketing and distribution capabilities of the proposed venture and is scored from zero for having very little in-house capability, to 10 for having a very strong global capability.

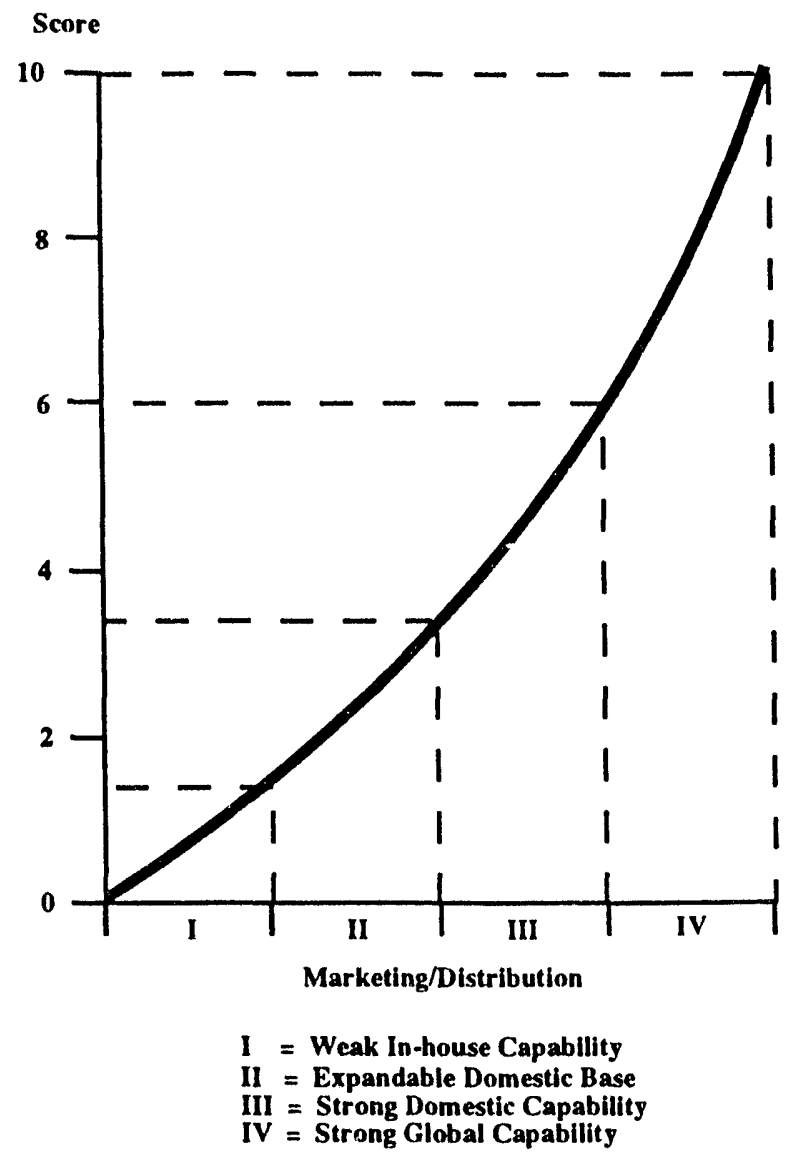

Success Criterion 8. Marketing and Distribution 


\section{Success Criterion 9. Manufacturing Competence}

This criterion addresses in-house manufacturing/production capabilities and is scored from zero to 10 based on capabilities ranging from none to developmental and prototype production, to a high level full production capability using flexible computer integrated manufacturing. Ventures based on technologies that do not require sophisticated manufacturing processes receive a score of 10 .

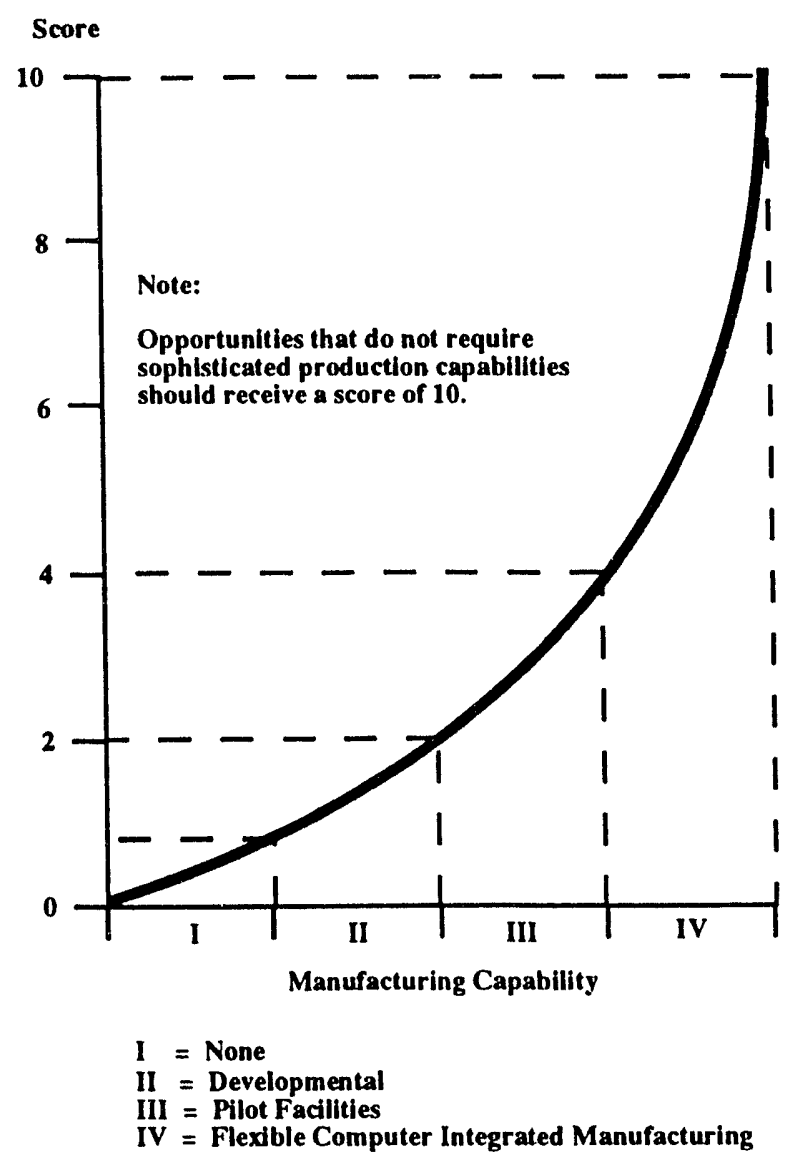

Success Criterion 9. Manufacturing Competence 


\section{Success Criterion 10. Technical Support Capability}

This criterion addresses technology support capabilities of the proposed venture company. This criterion is scored from zero to 10 based on increasing capability levels; the lowest level being limited to technical services to sales, increasing to incremental technology improvement and next generation technology capabilities, with having a global technology presence receiving the highest score.

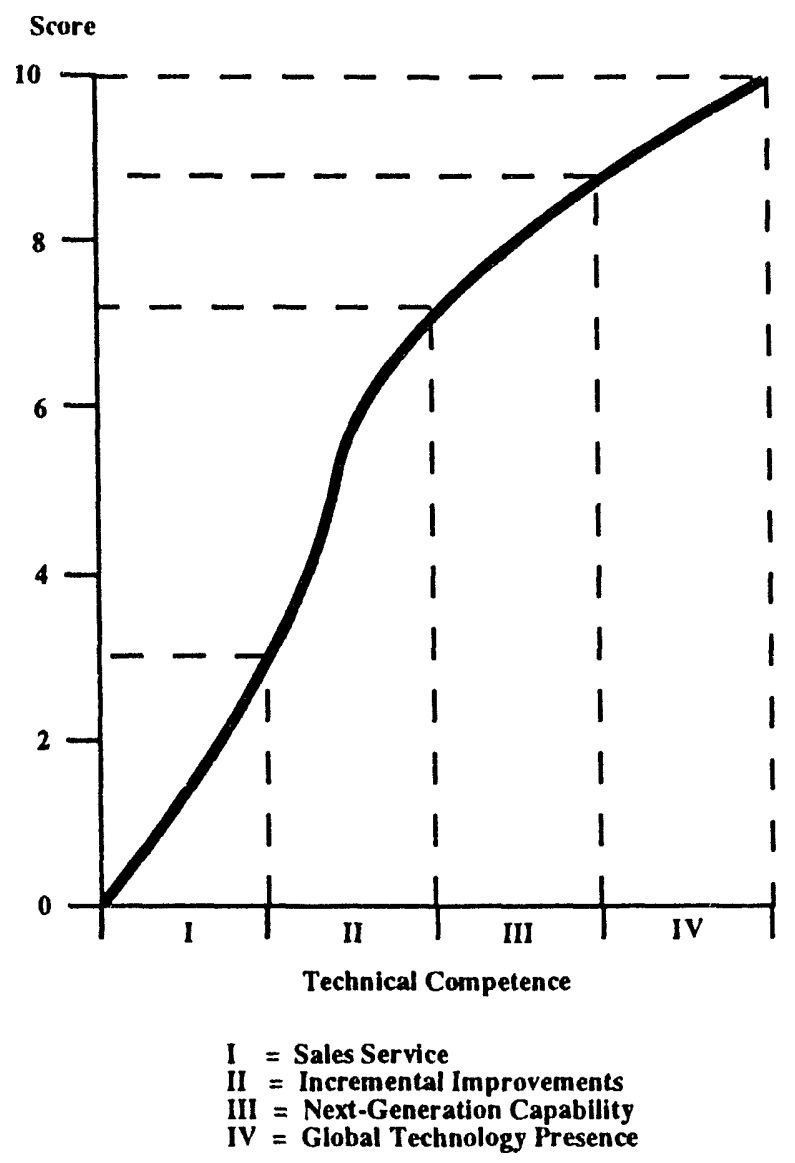

Success Criterion 10. Technical Support Capability 


\section{Success Criterion 11. Access to Critical Materials and Components}

This criterion addresses the sensitivity to disruptions in material supply sources, and is scored from zero to 10 , with dependency on sole source suppliers for critical materials resulting in the lowest scores.

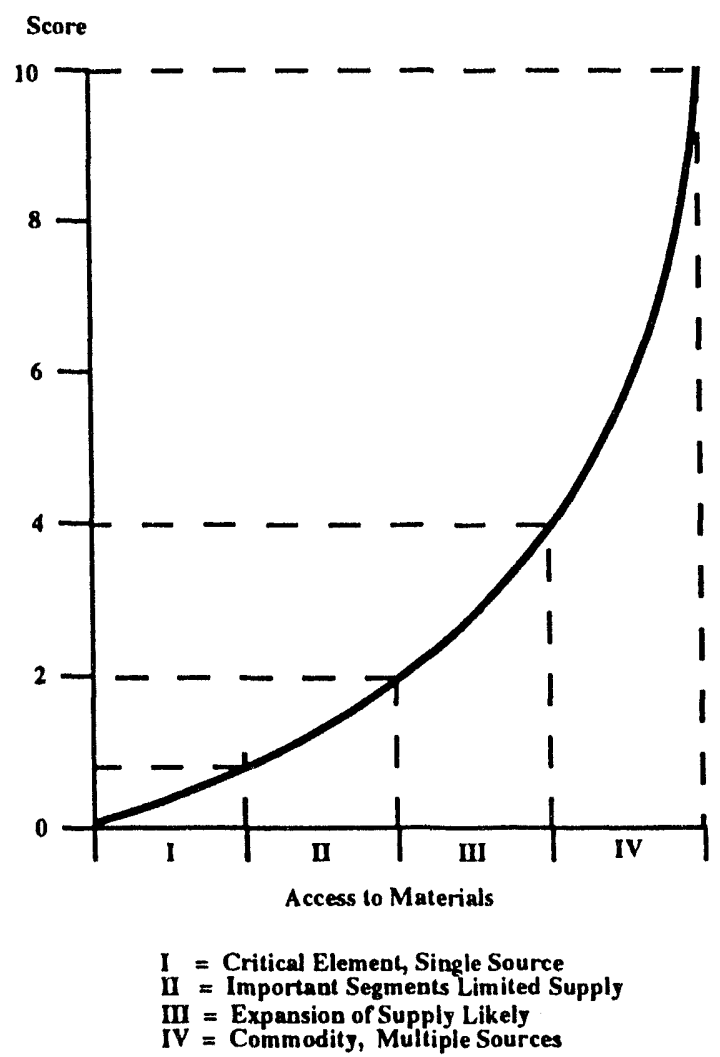

Success Criterion 11. Access to Critical Materials and Components 


\section{Success Criterion 12. Management}

This criterion, scored from zero to 10 , addresses different venture management environments. The highest scores are provided for scenarios which include a strong champion, top management support, and appropriate strategic alliances.

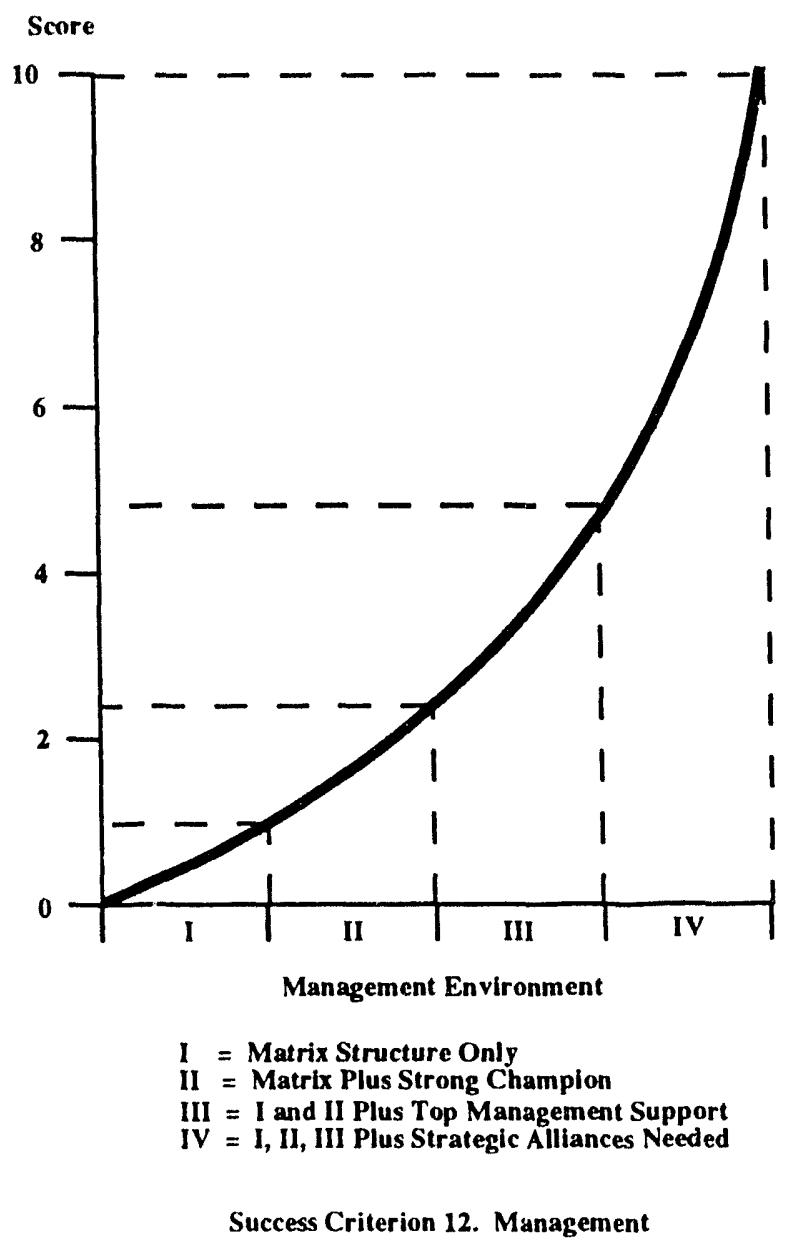




$$
\begin{aligned}
& 2 \\
& \text { 永盟 } \\
& \text { 売总 }
\end{aligned}
$$


Figure 3-1. Partnering for Commercial Success Interdependent Relationships

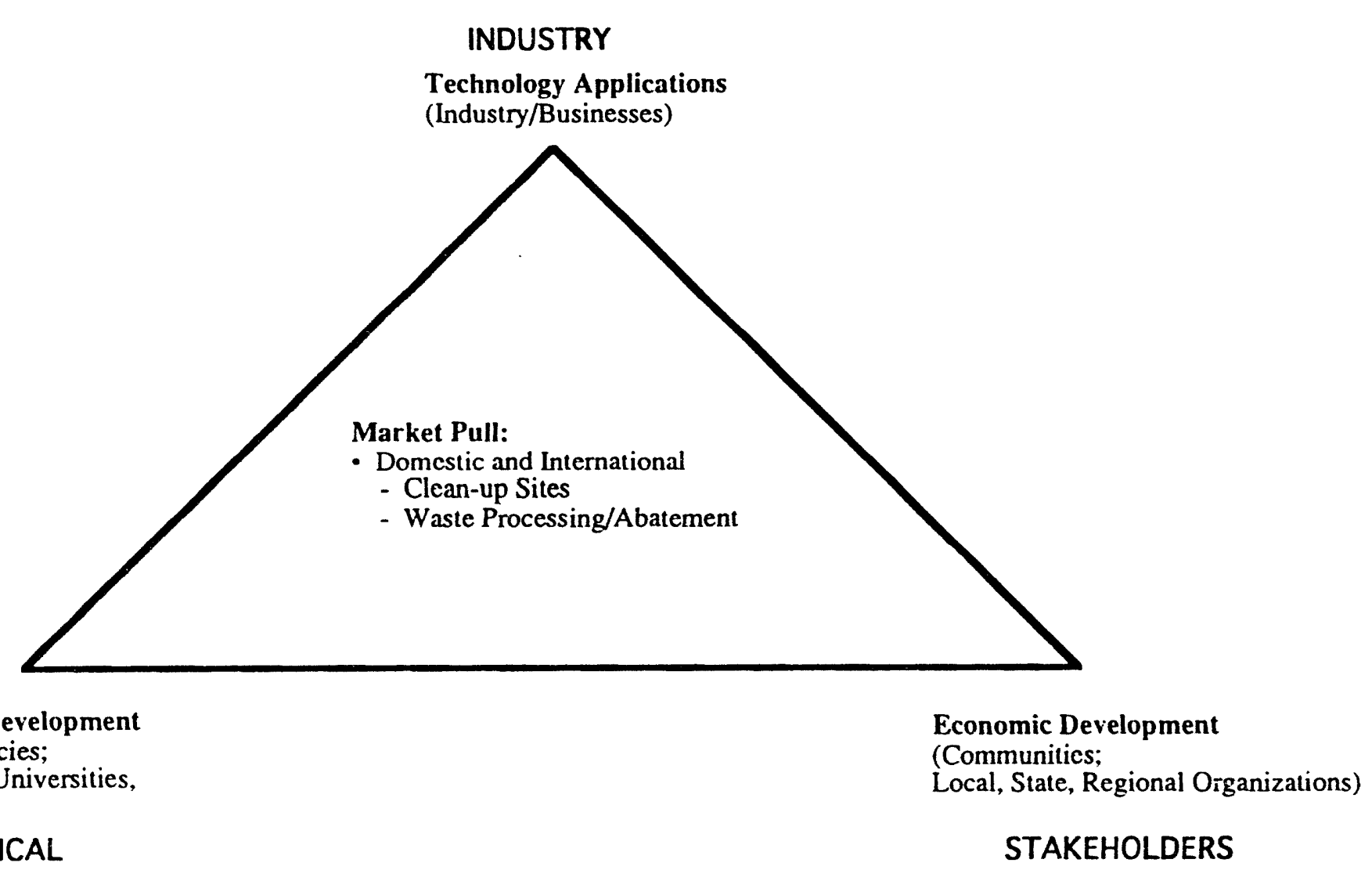

All are necessary and all must interact with and depend on the others. 


\section{B . PRIVATE INVESTORS' VIEWPOINTS}

The information in this section is based principally on background research and the results of interviews that were conducted with 25 venture capitalists and 10 corporate investors, most of whom were actively investing in environmental industry segments. In addition, 12 "Angels" (wealthy private individuals with experience as technology executives) were interviewed.

\section{Types of Investors - The Current Environment}

\section{Corporate Investors}

Many Fortune 100 corporations have pulled back from their equity investing posture in the mid1980s. Venture Economics, the leading chronicler of private equity capital transactions, noted in their 2nd Qtr. 1992 issue of "Corporate Venturing" that: equity deals done across all industrial sectors were down almost 30\% in 1991 versus 1990 (220 equity deals done in 1991 versus 300 in 1990). The reasons given:

"We are very selective in our investments now, and stick to what fits with our core business: waste water treatment, hydrocarbon cleanup, separation technologies."

"We are not looking to increase our liability exposure with new investments. And, the recession impacted our mainline businesses, so we're scaling back. In DOE work, we would be afraid they would go after our 'big pockets'."

"We have not done an outside environmental investment or joint venture in the last three years. In fact, we sold off a unit to a publicly-held water treatment company."

However, 1) aerospace companies are looking to diversify by acquisition into waste management equipment and, 2) larger publicly-held environmental companies are actively acquiring smaller firms while valuations are down amid the recession. They say:

"Our aerospace backlog is falling every month at our divisions. We are familiar with the demand for pollution control and cleanup equipment from our own metalworking facilities, and we see it as a growth market to possibly diversify into."

"We have our own cleanup problems to contend with and we're looking to blend our engineering expertise through acquisitions that give us environmental expertise we do not have in-house."

"We're looking to strategic opportunities and acquisitions that grow our core businesses nationwide. But, the company must have a solid management team."

According to the Environmental Business Journal's issue on "Mergers and Acquisitions" (Sept. 1992), M\&A activity rose in 1991 to an aggregate value of $\$ 1.4$ billion (excluding solid waste deals) versus $\$ 860$ million in 1990 . Engineering/consulting firms, instrumentation, and pollution control equipment deals were all expanding areas for corporate investment and consolidation plays in the last two years.

\section{Venture Capitalists}

In general, the capital market environment is improving for venture capitalists over the slump of 1990-91, especially as the technology-rich Over-the-Counter market continued to hit record highs in December 1992. Venture capital firms were able to take public many of their portfolio 
Table 3-2. Snapshot of SRS TTPs

\begin{tabular}{|c|c|c|c|c|c|c|}
\hline & & & DOE & Industry & Subcontract & \\
\hline Ret & Project & Project Partners & Funding & Cofunding & to Industry & Comment \\
\hline & & & & & & \\
\hline A & DNAPL DEMO & & $\$ 4,110$ & & & \\
\hline A1 & Characterization \& Monitoring & Clemson, USGS & $\$ 2,200$ & None & $?$ & Same TTP for all; why no more specifics? \\
\hline A2 & ER Lalson & Clemson, USGS & $\$ 100$ & None & None & Who are the industry partners? \\
\hline A3 & DNAPL Mobillzatlon / Moniloring & Clemson, USGS & $\$ 500$ & None & 400 & \\
\hline \multirow[t]{3}{*}{ A4 } & Remediation Tech Demo & Clemson, USGS & $\$ 1,300$ & None & $?$ & \\
\hline & & & & & & \\
\hline & In-Situ Remediation \& Tech & & $\$ 3.850$ & & & Some iech transfer if partners fit well \\
\hline$B 1$ & Inorganic Remedlation of GW-M8O & & $\$ 435$ & Could Be & $?$ & How is the pie divided? \\
\hline$B 2$ & Monitor Mag Sep Demo & \begin{tabular}{|l} 
Bradtec, B\&W, Rust, PNL \\
Bradtec? \\
\end{tabular} & $\$ 1,100$ & Could Be & $?$ & Need sensor companies \\
\hline$B 3$ & Removal of Inorganlc Contam & & $\$ 100$ & None & None & Why file a separate TTP? \\
\hline$B 4$ & Mag Sep Demo & Bradiec, B\&W, Rust, PNL & $\$ 205$ & Could Be & $?$ & SRS costs only? \\
\hline 85 & Char. of soil by Neutron Activation & WHC, WSTC, SEG & $\$ 250$ & Could Be & $?$ & How about a commercial firm? \\
\hline$B 6$ & HOPS (heurlstlc Optimlzed Process) & HOPS $\ln 17$ & $\$ 480$ & Good & $?$ & Good small business \\
\hline$B 7$ & Rapid Bloassessment Tech & Clemson & $\$ 700$ & None & None & Academic fodder; no commercial value \\
\hline \multirow[t]{3}{*}{88} & In-situ Bloremediation of Metals & WSRC, LBL, ORNL USC & $\$ 900$ & None & $?$ & A Natl lab sandbox projecl; no industry \\
\hline & & & & & & \\
\hline & Vitriflcation Center at Clemson & & $\$ 6,000$ & & & How about an industry consortium? \\
\hline$c_{1}$ & Plasma Demo on Mixed Waste & Clemson, MIT, Aerospate & $\$ 2,000$ & $?$ & ? & Plasma Pyrolysis Inc.? \\
\hline $\mathrm{C} 2$ & CIF Blowdown Ash Stablilization & Clemson, PNL, SEG & $\$ 1,400$ & & ? & What is the market for this? \\
\hline C3-NO & Nobel Metal Reclamation & Clemson, Zentth, Coming & $\$ 600$ & Yes; Amt.? & Poor Plan & Why so little? Beef it up. MMT? \\
\hline $\mathrm{C} 4$ & Vitrification of TRU Wastes & Clemson, Square D & $\$ 1,000$ & Yes; Amt.? & $?$ & Square D? \\
\hline C5 & Demo on Actual Mixed Waste & Clemson, ORNL, SEG, Rust & $\$ 1.000$ & Maybe & $?$ & No melter vendor identified. \\
\hline \multirow{4}{*}{ NO $=$} & Not recommended for funding by $D O E$ & & & & & \\
\hline & & & & & & \\
\hline & Funding flowing to Industry & & & & & \\
\hline & Generally, technology transfer is of & uded to, not lald out & & & & \\
\hline
\end{tabular}




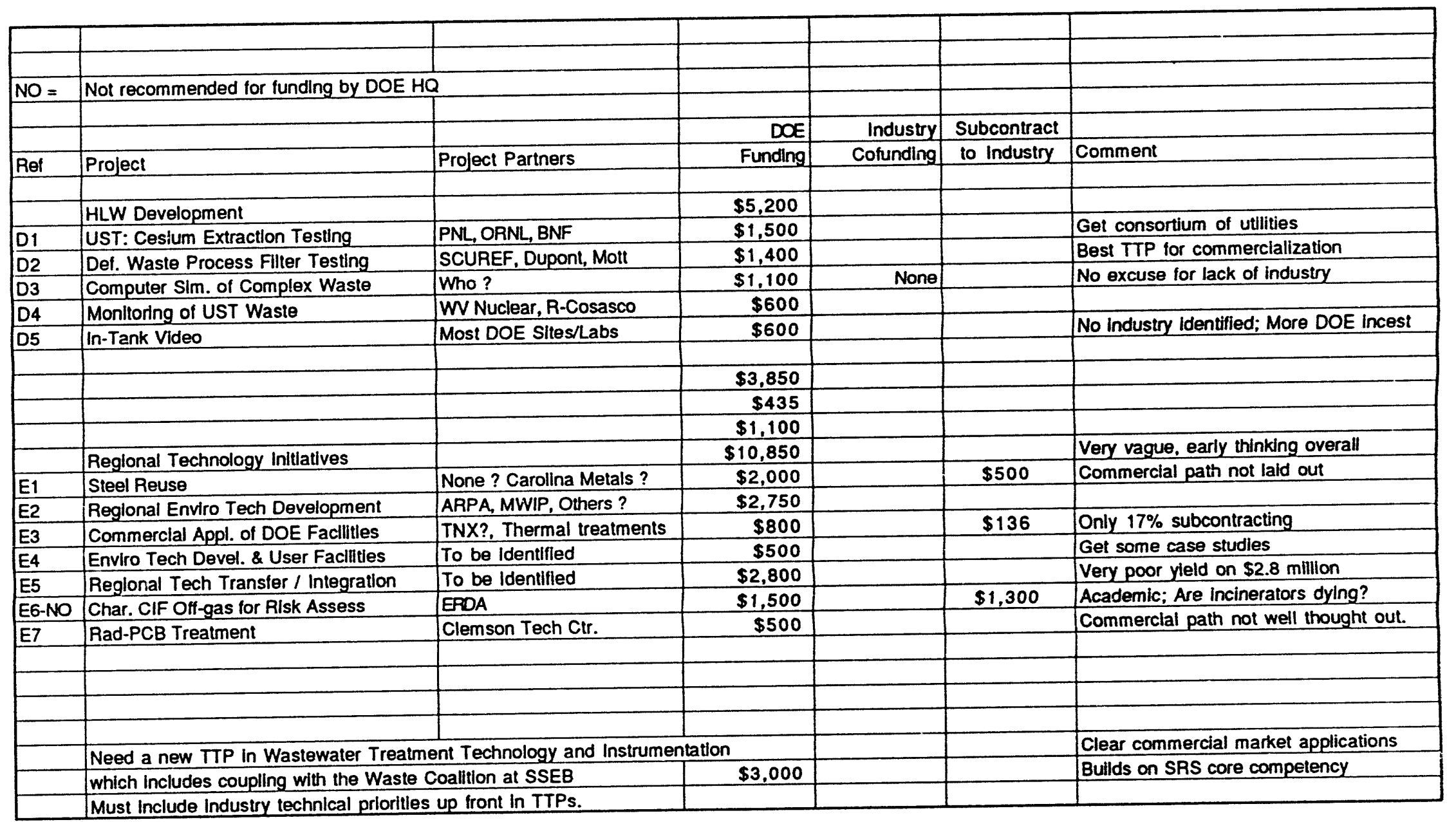




\section{B . PRIVATE INVESTORS' VIEWPOINTS}

\section{Research Findings}

The information in this section is based principally on background research and the results of interviews that were conducted with 25 venture capitalists and 10 corporate investors, most of whom were actively investing in environm "ntal industry segments. In addition, 12 "Angels" (wealthy private individuals with experience as technology executives) were interviewed.

\section{The Current Environment}

\section{Corporate Investors}

Many Fortune 100 corporations have pulled back from their equity investing posture in the mid1980 s. Venture Economics, the leading chronicler of private equity capital transactions, noted in their 2nd Qtr. 1992 issue of "Corporate Venturing" that: equity deals done across all industrial sectors were down almost 30\% in 1991 versus 1990 (220 equity deals done in 1991 versus 300 in 1990). The reasons given:

"We are very selective in our investments now, and stick to what fits with our core business: waste water treatment, hydrocarbon cleanup, separation technologies."

"We are not looking to increase our liability exposure with new investments And, the recession impacted our mainline businesses, so we're scaling back. In DOE work, we would be afraid they would go after our 'big pockets'."

"We have not done an outside environmental investment or joint venture in the last three years. In fact, we sold off a unit to a publicly-held water treatment company."

However, 1) aerospace companies are looking to diversify by acquisition into waste management equipment and, 2) larger publicly-held environmental companies are actively acquiring smaller firms while valuations are down amid the recession. They say:

"Our aerospace backlog is falling every month at our divisions. We are familiar with the demand for pollution control and cleanup equipment from our own metalworking facilities, and we see it as a growth market to possibly diversify into."

"We have our own cleanup problems to contend with and we're looking to blend our engineering expertise through acquisitions that give us environmental expertise we do not have in-house."

"We're looking to strategic opportunities and acquisitions that grow our core businesses nationwide. But, the company must have a solid management team."

According to the Environmental Business Journal's issue on "Mergers and Acquisitions" (Sept. 1992), M\&A activity rose in 1991 to an aggregate value of $\$ 1.4$ billion (excluding solid waste deals) versus $\$ 860$ million in 1990 . Engineering/consulting firms, instrumentation, and pollution control equipment deals were all expanding areas for corporate investment and consolidation plays in the last two years.

\section{Venture Capitalists}

In general, the capital market environment is improving for venture capitalists over the slump of 1990-91, especially as the technology-rich Over-the-Counter market continued to hit record highs in December 1992. Venture capital firms were able to take public many of their portfolio 
companies starting in October 1991 through May 1992, enabling the funds to return capital to their investors and replenish their own treasuries for future venture investing in 1993. Several venture funds are successfully raising new funds now:

"We generated a $20 \%$ compounded rate of return on our first environmental fund, and we will likely turn money away for the new fund which will top out around $\$ 90$ million. The first fund had built up a $30 \%$ annual ROI, until the public market valuations for environmental companies slid as the recession took hold."

As a benchmark, a Sept. 1990 survey of 42 U.S. venture capital firms by RIMTech and the Environmental Business Journal identified roughly $\$ 200$ million as targeted for environmental deals. More than that is now available due to the success of some funds, particularly First Analysis, Robertson-Stephens, Edison Ventures, and Advent International.

\section{Angel Investors}

Identifying and reaching wealthy private individuals ("Angels") proved more problematic due to their tendency to avoid "yet another solicitation for money." A few are generally aware of the scope of the environmental market and see it as a growth area in the 1990 s, especially with the Clinton/Gore Administration. However, several expressed concern about the potential additional liability and bureaucracy associated with environmental deals above and beyond the risk of losing the investment.

"Litigation risks are a big risk, and the bureaucratic delays in the environmental industry can kill small companies strapped for cash."

Additionally, many Angels were more familiar with other industries, e.g. software, electronics, telecommunications, where they made their money during the venture capital boom of the 1980s. Environmental deals attracted less than $1 \%$ of the $\$ 30$ billion+ of venture capital invested in the 1980 s, thereby generating relatively fewer "Enviro-Angels" familiar with the industry and high growth, high risk venture investing.

"We focus on businesses where we have expertise, experience and a strong local engineering base, such as electronics manufacturing."

Moreover, until the capital gains tax rate is lowered to where it was in the early 1980s, Angels, as private investors, (versus corporate investors) receive no tax benefit versus ordinary income for the additional risk associated with investing in early stage companies. Lastly, Angels, for the most part, have much less to invest (typically half-a-million to two million dollars) than venture capital firms or corporate investors that have the deeper pockets needed for growth companies with capital-intensive technologies required by the nature of DOE's cleanup problems.

Interest in Funding Development of Technology Private investors were very clear about their interest in funding commercial enterprises, not technologies. Corporate investors look for a definite strategic fit of the investment with their core businesses. Venture firms focus on solid management teams with a clear mission in a high growth niche market, preferably with a protected technology.

"We don't fund technology development; we fund high growth business development."

"We look for technologies with broad-based application to overcome uncertainties."

"We build management teams that can seize a dominant position in a clear niche." 
"Our firm targets proprietary technologies in an expanding market with knowledgeable founders. We will not invest in a deal where the customer is mandated; the product must have distinct economic advantages."

Investors' Perceptions of DOE Interest in Cost-Shared Development

Direct experiences of DOE by investors was limited. Some of the corporate investors had poked around the DOE National Laboratories looking for technologies with strategic fits, but often not necessarily environmental cleanup technologies. For instance, chemical companies look for catalysts or new kinds of composite materials and fibers.

Very few of the venture firms had any contact with National Labs or DOE contractors (except the special case of ARCH, a fund dedicated to Argonne National Lab).

"DOE labs have the wrong orientation; they never expect to pay the investors back. They have a technology development grant mentality, not commercialization. "

"We don't bump into the National Labs much; they're not part of our network."

"National Labs are not a good source of winning entrepreneurs."

"None of us graduated from Livermore Lab; Stanford, Berkeley or MIT are much more natural research organizations to interact with."

"The National Labs never coine to us. We've got plenty of people coming to us; we don't really have time to go to Labs."

"Name a highly successful investment based on a National Lab technology; name one...? It is just not in DOE's culture to take risks on commercial enterprises."

"The DOE labs are full of 'Super-Techies' with no feel for the marketplace."

"Co-funding is only attractive if the underlying business is sound; otherwise, it is just throwing more good money after a loser."

\section{Venture Capital Ratings of Industry Segments}

Not all environmental industry segments were rated equally by venture furms. For instance, "Solid Waste Management" and "Asbestos Abatement" received uniformly low ratings as potential industry niches for venture investment. The "Analytical Labs" segment is now seen by several investors as a crowded, maturing niche with price pressures cutting into profits.

"Engineering/Consu!ting" can be a difficult investment because the company assets commute home every night, and profit margins are often limited by contract, but investors were looking at niche players who may also have a proprietary technology, say in water treatment, that could boost margins.

The segments surveyed mirror the Environmental Business Journal's segmentation for monthly stock market analysis. Segments which received the highest rankings were generally in the "hardware" end of the business, rather than the "software" of services and consulting. Legislation played a key role in the ranking of the segments, namely, the passage of the 1990 Clean Air Act boosted interest in emission monitoring; and recent signing of the National Energy Act clearly account for those two segments rating high marks. The impending reauthorization of the Clean Water Act under a pro-environment Clinton/Gore Administration preserved a high rating for water. 
Ratings were averaged to a 10 point scale, $(10=$ highest potential for investment):

\begin{tabular}{lll}
$90 / 92$ & 1990 & 1992 \\
Rank & Rating & Rating \\
\hline $4 / 1$ & 7 & $\mathbf{8}$ \\
$2 / 2$ & 8 & $\mathbf{8}$ \\
N $/ 3$ & NR & 7 \\
$1 / 4$ & 8 & 7 \\
$5 / 5$ & 6 & 7 \\
$3 / 6$ & 7 & $\mathbf{7}$ \\
$6 / 7$ & 6 & $\mathbf{6}$ \\
N /8 & NR & $\mathbf{5}$ \\
$8 / 9$ & 5 & 5 \\
$10 / 10$ & 4 & $\mathbf{4}$ \\
$7 / 11$ & 6 & $\mathbf{4}$ \\
$9 / 12$ & 4 & $\mathbf{4}$ \\
$11 / 13$ & 2 & $\mathbf{3}$ \\
$12 / 14$ & 2 & $\mathbf{2}$
\end{tabular}

INDUSTRY SEGMENT

Air Pollution Control and Monitoring

Water Infrastructure/Treatment

Alternative Energy

Resource Recovery and Recycling

Instrument Manufacturing

Pollution Control Equipment

Hazardous Waste Management

Bioremediation

Engineering/Consulting

Solid Waste Management

Analytical Services/Laboratories

Gov't Cleanup: DOE, DoD, Superfund

Water Utilities

Asbestos Abatement
EBJ 1991

Mkt Size

$\$ 5.3$

$\$ 12.5$

$\$ 2.0$

$\$ 15.8$

$\$ 1.8$

$\$ 11.0$

$\$ 13.7$

$\$<1.0$

$\$ 13.4$

$\$ 27.4$

$\$ 1.7$

$\$ 4.6$

$\$ 11.8$

$\$ 3.0$

$\$ 125.0$

Billion

[Note; 32 venture capital firms were surveyed for 1990; the 1992 ratings are based on 25 firms so far. Most firms in both surveys were active in environmental industries. ]

Examples of Acquisitions in Environmental Industry

Largest Deals Completed - 1991 (based on information available, Environmental Business Journal)

Acquiring Company
Primark Corp.
NW Water Group PLC
Emerson Electric
USA Waste Services
Watts Industries
AWT
Republic Waste
Mid-American Waste
Sanifill
U.S. Filter Corp.

Total Acquisition Value

Acquired Firm
Analytic Sciences
Wallace \& Tiernan
Mallory Controls
ARF Landfill
Henry Pratt Co.
Metcalf \& Eddy
Stout Environmental
Inland Landfill
Williams Corp.
Alcoa Separation Tech

Alcoa Separation Tech

Industry Segment
Instrument Mfg.
Enviro Consulting
Instruments
Solid Waste
Pollution Controls
Enviro Consulting
Hazardous Waste
Solid Waste
Solid Waste
Pollution Controls

Price

$\$ 167 \mathrm{M}$

$\$ 130 \mathrm{M}$

$\$ 90 \mathrm{M}$

$\$ 64 \mathrm{M}$

$\$ 57 \mathrm{M}$

$\$ 51 \mathrm{M}$

$\$ 40 \mathrm{M}$

$\$ 35 \mathrm{M}$

$\$ 35 \mathrm{M}$

$\$ 32 \mathrm{M}$

$\$ 701 \mathrm{M}$

In addition to public offerings, an exit market via acquisition, clearly exists for venture investors. The acquisitions listed above, outside of solid waste, occurred mostly in the hardware end of the business: instruments, pollution control equipment and hazardous waste treatment, where technology and innovative approaches are valued. Acquisition trends and pricing, in turn, impact the preferences and deal activity of venture investors and other corporate acquisitions. DOE can benefit from leverage where its cleanup needs are congruent in fields where commercial industry is making acquisitions, e.g. in instrumentation for site characterization, on-site soil and ground water treatment, and hazardous waste minimization. 


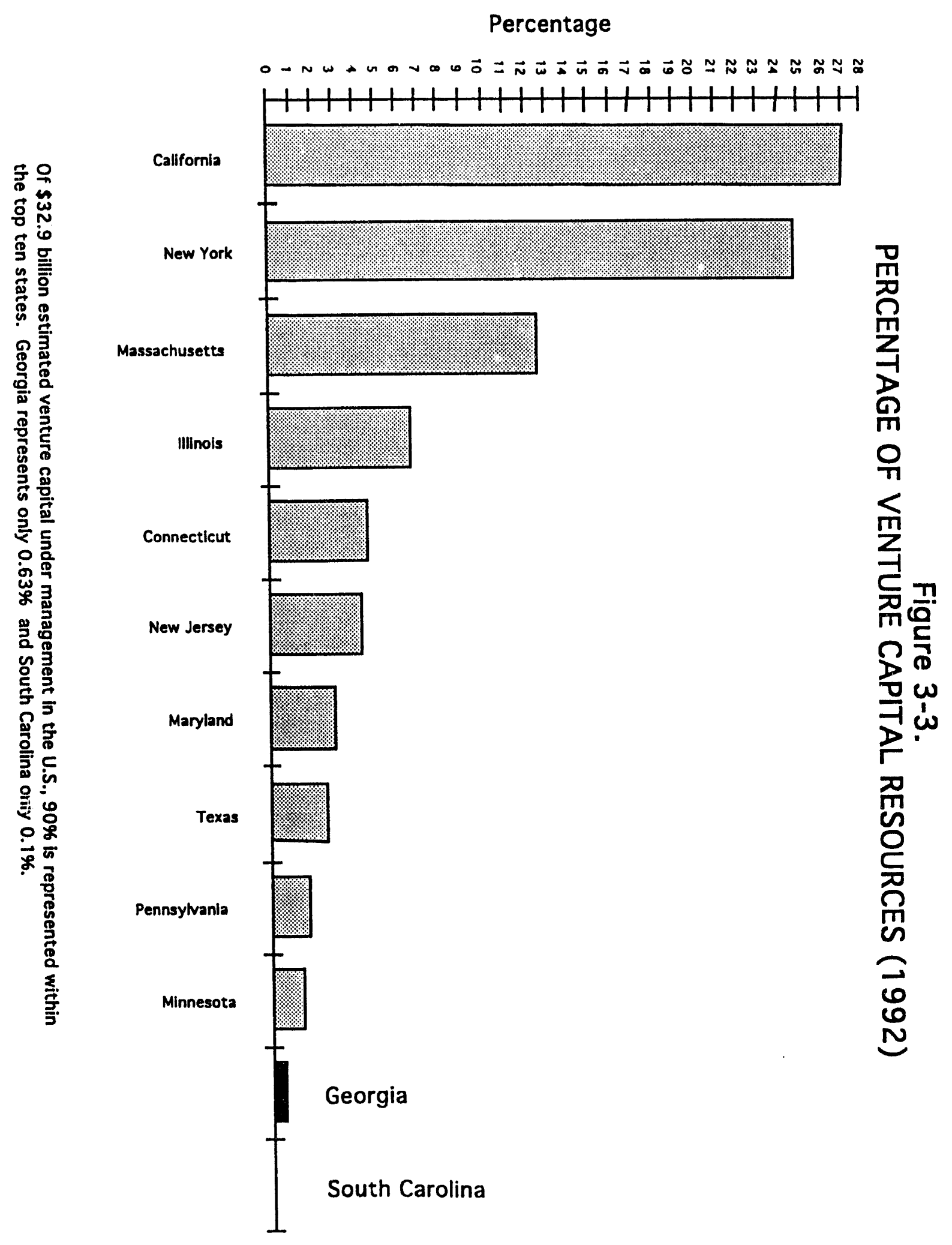




\section{REGIONAL ASSOCIATIONS}

\section{Introduction}

There are a number of organizations that are both non-profit, governmental, or quasi-governmental and which represent the states of the southern region, including Georgia and South Carolina. In fact, the concept of regional governors' associations had its genesis in the South, with the creation of the Southern Governor's Conference in 1934. The governors banded together to fight restrictive and punitive railroad shipping rates that hindered the economic development of the region. From the very beginning the intent was to influence national policy in ways that benefited the southern region.

Among the types of organizations subsequently created either by the governors or state legislatures are associations, such as the Southern Governor's Association (SGA) or the Southern Legislative Conference (SLC); interstate agreements, such as the Southern Growth Policies Board (SGPB) and the Southern Regional Education Board (SREB); and interstate compacts, such as the Southem States Energy Board (SSEB) and the regional low-level radioactive waste management compacts. The principle differences are the means by which the organizations are created. Associations are normally joined on a relatively informal basis and their charters are in no way binding on the member states. Interstate agreements are normally entered into by the governor or state legisiature and may or may not bind the state in some way. Compacts have the force of law and generally contain provisions stating the obligations and duties of the member states and means for entry and resignation from the compact. Compacts, which address an issue area in which the Federal Government holds a significant interest, such as energy and environment, normally require the consent of Congress. Thus, many compacts become creations of both state and the Federal Government.

The resistance to new organizations in the South is fairly strong. Governors and legislatures have been reluctant to create additional regional organizations which would place demands on evershrinking resources of time and money. Moreover, in 1982 the organizations representing the southern region entered into a Memorandum of Understanding outlining the responsibilities of each and coordinating such events as annual meetings. This was done primarily to reduce travel costs and the demands on the time of governors and legislatures.

\section{Samples of Existing Organizations}

\section{Southern Governor's Association}

The Southern Governor's Association has its offices in Washington, DC. Its membership comprises 17 states plus the Commonwealth of Puerto Rico and the U. S. Virgin Islands. It represents a large region of the U. S., roughly one-third of both area and population. SGA is an association voluntarily joined by its members and its policies are in no way binding on the states. SGA's funding comes through the Council of State Governments, a national organization based in Lexington, KY. It does accept grants and contracts from Federal agencies and, on occasion, industry.

Following the lengthy debates over low-level radioactive waste policy and other issues, primarily Federal funding formulae, it was decided that one organization should focus almost entirely on events in the nation's capital. SGA relocated from Atlanta in 1982 and was joined by reprisentatives of the staffs of SGPB and SSEB. The SGA maintains a small professional staff that tends to deal mainly with social issues, such as illiteracy, teenage pregnancy, and infant mortality. While of significant interest to the SGA, because of the MOU it defers to SGPB and SSEB in those areas within their purview. There is, however, a significant degree of coordination and cooperation among these organizations. 


\section{The Southern Growth Policies Board}

The newest of the major regional organizations, the SGPB was formed in the mid-1970s to provide a focus for economic development policy in the South. Its membership has varied during the years since its formation but generally has had from 10 to 15 member states. All of the members of SGPB are members of SGA and SSEB. From the beginning, SGPB has considered itself a "think tank" ruminating on the long-term issues of concern to the southern region. Every 6 years it is charged with producing a study of the future of the South. It maintains a small staff at its headquarters in Research Triangle Park, North Carolina. SGPB is an interstate agreement approved by the governors and legislatures of its member states but does not have the force of law. Funding for SGPB comes from state appropriations and contributions from associate inembers, mostly local governments, universities and colleges, and industry.

The membership of SGPB comprises the governor and two legislators per state, as well as, two gubernatorial appointees per state. The chairman is elected from among the member governors on an annual basis.

\section{Southern States Energy Board}

SSEB began its existence as the Southern Interstate Nuclear Board in 1961. SSEB exists as an agency of government in all of its 18 members, 16 states, the Commonwealth of Puerto Rico and the U.S. Virgin Islands. It has the same membership as the SGA less the State of Delaware. In 1962, Congress passed P.L. 86-573, which consented to the creation of the compact. Its basic charge was the safe development of nuclear energy for all purposes, including medical and industrial. Initial membership on the Board was comprised primarily of scientists, engineers, and doctors appointed by the governors. In 1972, the governors changed the focus of SSEB from nuclear energy to all forms of energy and the environment. This change was formally reflected by the new name adopted in 1978, and the governors decided that they would personally serve on the Board.

SSEB has a staff of about 13-15 at its headquarters in Norcross, GA, just north of Atlanta in the area known as Technology Park. Its main source of funding is from state budget appropriations based on a formula, and from grants and contracts from Federal agencies and industry. By its charter, it is empowered to accept money from any legitimate source to further the accomplishment of its mission. Board membership is comprised of the governor and two state legislators from each member state, with most governors and some legislators naming an alternate to represent them in their absence. The chairman is always a member governor and the vice chairman a member state legislator. A Federal Representative is appointed by the President in order to affect coordination and cooperation.

In 1991, Governor Campbell of South Carolina served as chairman of SSEB and, presently, both he and Governor Miller of Georgia are on the Executive Committee. Day-to-day activities of the board staff are supervised by the executive director, who receives his guidance form a ninemember executive committee, comprising of four governors and five legislators.

Over the years, SSEB has been involved in a wide range of both research and action-oriented programs involving states, industry, colleges and universities, and the Federal Government. One of its most significant successes was the creation of the regional low-level waste management compacts following the passage of the Low-Level Radioactive Waste Policy Act in 1982, and its attendant amendments in 1985. SSEB served as the umbrella organization and brought all parties together, reached consensus on critical issues, developed the legislative language, steered the legislation through numerous state houses, and worked with Congressional staff to obtain Federal approval. 
Southern Legislative Conference

The SLC, like the SGA, is presently under the umbrella of the Council of State Governments, from which it receives its budget. SLC is comprised of members of the region's legislatures and membership will vary in number from state to state. SLC has a small staff based in Atlanta and is perhaps the least active of all the major regional groups. The primary function of the SLC is to organize and conduct the annual meeting and a series of committee meetings held during the year. It defers to other groups to some extent for policy and program development.

\section{Southern Regional Education Board .}

SREB thinks of itself as an institute of higher learning, to the extent that the director is titled "President" and the group is located on Georgia Tech's campus in Atlanta. This group has little, if any, interest or expertise in technology commercialization issues.

\section{Georgia Research Alliance}

The Georgia Research Alliance (GRA) was charted by the Georgia legislature as a non-profit organization in 1990. It serves as an umbrella organization for 6 major research universities in Georgia. These are the University of Georgia, Georgia State University, Georgia Tech, Atlanta/Clark University, Medical College of Georgia, and Emory University. The board of directors is comprised of the presidents of the six universities and the CEOs of 10 large Georgiabased corporations. The primary purpose of the GRA is economic development within the state of Georgia.

The GRA focuses on three distinct areas: telecommunications, biotechnology, and environmental technology. The environmental technology effort is headed by a professor, Dr. Dale Threadgill, at the University of Georgia at Athens, who is also the head of the Georgia Environmental Technology Consortium.

Funded by state appropriations, the GRA also has industry funding and requires matching funds for any research project it supports. It primarily serves as a holding company for joint ventures among the universities and corporations, and all projects must involve cooperation among two or more of the universities. The industry input, provided by the ten CEOs, is to ensure that the research projects undertaken have direct application within the business/industry communities in Georgia.

\section{Discussion of Organizational Alternatives}

WSRC is concerned with the accomplishment of two distinct, but not necessarily separate, goals:

1) the successful commercialization of technology, products, commodities, or services at SRS; and

2) economic diversification within those parts of South Carolina and Georgia immediately

surrounding SRS. To date, the WSRC plan to accomplish this is described in the SERA proposal, which, in short, envisions the coming together of a coalition of existing groups, new organizations, and agencies of state government. The approach, as outlined, presents some concerns. First, the plan calls for a 5-year ramp-up period and, unless there is significant progress in the first year, a) the continuation of state funding would likely be challenged; and b) many technologies would miss their opportunity in the marketplace. It also duplicates functions already being performed by existing groups that bring a long track record and political connections to the table.

The requirement that a sizable percentage (28\%-30\%) of the special economic development appropriation be spent directly funding industry partnerships could be far more easily satisfied if the authority to allocate these funds resided outside of the DOE system. For example, using the 
procurement process presently employed without choice, by WSRC will render the chances of early demonstrations in partnership with industry difficult to achieve. With the authority resting within a non-profit, outside organization, but controlled by WSRC employees seconded to the non-profit, virtually all of the impediments to real time contracting would be overcome. Benefits to both the non-profit group and WSRC would result from this approach. WSRC can second a group of employees to manage the project(s) within the offices of the non-profit, thereby eliminating much of the up front costs associated with starting up a new organization. The nonprofit would not have to staff up and then later eliminate positions should the project end.

Moreover, a regional group with strong political ties will be in a position to assist WSRC in engendering support for, and interest in, economic diversification activities. A presentation before the annual meeting of the Southern Governors' Association, for example, would likely result in greater exposure and advertising that cannot be gained elsewhere.

Greater consideration should also be given to groups that have proven successful in some aspects of commercialization, rather than creating new groups to be launched on a fairly long learning curve. NETAC, out of Pittsburgh, PA, may have more directly related and immediately applicable experience and expertise than all of the groups identified in SERA combined. The one thing NETAC would lack, however, is the political ties in the South, which are vital to the overall success of the project.

Attention should be given to the existing business/industry associations that exist in the two-state region. For example, Leadership in South Carolina is an association of business men and women concerned with the economic health of the state. The group meets at Clemson University at least a couple of times each year. Other such organizations also exist in Georgia and South Carolina and should be sought out for support for any venture undertaken as a result of WSRC's endeavors.

In summary, there are a variety of regional organizations in South Carolina and Georgia with an economic development objective. Some will be more useful to WSRC's goals than others, and they are operational, immediately available, and provide an efficiency for WSRC in meeting critical success criteria. 
SECTION 4

INDUSTRY PERSPECTIVE 


\section{INTRODUCTION}

This section is a summary of comments from the environmental companies and organizations in this country. Participants were selected from a cross-section of companies that have environmental/process problems, perform remediation, or develop and sell environmental cleanup/waste processing technologies; suppliers/fabricators; investors; and industrial associations. These companies and organizations were represented by their CEOs, Presidents, or Vice-Presidents.

Part $A$ is based on nation-wide series of roundtables conducted by DOE-EM to get industry's perspective on doing business with DOE-EM, particularly with its major environmental and waste management problems to solve and to discuss "enterprise" initiatives. Part A gives highlights of:

a) Major issues raised/problems of working with DOE and its Labs/M\&Os.

b) Suggestions/recommendations to an $\mathrm{M} \& \mathrm{O}$ that would make progress in meeting its mission and goals.

c) Advice and principles to achieve successful commercialization.

d) Points to consider for DOE and its M\&Os/Labs regarding technology commercialization.

Part B is from the Western Governors Association's DOIT Committee, who also held industry roundtables. Its objectives were to discuss technology demonstrations and the commercialization process and to ensure that business and market criteria were included in technology selections for site demonstrations. Part B includes:

a) Major recommendations for successful technology demonstrations.

b) Ratings and analysis of critical elements for successful demonstrations.

c) Successful commercialization as seen from different organizational points of view.

These comments give a good business and market perspective to DOE-EM's mission and objectives. They are based on the realities of the political, regulatory, and bureaucratic barriers that the environmental industry has had to face in this country; and on what has worked for those that have been successful in the private sector. 


\section{A. IOOE INDUSTRY ROUNDTABLES}

\section{DOE TECHNOLOGY COMMERCIALIZATION: INDUSTRY PERSPECTIVE}

\section{Major Issues Raised/ Past Problems}

"Why are the M\&Os/Natl. Labs doing demos on technologies that are already being applied successfully in the private sector?"

"If they don't generate sales, demos are a waste of time. They cost money, with no return. DOE keeps asking us to do demos without any work on the other end."

"If we do a demo at a DOE site and our technology works, then why can't we get the contract to do the actual work?"

"Transferability of demos is important. If you demonstrate a technology at a federal site -- then what? Will the regulators recognize/approve that for the next site? Will DOE? Single sites are not a big enough market to be attractive."

"National Labs and M\&Os need to realize when they are competing with industry.

- If industry can do it, why are the Labs/M\&Os trying to do it?

- Industry can do market assessments, cost analysis -- and do it better.

- National Labs also compete with each other to be enviro-tech centers."

"Why are the Labs/M\&Os serving as 'centers'; they aren't near industry! And they aren't in the center of the marketplace!"

"What do the 'centers' do in terms of getting remediation done?"

"If a National Lab/M\&O invented cornflakes, it would be packaged in a satellite. It doesn't come in a simple form that you can instantly sell. They don't know how to be cost-effective; they don't consider return on investment in short, they are not competitive and they are not endresult oriented."

"The M\&O cannot be the interface with EPA, since the M\&O is seen as the generator of the pollution problem, not the solution."

"The M\&Os/Natl. Labs soak up all the money, with little cleanup to show for it."

"Too much money is going to consultants and research [study, study], not real cleanup. 95\% of the money goes to services, not equipment (commercially available technologies)."

"Natl. Labs/M\&Os steal small businesses' technologies. They ask us in, we do a lot of up front work at our expense, then the job goes to the Natl. Lab or M\&O. Sometimes the job goes out for bid to an $A / E$ (who works from the plans we give the $M \& O$ ) or to some fly-by-night outfit."

"Procurement cycle is too long, cumbersome, and mysterious." 
Other procurement issues:

- "If I successfully demonstrate my technology, why does that disqualify me from doing the actual work?"

- "Why can't the DOE sites just issue fixed price orders, hire companies that can put equipment in, and get the job done?"

- "Why can't the M\&Os break the work down into more specific packages and put them out for bid?"

- "Why does it take so long (months/years vs. days/weeks)?"

"There is not much incentive to try new technologies.

- Not only to industry to help DOE clean up its sites, but also to the M\&Os and Natl. Lab staffs, either to develop/commercialize their own technologies or to use commercially available technologies."

"Environmental market is very fragmented; it is not one big ' $\$ 200$ billion' market."

"Must understand that right now, regulators are site specific; there is no national market. The regulators don't permit technologies; they permit locations."

"Regulations need to define what constitutes cleanup first, then cost and profit issues follow."

"Indemnification is a problem for businesses to cleanup federal sites." 


\section{DOE TECHNOLOGY COMMERCIALIZATION: \\ INDUSTRY PERSPECTIVE}

\section{What an M\&O Can Do}

"Provide an opportunity assessment. Give industry a definition of opportunities. Make it attractive to industry. Give more information on your site, your capabilities, your test facilities, your remediation and waste processing problems; your point of contact."

"Give industry the process benchmarks (identification of remediation problems/areas, demo phases, bids, contract awards) that would reduce industry's technology and capital risks."

"Use technology from private industry for immediate cleanup problems; M\&Os/Natl. Labs can provide technical support."

"Look for where industry puts money, which technologies."

"Leverage investment into companies, not drain it away."

"Use your research strength to solve private industry's need for timely applications and competitive packaging."

"Use your site to become a "reference" site where a small technology company can get data that the government buyer needs to put that technology to use."

"Help get public acceptance of a technology."

"Utilize industry associations, pooled intelligence, common problems."

"Provide financial incentives for industry."

"Set up your commercialization program as a source of funding, not a cost."

- "Why should industry fund a National Lab or M\&O? They already have our tax money."

- "Pool some money from the National Labs/M\&Os; they really won't cooperate unless they are grabbed by the purse strings. Then make the pool available competitively to joint projects with industry and the Labs/M\&Os."

- Money could also be pooled from other federal programs: DoD, Superfund.

(Superfund spent $\$ 12$ billion with little to show for it; they need leverage).

" Don't expect CRADAs to attract the entrepreneurs; CRADAs are useless to smaller companies; there is no cash."

"Must define the size of the risk, especially for environmental technologies where regulations play a significant role."

"Work with the regulators on a broader permit and more realistic regulations, or the interpretation of regulations."

"Get the EPA at the table."

"Use something like the Western Governors Association [DOIT] program which brings a lot of vital stakeholders to the process, and garners local regulatory buy-in." 
"Streamline performance data approval; one-stop permitting."

"Address regulatory/permitting issues up front, reduce uncertainty, because the Time-to-Market is too long to justify up front investment."

"Address regulatory/permitting issues for DOE site-to-site."

"Intellectual property must be protected from M\&Os and foreigners."

"M\&Os need to demonstrate innovative procurement, not just technology. Reduce the complexity and length of time to get a contract."

"Deal with procurement bottlenecks and conflict-of-interest barriers."

"Put out the performance specs for a remedial or waste handling problem; don't name a specific technology, just describe performance. Low bidder wins."

"New technologies need to consider process engineering parameters, cost effectiveness and technical feasibility--this includes capital cost and operating data."

"Don't try to reinvent the wheel."

"A clearinghouse of technologies and needs would be useful."

"Truth of your program will be in implementation."

"The M\&O program needs to be designed not so much as to spend money, but to attract money."

"Ready, fire, aim! Start somewhere, anywhere; get some specific bids on the street. Learn as you go." 


\section{DOE TECHNOLOGY COMMERCIALIZATION: INDUSTRY PERSPECTIVE}

\section{Successful Commercialization}

"Know where you lead; where you follow. Don't move on a market unless you know if you have a solution. Be accountable for what you do. If you have a window of opportunity, move on it (time is of the essence). Know what your effort will cost. Also consider cust to the community."

"Decide what business you're in and what you're not in."

"You don't have to have as big of an economic return if technology development gets you in a new market soon enough."

"Don't forget the basics: function and cost."

"Government funding can play a critical role bridging the capital gap over the 'Valley of Death' from prototype to expansion for market entry."

"Reserve some money for commercializatior. vs. technology development. Commercialization, including manufacturing and marketing, is expersive."

"You must shift the cost curve for the end user, in order to be viable or show a potential for savings."

"Start small; build on your strengths, supporters, and successes."

"In the environmental business, if you do not have at least a half an order of magnitude in performance [pollution or liability reduction], then you do not have a product. The bias against switching is too high a barrier."

"Technology must markedly shift the cost and uncertainty curve down for the customer."

"Remember, the end product for the customer is regulatory compliance, not technology."

"Measure progress. Look for intermediate milestones, not just long-term."

"Look for Return on Investment: Sales, profits."

"Though it is regulated and takes a long time, biotechnology attracts investors, because the pathway to market and milestones are clear. Environmental technology is less attractive; the ROI pathway is not clear."

"The environmental industry is a multi-pronged industry. You need comparative analysis, solid market research, and a plan; don't just crunch numbers."

"Need an FDA (Food \& Drug Administration) type of universally-recognized approval for environmental technologies to facilitate use in national and international markets."

"What are some of the upcoming regulations that will lead to new markets?" 
"Provide incentives for:

-the small business to reduce risk of failure;

-the M\&O engineer to identify the site applications; and

-the Natl. Lab scientist to develop and commercialize his technology."

"This is the easiest test of all: The market decides. Sales = Success." 


\section{DOE AND TECHNOLOGY COMMERCIALIZATION}

\section{Summary Points}

Mission: Accelerate the commercialization of environmental technologies that reduce the tremendous cost of DOE/DoD cleanups, while supporting the development of globally competitive American environmental firms.

Qbjectives (based on comments at Industry's Roundtables):

- Must address key barriers to speeding up technology commercialization.

- Must build on resources in place, e.g., DOE Labs. and military bases.

- Must integrate private and international sources of technology.

- Must mobilize private capital and co-funding of commercialization.

- Must be a source of funding itself to initiate real change (e.g., ARPA).

- Must develop accelerated process collaboratively with regulators (EPA).

-Regulatory buy-in is a show-stopper for commercialization -Procurement process is overwhelming

- Seek to leverage public investment with private resources in pushing forward the commercialization process of technology.

\section{Potential Payoffs Worth Risks:}

- Pioneers new alternatives for putting government capital into play as true "investment" with private leverage (vs. just government spending).

- Encourages more risk-taking on cutting edge technologies than either the public or private sectors might otherwise fund.

- Moves DOE-OTD into real role as "investor" with ROI orientation can push DOE Labs to play by new market-driven rules.

- Insulates government funding more from pork barreling.

- Moves cost-effective technologies into commercialization faster.

- Return on investment not just measured financially, but also "fiscally", as cleanup cost reductions, jobs created/saved, revenues generated, exports. 


\title{
B. PERSPECTIVE FROM ANOTHER REGION (WGA)
}

\author{
DOIT Industry Roundtable on Commercialization \\ Aug. 19, 1993 - San Francisco, CA
}

\section{Purpose:}

- Define how technology demonstrations fit in commercialization process.

- Ensure that site and technology selection criteria for demonstrations foster commercialization and address market challenges.

- Identify other opportunities for DOIT Committee in commercialization.

\section{Major Recommendations to DOE:}

- Market Development ahead of Technology Development.

"Demonstrations without market development are worthless.

We need customers to buy once we have proven it by demo."

- Demonstrate procurement reform, not just technology.

- The DOIT demonstrations can be utilized to illustrate innovative procurement as well.

- Industry is not looking to circumvent competitive bid, but simplify the process.

- The regulations ensuring "fairness of opportunity" stack the process against innovators and in favor of the usual government contracting crowd, M\&Os, engineering firms.

- Standardize performance data formats for technology.

- A standard or modular format would help streamline permitting and market acceptance.

- Perhaps this could be coordinated with EPA-SITE, since they do it anyway.

- However, EPA-SITE and other federal programs take too long to generate reports.

- Facilitate interstate permitting for regional markets.

- This would create a larger market by streamlining regulatory approval.

- Timing seems to be excellent for this as a number of state environmental agencies have already been meeting with WGA to move forward in this area.

- Cal-EPA is moving aggressively on regulatory reform as part of its Environmental

Technology Partnership that is very focused on commercial issues.

- Delineate liability limitations for demonstrations.

- Few innovators and investors will play in the federal sandlot without liability limits.

- National Labs, bases can play a role here by serving as test beds where liability is bounded.

- Compile and communicate federal market data.

- Especially on federal procurements: who's getting what, where, how much, etc.

- Widespread consensus that federal purchasing was poorly compiled and articulated.

- A good candidate for privatization though, rather than having a government agency do it. 
- What are the critical elements for industry in demonstrating innovative environmental technology?

(A budget of 10 votes for each person; up to 5 votes on a single issue)

\section{Ratings}

35 Clear procurement path if demo is successful

22 Independent report on performance and costs

17 Integrated permitting (state/Federal, cross-media)

16 Waiver of cleanup liability for demo

14 Well-defined performance criteria

12 Preservation of company intellectual property

10 Funding or partial funding (cost-share) of demo (one group rated funding of demo high)

\section{Analysis of ratings:}

- All groups underscored the lack of urgency in government operations vs. the more rapid time cycle in industry in response to demand for return on investment.

- All agree with industry that procurement is a problem.

- Procurement complexity dampens enthusiasm of investors and technology developers to pursue federal market at all. What if you threw a party and only your in-laws came--the inlaws you paid to come."

- Performance data is seen as critical to bridging the gap to commercial markets for payoff.

- Integrated permitting is complementary to securing performance data to open markets.

- Liability is important, but some have found ways to manage it by being selective on projects.

- Performance criteria are useful, but other issues seemed more pressing.

- Intellectual property is a hygiene factor, i.e., it becomes a problem if not taken care of.

- Funding of demo is helpful, but not as important as clearing up the bigger procurement path. 
What is

"Successful Commercialization"?

VIEWPOINT

National

Laboratory/

$\mathrm{M} \& \mathrm{O}$

ORTAs

Government

Contractor

Startup Tech-

nology Firm

Growth

Company

Venture

Investors

Regulator

\section{MEASURE OF SUCCESS}

Technical brief filed; Patents

Inquiries from industry

Information Outreach

- No real business; limited sense of market

Conferences with industry

CRADAs, Licenses negotiated

- No product; may not be market-driven

Large scope of work approved

Technology demonstrated to Government

- No regard to cost, nor market demand

Contract for R\&D (e.g. SBIR grants)

Demonstration in field

- No manufacturing ramp up

Sales; Repeat Bookings

Net Positive Cash Flow

- Commercial application

Profitable Sales with ROI

Significant Market Share

- Commercialization that returns investment

Pollution Prevention and Cleanup 


\section{Barriers/Incentives from the Company/Investor Perspective}

\section{Stage of Commercialization}

Research and Technical Concept

Proof of Concept Testing/Simulation

Prototype Development and Business Plan

Pilot Fabrication and Demonstration

Production Engineering

Full-Scale Use; Commercial Introduction

\section{Barriers to Commercialization}

- Poor communication/market intelligence

- Lack of early stage capital

- Need for identification; market-driven specifications

- Poor communication/market intelligence

- Lack of early stage capital

- Need for identification; market-driven specifications.

- Multi-level regulations and permitting

- Inexperienced company management

- Excessive liability exposure even on small demonstration volumes

- Lack of indemnification

- Public skepticism

- Lack of performance/cost data

- Risk-averse industrial customers

- Multi-level regulations and permitting

- Low contract margins (DOE/DoD)

- Inexperienced company management

- Ill-defined distribution in marketplace

- Joint and several liability

- Public skepticism

- Cumbersome procurement procedures

- Inconsistent enforcement

- Lack of "good old" engineering practice

- Sole ownership/exclusive license of government-funded technology

Examples of Incentives/Programs to Overcome Barriers:

- Industry-DOE/DoD joint technical conferences; journals

- Public: PRDAs, SBIRs/private SBICs, incubators

- Environmental technology databases

- Streamlined permitting (e.g., at test beds, demonstration sites)

- Investor screening

- Bounded liability for innovative demonstration (e.g., DOE-site)

- Predefined indemnification (as in DOE-site) 
- Facilitated site agreements/hearings

- Fast-track for demonstrated technologies

- DOE/DoD demonstration sites $\rightarrow$ performance data + approval

- Integrated regulatory approval for treatment trains

- Enviro-Industry Association forums; investor screening

- Industry trade shows, engineering firms, ERMCs

- Bounded liability under Negligence Standards

- Contract set-asides for small business, licenses

- Cluster teams; regional agreements

- Funding to firms for experimentation, innovative demonstrations. 


\section{A. PILO'T PROGRAMS CONCEPT}

\section{Introduction}

This is a concept of establishing "centers" or "networks" of industry, entrepreneurs, investors, regulators and Federal sites to most effectively support technology commercialization and business growth by drawing on the collective resources of the governmental, academic, financial, and industrial communities. It would focus on an environmental/waste need of not only DOE, but also regional industries, such as the pulp and paper industry.

\section{Purpose}

The purpose is to promote the development and commercialization of technologies related to Savannah River Site core competencies in accomplishing the environmental restoration and waste management objectives of DOE-EM, while addressing critical regional environmental economic priorities.

\section{Objectives}

The following objectives have been set forth by the pilot:

- Based on posiuive market assessment vs. research focus;

- Bring together a "critical mass" in science and industry for a vital growth sector;

- Utilize SRS technical resources, facilities and environmental priorities - build on SRS and regional case competencies;

- Partner with local universities for scientific resources and technical talent;

- Allow industry a lead role in prioritizing funding and project selection;

- Focus on "dual-use" technologies that address environmental problems common to both industry and DOE/DoD, with an eye to exports;

- Work with regional organizations to garner regulatory buy-in and economic development/community support; and

- Foster links with similar international organizations to facilitate exporting.

\section{Description}

- The concept could be a non-profit entity that would network with various industries, regional economic development organizations, investors, state, local and Federal governments, academia, industrial associations, professional organizations, and others.

- It would be a small cadre and include the collective expertise and resources of
a) SRS technologies, facilities and its commercialization programs,
b) specific remediation or processing problems and technologies,
c) new business start-up or expansion and management,
d) community-economic factors,
e) market analysis, and
f) capital financing. 
- It would collaborate with any or all of these groups to support environmental technologies, such as innovative waste minimization or optimum treatment processes, and ensure investments are made in those technologies and processes with the highest potential for environmental and economic success.

- Funding levels and related resources must be established. In addition, the pilot must be a source of funds to attract private capital, matching resources, and worthwhile commercialization projects that stimulate economic development.

- The organization would be renewed on a 3 to 5 year basis after review and evaluation.

- It would involve regulators early in the technology/process development in order to facilitate permitting and other regulatory buy-in, as well as, necessary market development.

- This could be a series of pilot technology commercialization initiatives that have a specific environmental, technical, and economic focus, (such as water resources, mixed waste processing, hydrogen science, stainless steel reuse, etc.).

The following description of a "Water Resources Technology Center" shows how these pilots could be implemented.

\section{B. EXAMPLE: WATER RESOURCES TECHNOLOGY CENTER}

\section{COMMERCIALIZATION PILOT}

\section{Purpose}

The purpose is to promote the development and commercialization of technologies related to water resources, including groundwater, surface water and wastewater monitoring, usage and treatment, particularly as it responds to regional environmental and economic priorities. It should encourage industry-government partnerships and leveraging resources to solve common environmental, waste, and pollution problems.

\section{Technical Areas (that build on SRS Competencies)}

- Groundwater assessment, modeling and treatment;

- Wastewater/contaminant monitoring (real-time), instrumentation and treatment;

- Manufacturing water reuse/ recycling;

- Aqueous waste processing and sludge treatment;

- Advanced computer simulation, methodologies and technical training;

- Biotreatment processes; and

- Physical/chemical processing to improve water usage.

\section{Funding Sources}

Possible funding sources that should be examined are:

- Federal Agencies--DOE, DoD, USDA, NIH, DOC;

- Pulp and Paper, Timber Industries;

- Textiles (AMTEX);

- Chemical and Pharmaceutical Industries;

- Electronics and Industrial Manufacturers; 
- Water and Power Utilities;

- Beverage Makers (e.g., Coca Cola); and

- Food Processors.

\section{Resource Partners}

Listed below are several resource partners considered to be "at stake":

- Municipal Water Treatment Works;

- American Water Works Association;

- Agricultural Associations and Farming Combines (Farm Bureau);

- Regional Government Organizations;

- Regional Economic Development Organizations; and

- Universities (graduate students, research base). 


\section{Implementation}

WSRC will offer a solicitation for proposals to establish the "WRTC", based on selection criteria (listed below).

WRTC would then offer matching funds on a "challenge" basis to generate interest from companies that have garnered private capital and are developing a technology or process. WRTC could also coordinate SBIR grants. The matching funds help kick-start the effort by providing and stimulating private investments in companies that support job creation and commercialization in this region, rather than just funding activities with minimal or no potential for economic development. WSRC/SRTC would provide project management, test facilities (such as the Effluent Treatment Facility), testing equipment, and technical expertise; and provide the interface with DOE.

Interested industries/industrial associations with problems or projects would submit their proposals to WRTC. In turn, WRTC would also select commercialization projects based on "greatest potential for success" criteria. (Criteria are based on historical and statistical data on technology-based businesses.)

The successful project will be one that has private or venture capital or some matching of other resources, such as an industrial association or consortium, or a university partner or perhaps from a local utility or municipality; with the objective of creating a business, spinning off a business or expanding a business, into new markets, and thereby, increasing the availability of jobs and diversifying the economic base.

\section{WRTC Criteria (example)}

1. Essential Criteria

- Economic development and employment in the 5-county region.

- Must have the following represented in the team/partners

(i.e., show demonstrated background or experience):

--Industry, preferably representative of the region;

--Industry concerns with water resources;

--Understanding of entrepreneurship;

--Strong university-based research capability;

--Private matching resources, including facilities, equipment, people;

--Environmental regulatory expertise, including local and regional;

--Represent both South Carolina and Georgia; and --SRS familiarity.

- Private matching capital and capital-formation capability.

2. Desirable Criteria

- Links to other DOE sites/facilities.

- Utilizing minority-owned, women-owned, handicapped, veterans businesses.

- Working knowledge of commercialization models and mechanisms.

3. Supplemental Criteria

- Developed computerized databases.

- Experience with establishing coalitions, networks. 


\section{APPENDIX 1}

SUCCESS FACTORS IN TECHNOLOGY DEVELOPMENT a Paper by John T. Preston, M.I.T., Director of Technology Development and Manager of the Technology Licensing Office 
John Preston is the Director of Technology Development at the Massachusetts Institule of Technology. As Director, ne manages the Technology Licensing Ofrice which is responsible for gatenting and licensing of M.I.T. Lincoin Laboratory and Whitehead Insurute inventions and software. He is a member of the Board of Direciors of Molten Me:al Tecinnology, Envionmental BioScience. and is Chairman of the Technology Transfe: Advisory Panel for the Stratesic Defease irivative of the linited States Deparment of Deiense.

Mr. Preston received his Bachelor of Science Degree in Physics from the University of Wisconsin, and his M.B.A. from Noriwestem University. His professional activities have been directed ioward technology transier, and speciñcally toward issues related to staning new high :achnology comoanies. He has founded. or assisted in founding, companies tha! are curtently wort several hundrec millions of dollars. In addition. about +0 companies, mostly spin-offs of M.I.T., have been siared. in par, through his effors.

\title{
SUCCESS FACTORS IN TECHNOLOGY DEVELOPMENT
}

\author{
By: John I. Preston (Revised 9-26-92)
}

\section{RTRODLCTION}

Liniversicies in the United States have a significant impac: on business through the transier of technology. This transfer of technology takes various forms. inciuding faculty commurications (such as leciuring and the publication of research resulis), faculty consulting activities. and the direct transier of technology through the licensing of patents. copyrigints and other intellectual property to industry.

Well-tained students and professional safff who leave the university to work in industy probably represent the universities' greatest contrioution to industry. These persons stimulate creativity and oring rew ideas and perspec:ives 10 industry.

Perhaps the most dramatic form of technology transier from universities, is the creation of new businesses. A 1988 study of MIT spin-off comparies by the Bank of Boston revealed that its personnel and technology were involved in six hundred and thirty six companies localed in Massaciuse:ts. In 1988 . these companies emploved over 200.000 Massachusetts resicients, with annual revenues of $\$ 39.7$ billion. Hac ail of these revenues been within Massacinusers. it would have amounted to about one-third of tia Commonweaith's entire economy. A 1989 siudy by Chase Maniatian Bank identiried $225 \mathrm{MIT}$ spin off companies in Silicon Valley with annual revenues ove: $S$ ? 2 billion. A study of Stanford spin off companies would probably show similarly impressive economic impac:

Regional economies receive a double benerit from these ingh tech, spin ori companies. Several siudies have incicaled that for every high technolog' joo crealed. four or ive low lech jobs (retailing, govemment. hoteis. construction ...) are also created.

Companies Eounded by MT people inciuce Digital Eọuipment Rayutheon, Analog Devices, Lorus Deveiopment. Inie!, Genentech and several other large businesses. Many MIT spin ofi companies achie:e tremencious growth ales. Such companies are oten characterized by the following: seed 
inarcial investment secured from a ouvitr: source of apital; talented entrepreneurs wi:- diverse and complementary management back govids: and a core achnolegy with oroad appi:ability. aure:ous produeis, and consideracle s:owin foteniaj. These companies seem io pla: an enormous role in simulating the ecor any and creating joos.

Intenational competitive factors are forcing America to wake up to the inporance of encouraging technology transfer and the creation of high tech companies. The Linited States spends more on research and development ihat any othe: counzy. In taci its research expenditures are roughly equai to the combined research of Japan. Gemany, United Kingdom and France. The LS Govemment has recognized the imporance of domestically capturing the value added of our research and numerous laws have been passed that streamine iechnology transfer. Tre net effect is that there has been enormous growth in formalized technology unansie: from US resarch instirutions to industry ove: the last five years. Universities and Govenment Laboratcries have become much more aggressive in finding mectianisms to get their technology commeralalized. no longer relying only on publishing research results and tansteming trained people. To support this conciusion the following are interesting examples:

- MIT licensing income has increased irom 51.8 million in 1985 to $\$ 16.2 *$ raillion in 1992 (*includes equiry taien in lieu of royalties).

- During the same period. Stanford licensing income has increased frcm $\$ 3.9$ million to 525.5 million.

- University of Califomia licensing income has increased from $\$ 5.4$ m:ilion in 1987 to $\$ 31.4$ million in 1992.

- Research Corporation (which handles the licensing of several US university patents) increased its revenues from 310.3 million in 1987 to $\$ 43.3$ miijion in 1991.

- British Technology Group (which licenses several UK university patents and recently set up in the US to handle US patents), increased licensing revenues from $\$ 28.9$ million in 1987 to $\$ 43.9$ million in 1992.

Often a single very imporant invention can skew the royalty figures above. For eximple, the basic gene splicing invention (Cohen Boyer) accounts for about eignty percent of Stanford's royalty income and a significant portion of the University of California's royalty incorne (the invention is joirily owned by the two universities and licensed by Stanford for both). Similariy, BTG's results nave been enormously effected by cephalosporin (an antibiotic which made over 5250 million in royalty income), pyrethin (pescicide), and raggnetic resonance irnaging (MRD) technoiogy. University of Forida receives mosi of is royaity from the Garonde trademark Univexity of Wisconsin receives large royalties from viumin D patents and Michigan State through Research Corporation receives most of is royalties from cis-Platir an anti-cancer dug.

The effect of single imporant inventions can be isolated by ignoring royalty income and only measuring towal number of licenses. This exercise vieids similar growth rates to the rovalty data. For example, during the period above. $M \Pi$ increased from 15 new licenses in $19851080^{\circ}$ in 1992.

\section{GOALS OF THE WIT TECHNOLOCY LICENSNYG OFFICE}


There are + major goais of MTT's Technology Licensirg Office. The inrst goal is to bring about the äicient tansier of tecinolog! as a way of maring the lecinology available to the pubiic. To accomplish this end. MTT is $\cdots$ iiling to give a'w'ay :echnology when it is in socie:y's best interesi. WIT receives nearly $\$ 650$ million annually in :esearch funds from the LS government--NiTT thus $\because$ iews the public trust and is obligations to society as ver: imporiant. With some technologies. the puolic is beter served if it is re!eased to the public domain, especially so if the tecrinology has a very low cost thresinold to reacis the market Soinware is someimes a good exampie oi a low inresnold lecinoiog' ard, ir. izcl, ore of the leating sofiware packages. X-Window's, is licensed tor free by MIT.

By way of contrast. if biomedical products are placed into the public domain. they may never reacin ife marketpiace--ihe cost and regulatory hurdles to bring a new phamaceutical io market are simply too high. For exanpie. if someone invented aspirin today and patent protection was not sought. the irst company that commercializes this technology would bear much larger expenses than the second company and would have an enomous commercial disadvantage. The cosi of proceeding through the FDA approval process may be as nuch as S150 million--no company vould spend this money if a comperitor could susseouendy follow the initial company aro make ine product without having 10 incir ine research and reguiatory expense.

The second goal is to manage conflicts of interests that are inherent in faculty-indusiry interacions. WIT has created a set of policies to manage and prevent conflict Tnis goal has equal priority to the irst goal. In other words, tecinology transfer siould not occur unless potentiaj connlict is managed.

The third goal for MIT's licensing oîrice is to make money for the institution and the scientisi In addition to provicing motivation, royaliy sharing gives positive feedback.

The fourih goal is to generate good will both internally with MT sinff and extemally with the licensees

\section{MIT'S LICENSING PHILOSOPHY}

The TLO has undergone a radical chilosophical tansition over the last 7 years, resuling in a number improvements in the technology irasier process.

The furst change was to move the marketing of inventions away from attomeys and instead hire technology-trained business people. These pro:essionals are MII s catalysi for technology iransfer. By contrast the lauvers concentratec on the protecion of the intellectual property more unan the transier process.

The secono phïosopinical change is that $M \Gamma$ is woiking with a greater number of small or star-up companies. When dealing uith an emoryonic tecinology. Formine 500 companies are ofien not pariculariy well suited to license and develop the echnology--rather. small star-up companies can ze betrer suited to cormerciaize ne $v$ and earjy sizge tevinologies. This is paricularly urue urien the tecinnoiogy lowers the value of ine comparies prior investnents in capial eopuproent A good example of this is the quarz watch. wnich was invented by the Swiss. The quarz watch did not -alch well with the Swiss uatch indusury insiniled base of fune macinining and was dismissed by the indusiry as not able to compes. Tnus they iaited to patent and were even conidient enougin in : be presented at a trace sinow. Iwo companies ai ise trace sirow, Seiko and Texas instruments, recognized the imporance of the ouarz watcin - nameiy its iack of machined pars and stared eiforts to commercialize this new product Witin ten years of the rade snow. the Swiss 
World wide market sirare had dropped from $\$ 550$ to 15\%. It is human natu:e to be biind to changes that do not fit our prior experierce of success - thus the Swiss were blind to their own inven:ion. A favorite qucte tiat drives this point home is from vapoleon. which is: "What sir. you mean to tell me that by lighing a bon tire under the deck of a ship you can make it sail against the wind and the curents? I pray you excuse me. I have no time for sich nonsense." He then showed Roier Fulton out of his ofince.

Small companies do not have these ingrained success paracigms and are thereiore more willigig to accept ideas that shift the former success modeis. They also have less invested in intemal research and development and are more willing to "impor" ideas. Furthemore they are often more wiiling to take high risi and to develop and prove the product concept bridging the funding gap benven concept and protorype. After bridging the gap small companies of:en develop parmerships with la-ge companies to accelerate market penetration and obtain funds tor scaje-up. It should also be noced that a dollar spent by a small company for technology development usually accomplishes more than it would in a large company. This is explained below by the differences in passion.

About fifty percent of :IIT's license agreements are with small companies. with fewer than $1 C^{\prime}$ ) employees. Ten percent of the license agreements are with new companies. created around the technology and the remaining forty percent goes to large companies (rypically Fortune 1000).

MTT snares risk with its licensees by deferring royalty payments or taking equity in lieu of royalties. This encournges companies to take the up front risk necessary to commercialize iIITs iechnologies. If $\mathrm{WIT}$ charged a company acquiring the early stage tecinology a large up-front pavment. the risk of failure is transferted completely to the new company. If a cash fee is deferred, if no fee is charged, or if the fee is taken as equiry, without an inidial license fee, the development risk is sinared with the licensee. MTT typically requires an initial payment-technology is not licensed only for eouity and/or royalties--but its up-front license fees are on average lower when the office was managed by lawyers, and as compared with other licensing offices which are run by lawyers. Also MIT's running rovalty rate is low relative to most licensing offices. One could auestion the wisdom of our approach. Why not try to optimize the returns from each deal? Interestingly, optimizing the royalty rates and up front payments may not opumize the long term reward. The larger the piece of the pie taken by licensor the lower the interest of the licensee. If a new opportunity presents itself to the licensee and the profit is marginal for the original license, there is a good chance that priorities will be sinifed. The worst thing to happen to a licensor is to have your custome: shift your project from priority one to priority twenty-seven. This almost always means the slow death of the project and is mucti worse than a crisp temination, which might allow the technology to be salvaged through another license. In the section dealing with passion below, this will be discussed in greater devil.

An audicional reason for limiting the amount of the inivial license fee (thus sharing in the risk and success of the siar up company) is that by doing so, the probability that the company will succeed may te enhanced. For example, if a new company has $\$ 2$ million in venture iunding, and pays $\$ 1$ million as an inicial license payment the likeliniood that it will be able to develop the tectnology prope:ly, and acnieve its business goals has been reduced tremenciously as it now only has a milition dollars left to build the business. Success factors for new companies are imporant to consider because the licensor's reward is greatly impacted by the likelinood of success of the company. Licensors are often berer advised to devote time and et̂́n increasing the probabiity of success of the licensee. rather than increasing the rovalty rate. Stated differenty, it is much more $v$ aluabie to create a business with an eignty percent likelinood of success, and a two percent royalty rate, thar to create a business with a twenty percent probability of success and an eight percent royaity rate.

A heaithy attitude for a university of Government licensor is to think that your licensee is giving you a small amount of money for the privilege to spend an enormous anount of money making 
your tecinology work, and if it worles both you and the icsesse uill make a good amount of money. Corporate icensors ci more develored technolog!es should be more mercenan in pricing.

\section{MMPORTANT FACTORS FOR SUCCESS RN NEW BLSNESS FORMATION}

There are several imporant variajies that impac: the probability of success for any new siari-up company or a new business unit within an existing company: These variables inciude the guality of the technojogy $(Q t)$, the quaity of the management team developing the tecinnology $(Q m)$, and quality of the source of money or investors (Qinv).

When staring a new business, the probability of success (Ps), is proporional to the produc: of the variables. and although this snould not be iaken too seriousiy, could be expressed by the following formula:

$$
P s=Q_{t} \times Q_{m} \times Q_{i n}
$$

The variables are ranked from zero to one. with one being the best score. Thereiore if all variables are given the highest rating, one. the business is guaranteed to succeed, but any zeros guarantee iailure.

\section{Quality of Technology (Qt)}

Technology receives a high rating if the invention has the potential to create a number of new products "product pipeline"; has a strong patent or copyright position; and has considerable market potenial.

An invention that has the capacity to create many products greatly diffuses the risk of technolog: faiiure in a new siart-up company, and offers more opportunities for success. Genentech. Inc. is a good example of having a viable produci pipeline--its gene splicing technology can be used to generate many different products. e.g., TP.A and Insulin. Bỵ contrast. Lotus Development Company t:ad only a singie product. 1-2-3. Despite Lotus' success, I would argue that Genentech's technology had and has a highe: probability of success. Perinaps the problems trat Lous Development Company experienced with Jazz and Simphony (subsequent products) stems from the fac: that its a core tecinology did not provide a big advantage to designing these products

Another crivical factor for success reiates to the need for a stong patent (or intellectial property) position. unich provides a wider window of opporinity for a company to develop and commercialize it producis without direct competion. A sirong patent position gives a monopoly to the patent holder, keeping other companies at bay from the protected tecinology. Ine Japanese someimes address a patent that they wish to have access to by illing "piciet fence" patenis. In efîect. the Japanese company wiil fïe patents that represent small incremental innovations around whe core tecinology they wisn to acouire. If the incremental innovations represent the prefered way in which the base tecinology may de used commercially, a basiser to the effective use of the iesinoiogy is created. They are then in a position to force cross-licensing of patents to acouire the core technoiogy. Tnis can be prevenied by carent pianning and a oroac patent esiale--if you have 20 patents, with 20 ciaims each. it would be difficult for someone to work around the patent esiate. or to patent ail the incrementai improvements. This grealy eninances leverage of the owrer oi the core tecinology in atracing parne.s a riher than compecitors. 
The marl:er potential of the tecinnology is ocviousiy inforiant A technoiogy with a billion dollar business potental will have a nigher probability of success than one witt a million dollar market.

Quality of the Management (Qm)

The quality of the management is crucial to the success of the vearure. Management gets high cualiry ratiogs if it mainiains a healihy balarce shest: has a clear!y focused strategy: and is realistic about marketing. A healthy balance sheet is the best way to assure that the tinanciers will be interested in maiving additional investments at later stages in the business's development Almost every rapidly growing business will require additional funds as it prepares to produce products. or (in the case of bioiecinology /phamaneiutical products) begins clinical tials of its products.

A clear strategy is essential because of the riluid narure of a new business--numerous paths that appear interesting will be presented. and must be filtered through a well-conceived strategic plan. Management that fails to do this will expend enormous energies on sub opimal eifors.

Good managers musi be realisuc abou: the market for their prociucts. Much effor should go into the analysis of the market with a clear understanding of why products wiil or will not be purchased. and a clear understanding of how compeciuve products will respond.

For example. when the transistor was invented. the vacuum tube manufacrurers redoubled their R\&D and mariecting efforts. As a resulh vacuum rubes shrunk to half their size. half the power consumption and half the price within 5 years from the invention of the transistor. In fact. they were doing a great job of protecting their market unil Texas Insuruments developed an application for the transistor where vacuum tuoes could not be ensily used. i.e.. hearing aids. The hearing aid saies enabled uransistor manufacturers to reduce the price/periomance ratio of the transistor sufficiently to compete with the vacuum tube in other iusinesses. A good counter example is the thirty year-old competition between silicon ( $\mathrm{Si}$ ) and gallium arsenice (Ga-1s). GaAs is much faster than $S i$ and from a fundamental viewpoint should displace $S i$. However, innovation in Si has been just fast enough to keep a better price/periomance ratio than $\mathrm{GaAs}$ in the broad markets, leading to the joke that GaAs was, is, and always will be the material of the furure. By ancicipating the reaction of the competition, and positioning the new technology properly in the mariet place, good managers can successfully commercialize new tecinnologies to the markerplace.

Quality of the Investor (Qv)

The first rule of ouilding a business is that it will take more money than you think.

There are a number of factors that influence the quality of the investor. first the track record in building successiul businesses; second, the network of connections with potential parners or customers; third, the level of personal involvement the investor is willing to devote to the business; and fourh, their access to money and long-term vision.

There are several examples of venture capilalists who have funded dozens of new companies over the last ten to twenty years. with only two or three failures. where failure is defined as a company in wirich the originai invesior failed to break even or is unlikely to break even. Clearly, the involvement of an investor with such a strong track record raises the probability of success.

Similarly, the investor's nerwork of connecions and abuiity to influence juategic parners impacis the probability of success. A venture capitaist with high-leve! contacts in industry can make $a$ substantial differences in developing parneships where such association could reasonably exiance the likelinood of success of the ne'v technology deveiopment process. 
Access to additional funds can determine winether a star-up company fails or succeeds. Federal Express. for example. went through five rounds of venture invesiment before finally achieving stabiity and outgrowing the need for venture iunding. A large number of rounds of venture capital is usually "painiul" for the star-up and indicates that the long term fundamentals look good, but the snor term results are disappointing. In the case of Federal Express, Rothschild Ventures took the lead in all five rounds-- the iact that Rotitschild had access to large amounts of money was tinerefore a major deleminant of success. Otienwise Federal Express might have failed for the wrong reason -- lack of cash.

\section{Passion for Success $(\mathrm{Pa})$}

The second rule of building a business is that it will be harder than you ihink.

The passion of the various players is a key determinant of success. Worded differenuly, any new business will encounter hundreds of barriers beiore it succeeds. People with no passion will use the first barrier as excuse for iailure, while people with high passion will do whatever it takes to overcome the barriers.

The formula is now modiiied as follows:

$P s=P_{a} Q_{t} \times P_{a m} Q_{m} \times P_{i n v} Q_{i n v}$

where Pat is the passion of the technologists. Pam is the passion of the managers and Painv the passion of the investors. Note that in this overly harsh formula. any zeros guarantee failure while all one are read to guarantee success.

Should any of the three groups be indifferent about success, the future of the company will be greatly impacted. Some companies succeed despite low marks in one or more areas, but as competitive pressures increase, it becomes more important that the start-up company have dedicated personnel. People with high passion will achieve speciacular results, and do whatever is necessary to reach the goals. As a result, it is imporant to evaluate and modify, if possioje, the strength, determination and commitment (or "passion") of the technologists, the managers, and the investors.

There are many ways to kill passion, but greed takes first place. Greed in the form of equity distribution is probably the single largest barrier to creating companies. All players in a new company are irying to maximize their ownership. Often inventors feel they should own $100 \%$ of the company. These people pusin very haro for a hign stock price when they raise venture capital. This betiavior typically drives them to raise money from seconcary sources, (relatives, weal thy friends or unsopinisticated investors). This lowers the quality of the investor (Qinv). Second, they are very stingy in incentive stock plans for their employees, which again attracts second rate players. Worse yet. in addition to gering second rate employees and investors. the passion of the employess and investors fades rapidly as they come to realize that the probability is small that they will make significant money irom the overalued stock they acouired. This means the employees will be unwilling to work long hard hours and the investors wiil not be willing to come forward when (not if) the company needs more money.

Greed can take many other forms. Within a large company, equiry is not the primary motivater tecause it is much less like!y to make significant gains. Howeve: credit for good periomance is a key incentive. Managers that claim all the credit when anyining good happens and doc se biame when probiems arise are killing the passion of the employees under then. 
Other killers of passion are destrucuve crivic:sm. Many groups of individuals are dedicated to criticizing plans to prevent rnistakes. For example, the Food and Drug Adminisuration is designed more to prevent a drug winich does not petiorm to standards from reaching the gexeral public than to facilitate getting new he!prul drugs to mariet Within companies comminees and lawyers provide the watchdog function. These people serve an imporant function much like the brakes on your car, but ofien can have devasuating effects on the early stages of any new business development. The psychology of these individuals is that when their advice is sought over some new business idea; they can only iake credit for "preventing a negative event" rather than "facilitating a positive." Worded differenty, they cannot taie credit for the original idea. only finding its problems. A large dose of such criticism kills passion.

\section{The Image of the Company (I)}

The final complication to the formula is to include the image or credibility of the new business as a whole. Thus the formula is now:

$$
P s=P_{a} Q_{\imath} \times P_{a_{m}} Q_{m} \times P_{a i n v} Q_{i n v} \times I \text {, }
$$

where I is the image. The image factor is the way the company is perceived by potential strategic parners. investors, customers, ernployees.... For example, a biotech company with a Nobel Laureate on its Board of Directors will have more credibility in presenting a joint venture plan to a large pharmaceutical company than a company with unknown scientists. Similarly, a computer company in parmership with IBMI will have an easier time selling its next products than a company without such an endorsement. Also, a company deriving its technology from Stanford. Harvard, or MIT will have a higher image rating than technology from a lesser known university.

There are many examples of image influencing outcome. If a company has a high image, people will expect success and therefore want to invest, partner or work with the company, creating a success induced success syndrome. If a company or person has an adverse image, failure is expected (failure induced failure). Within one year of the introduccion of Lotus 1-2-3, for example, other companies had developed competitive products, which based on their price/performance ratio should have eroded Lotus' lock on the business use of spreadsheets. Lorus, though, had built a superb image through its marketing campaign. This marketing effor was enormous compared to other sortware companies, and focused solely on business users. Lorus' competitors were not able to overcome the momentum created by Lotus' marketing program. In fact, the image created by Lorus' marketing program was so strong that 1-2-3 became synonymous with spreadsheets. One venture capilalist, in 1985 , defined the worst possible investment as a "1-2-3 clone."

\section{LEVEL OF RVVESTMENT}

There are many different strategies for investing money in a new company. One end of the spectrum is typitied by companies that adopt the minimalist approach (" $A$ " curve). Namely, companies raise the rninimum amount of money required to move the technology forward. Such companies may even try to "bootsurap" the new business without raising capital. One benefit to this approach for start-ups is that the founders rewin control and almost all ownership. Sucin companies are often arracied to and take advantage of the services. space and equipment made available by science parks and incubator facilicies. 
I- money is raised. the invesinent is viten too small io generate sigrificant passion on the ga- of

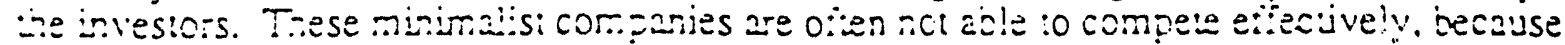
:ecrnical and business developmenis move forvard at a siow pace. Many of these companies also spend an irordinate ancunt oi senio maragement ime and etion in raising small arncunts of capial needed to reep the company aive. Tnis effor rould have been devoied to developing the business had more ivinds besn rasec initially.

The other end of the spectun (e.g., excessive initia sapital) is citen worse ihan the minimalist azroach. The managers of these companies ofien lose the vajue of money, ripicaly pay high sajaries and buid !avish ofijces, and spend the: weekends on tieir boats even when critical ceadines are imminent I reier to this bena:rior as the "Taj Mahal syndrome." Aitier spending iarge sums of money, these comparies often frustate investors by failing to show significant resuits. This frusiration ofien leads ihe invesiors io cut off furure invesiments and thus kill the company and if the company resiars it will resur on the minimalist curve because the investors wiil be rwice cautious after ine failure ("C" curee).

Somewhere benveen these nwo strategies is the optimal approach ("B" curve). Namely, sufincient iesources are avaijabie for ine company to deve!cp its tecinology rapidly, but not so much that the managers loose the value of moray.

The foilowing ciar demonsirates these three scenarios. It is interesting to note that passion in the coiimaj curve inc:eases ove: time, while the minimalist comeanies tend to loose passion. The reason is that the emplovees and investors see the company moving toward a pucilic offering while the emplovees in the minimaiist companies see litle nope for sale of their stock vennre capinalists cail sucin companies the "living deac."

Figure 1

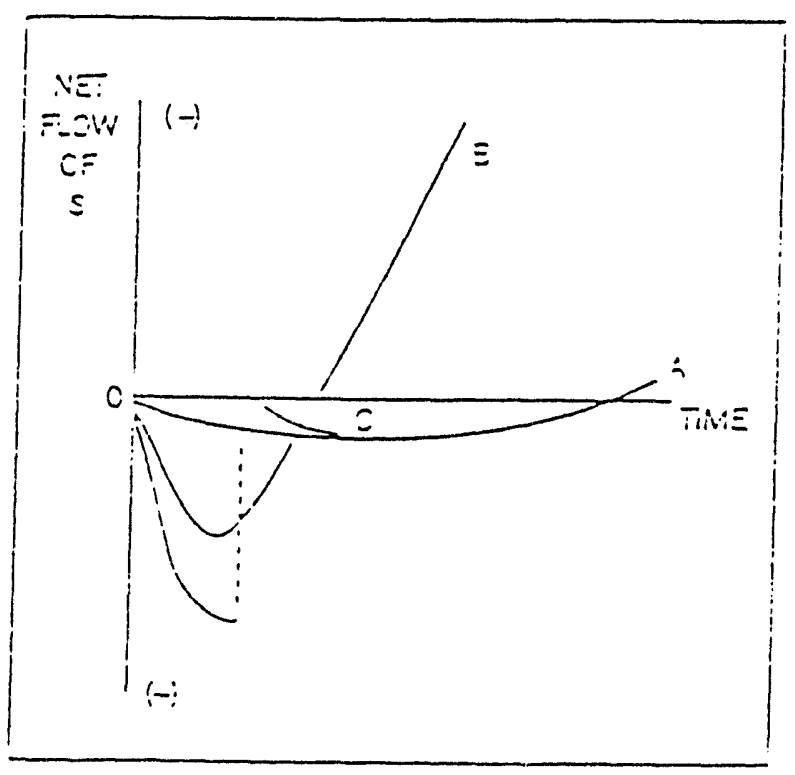

$A$ is the Mirimalisi Curve $B$ is the Optiral Curve $C$ is the Taj Marial Curve 


\section{LICENSIIG TO L.ARGER COMP.ANTES}

Many factors discussed above re!ate direcly to the creacion of new businesses or product lines within existing companies. Using the tomula from above. Qt and $Q m$ have the same meaning. The Qinv tem. though, refers to the Quality of the Sponsor within the company. Most intermal operations within a large organization generally require someone at a high level, a sponsor or champion, to provide funds and $g_{1}$ Jance for the new venture.

The sponsor's roie is analogous to the venture investor's cole. Similar to the venture investor, the sọonsor must have experience building businesses, and a strong network of connections, especially within the company. These connections are imporiant to avoid political pressures within an organization that would discourage innovation and enurepreneurial behavior. Also. large companies often have internal markets or access to external markets that are valuable to the new business unit. The sponsor plays a key role in arranging for acsess to these internal opportunities. Linlike the venrure investor, a sponsor must also be skilled at the internal politics of the organization.

Large companies have numerous advantages over suat-up companies in developing new businesses. The advantages include access to markets, both internal and extemal. and greater access to resources than a stari-up. The disadvantages include a reward structure that is not as conducive to the creation of passion. and a greater need for communication--this tends to makes cecisions more deliberate and cumbersome.

Tne requirement for passion is greatest when the idea is extremely embryonic and opens new markets. In these cases a ne'w start-up might have a greater probability of success ove: an existing company. If the technology is closer to an end product (e.g.. within 2 years), and if the product(s) are readily marketed by existing companies. the licensor mignt do betrer by licensing the technology to an existing company. In these later cases, the challenge is to generate passion within the large company and overcome company ineria that resists change and extemally generated ideas.

Many large companies focus on short term performance (e.g. next quaner's eamings). This strategy is encouraged by the siock market which weighs quarterly results as more imporant than long term potencial. It also drives management to benave along the minimalist curve (curve " $A$ " in figure 1). In other words, a manager is not rewarded for invescing in long :arm profit potencial ("B" curve in figure 1); insiead, if costs are reduced to the minimalist curve (" $A$ "), the company's profit improves in the short term. I refer to such behavior as the "iviBA Syndrome." Such managers can during a short period snow increased profits and often get promoted or hired away before the long tem disaster occurs. The irony is that if promoted, the manager has the opporturity and incentive to destroy a bigger piece of the company. The NIBA Syndrome occurs in large U.S. companies for two reasons: 1) average U.S. job tenure is snon (e.g. 3 years); and 2) the investors in U.S. companies are ty: cally speculators who care only about shon term performance (e.g. pension funds).

There are, fortunately, large companies that avoid this syndrome. Companies with large blocks of sinares owned by one family are wïling to invest for the long term. Farmily owned companies invest along the " $B$ " curve because the family has no intention of selling its stock, instead. they plan to pass their shares on to their heirs. A number of publicly uaded companies. such as .Motorola Coring and Ethyl have !arge blocks of shares held by a single iamily. Companies with family ownersinip of 10 percent or more of the outstanding shares, winich were aiso pubiicly traded nearly doubled the periomance of the Standard\$:Poors 500 companies over a four year period (1984 - 1988), according to a study by Mark Cunningham of Alliance Capital. These some what incredible resuits are explained by the long tem investrnent sirategy of the owners. However. Cunningham's study becomes even more astonishir.g when the se!ection criteria includes active 
involvement of the iamily in managing the company. Cunningham has found that such selected iamily companies outperiormed the S\&P 500 by three and a half times during 1984-198S and tenfold during the period 1968 to 1988. These data provide compeiling evidence of the benerit of long term investing.

Short term investments are ofien intended to shifi wealth, while long term investments create wealth. Clearly, sociery is better sened by wealth creation.

\section{REWARDS TO THE LICENSOR}

If the technology develops as expected, the university or licensor should expect a return equal to the royalty rate times the technology's realistic market potential times the probability of success.

However, there are several complications that will impact the licensor's rewards. For example, a poorly writen license agreement could eliminate the licensor's rewards. One advantage in this regard is that universities can trade heavily on "good will." Companies will hesitate before alienating the university because the possibiliry of obtaining rignits to future inventions may be jeopardized.

A significant factor limiting rewards to the university licensor is the level of hostility generated in negotiations. If the licensing company has grown to dislike the licensor because negotiations were one-sided, the licensee will view the royalty payments as a tax that should be avoided in any way possible. Energies will be expended, often subconsciously, to design around the patent or the agreement

It is thus crucial that the paries soucrure a well balanced agreement. The agreement is best wriiten to provide for similarities between the winning scenarios for the licensee and licensor. In the case of a start-up, this creates strong incentive for the licensor to take equity in parial payment of the license. If the up-front payment has an equity component, the equity payment is not resented by the licensee as it coes not remove resources from the technology and business. Also, subseauent design changes winich may work around the patents do not impact the value of the equity, allowing the licensor a win in even the case its technology has shor lived value.

\section{OTHER SUCCESS FACTORS}

Success factors for licenses are influenced by many factors other than those expressed above. For txample, the quality of an invention is influenced by the industry which will use the invention. One could almost envision a parameter called "industry". ranked from zero to one, which describes the "adoptability" of patents in that industry. Cerain industries, such as utilities or the automotive industry, are often not as receptive to externally generated technologies as other industries. If the technology has not been proven and establisned for many years, few people in these indusuries wish to taike the risk of developing the invention. Otier industries. such as the computer industry, have reduced the imporance of inventions by extensive cross-licensing of patents. For many computer companies, the freedom to pursue a business surategy is a more dominant concem than using a patent to proteci a monopoly. Also, the computer industy' can more readily design around patents than mosi other industries.

Other industries. such as biotechnology and pharmaceuvicals regard patents more highly. Also parents in these industries are more difincult to design around. 


\section{APPENDIX 2}

\section{CONSTRAINT ANALYSIS FOR ASSESSMENT OF BUSINESS RISKS -}

a Paper by Dr. Bruce Merrifield, Blandstrom Executive Professor Wharton Business School, University of Pennsylvania 
The formula above could also be modified to refleci cultural differences. For example. both Japanese and European cultures tend to be more accepting of imporing new technologies into large tirms, whereas in the US it is the small companies that are most supportive of imporing new Lechnologies.

Lastly, the role and significance of iming is crucial. For example, $X$-ray lithography has finally emerged as a commercially viable technology, just as MITs fundamental patents are beginning to expire. The imporance of timing is difficult to assess. It plays a key role in the development of markets for new technologies, and therefore a factor in assessing the quality of the invention.

\section{SUMDIARY}

Start-up companies and technology transfer to existing companies will continue to play a major role in economic development. The positive impact from new business creation can be increased by targeting appropriate technologies; finding strong managers and quality investors or seonsors; enhancing the image or credibility of the business; and finally, encouraging passionate behavior by the key players toward the success of the new business. These gualities, coupled with a well writuen, balanced agreement and good will on the part of both the licensee and lice:asor will greatly enhance the likelihood for success of the venture and rewards to the licensor. 


\section{APPENDLX 2}

\section{PREFACE}

This appendix is the work of Dr. Bruce Merrifield, Wharton Business School, University of Pennsylvania. This is the most recent version of Dr. Merrifield's commercialization model, and is used here with his permission.

Dr. Merrifield's model is based on regression of statistical data from numerous commercial businesses based on technologies developed at various institutions. The model is currently being finalized for publication in a professional journal, and has been presented in an earlier form as part of a study completed by the Atlantic Council of the United States titled Transfer of Technology to Industry from the U. S. Department of Energy Defense Programs Laboratories, dated July 1992.

The Atlantic Council report is an additional recommended reference. 


\section{CONSTRANT ANALYSIS FOR}

\section{ASSESSMENT OF BUSINESS RISKS}

(Revised February 28, 1994)

D. Bruce Merrifield

Blandsuom Execuuve Professor

Wharon Business School

University of Pennsylvania 

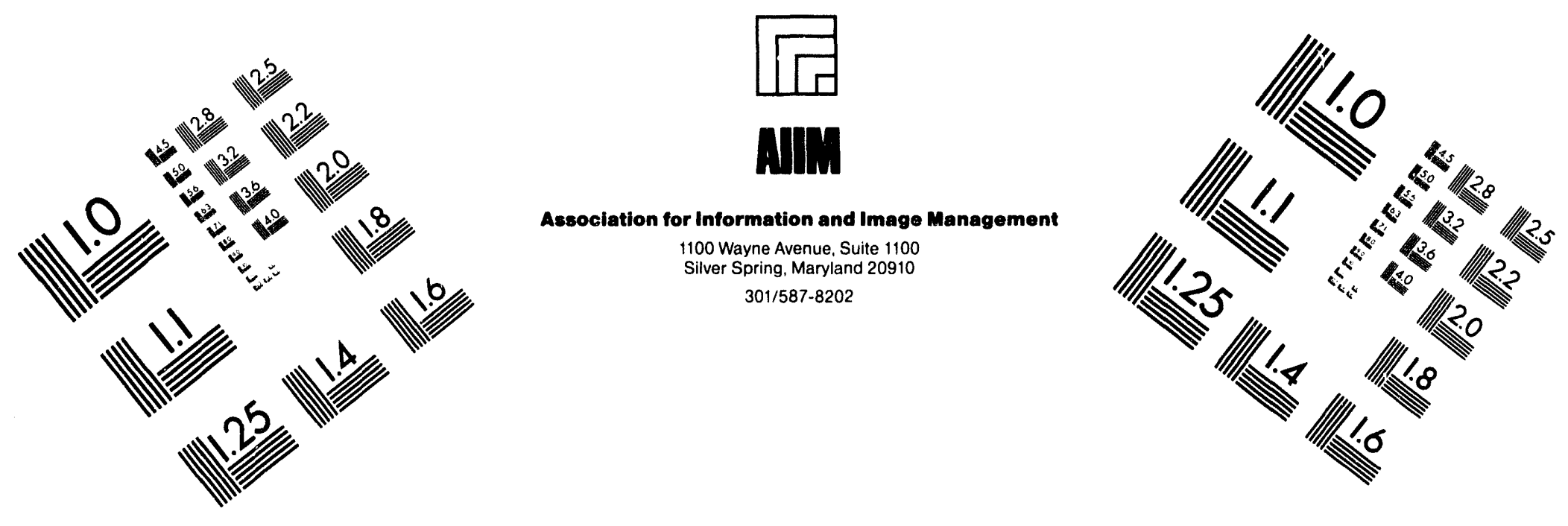

\section{Centimeter}

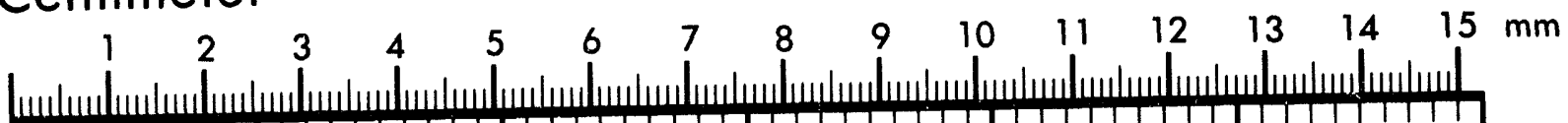

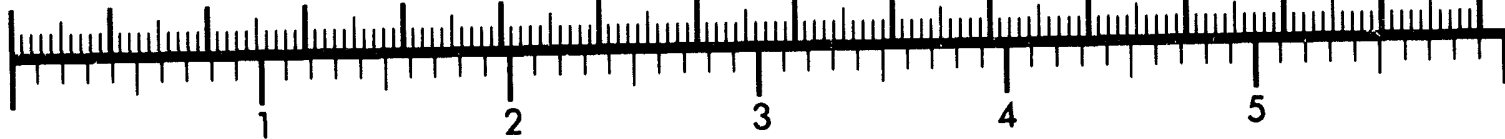
Inches
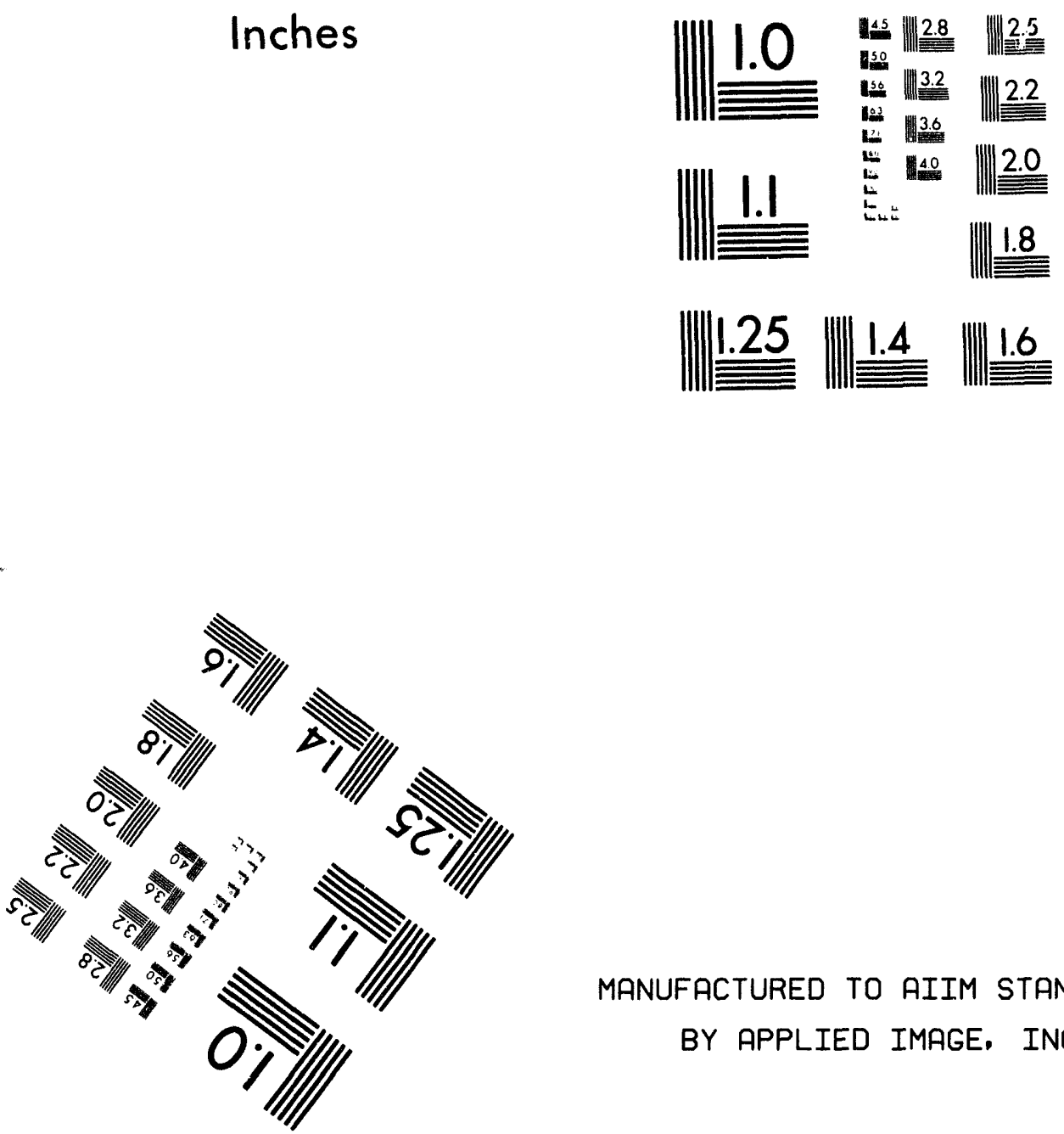

MANUFACTURED TO AIIM STANDARDS

BY APPLIED IMAGE, INC.

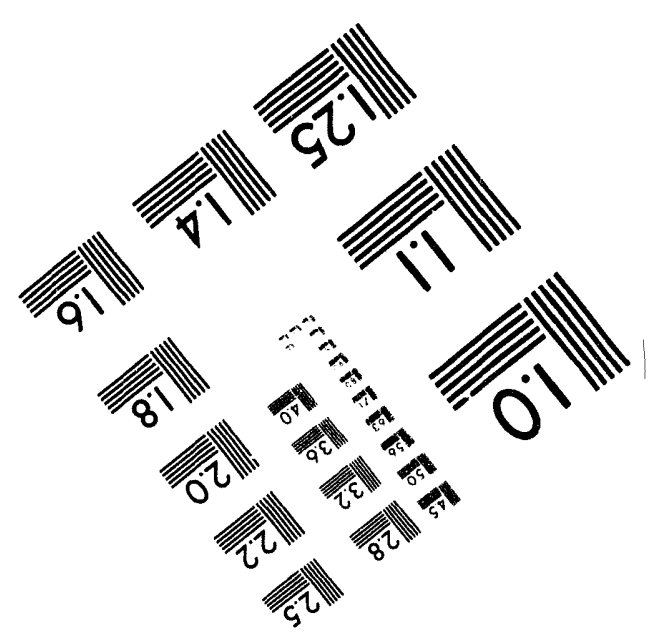



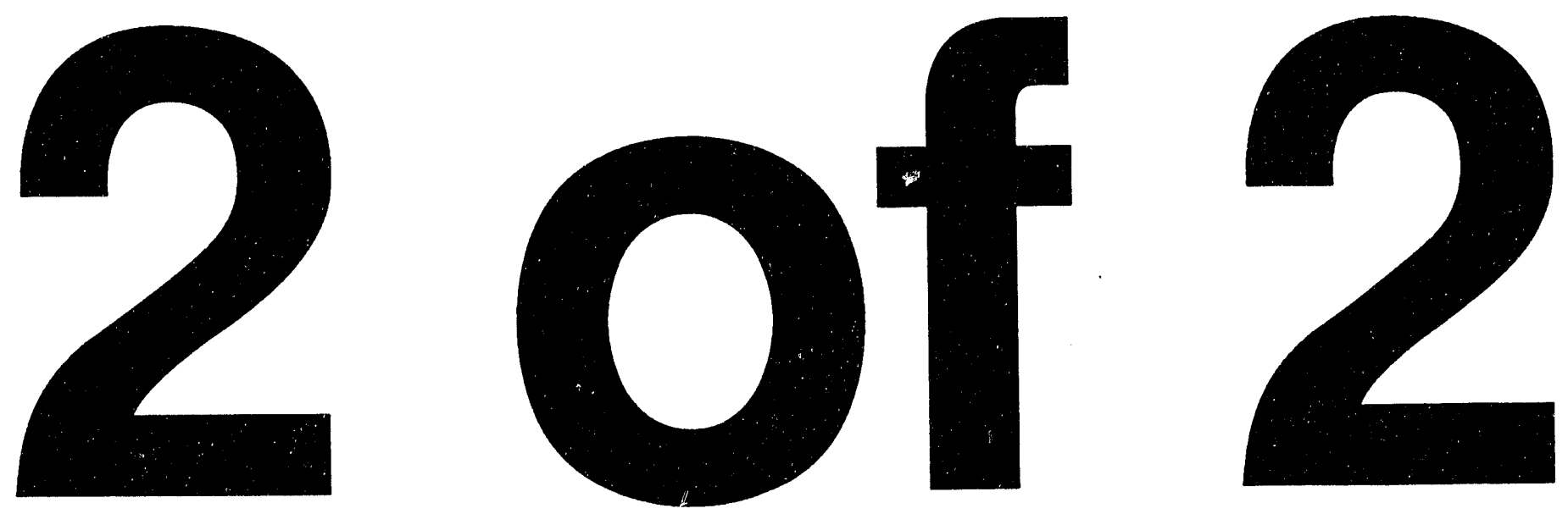


\begin{abstract}
Screening methodologies frequently used to select invesoment opportunities have had limited ability to predict comrnercial success. Statistically, only 2 or 3 out of 10 such investments produce substantial growth businesses, that result in positive cash flows and an acceptable return on investment.
\end{abstract}

However, regression analyses, involving many both successful and unsuccessful ventures, have identified a dozen critical factors that when satisfied in substantial degree, predict successes $80 \%$ to $90 \%$ of the time. This methodology, called the "Constraint Aralysis", is equally useful both for measuring the current and future viability of an existing business, and for benchmarking it against global competition.

The Constraint Analysis separates "Intrinsic Business Attractiveness", or "Value-A ided" factors, involved in a given opportunity, from the "Fit Factors", required to develop. commercialize, and effectively manage an ongoing business, in such a way that it can sustain a competitive advantage. 


\section{ENTREPRENEURIAL RISK ASSESSMENT}

\section{Perspective}

An opportunity for investment must be seen as able to provide a return on investment sufficient to justify the entrepreneurial risk involved. However, most failures can be traced directly 10 inadequate assessments of risk. The following analytical scheme involves a semiquantitative methodology which distinguishes furure successes from failures 80 to $90 \%$ of the time.

The scheme uses an index of merit $\left(I_{M}\right)$, which for a given opportunity can be expressed as a function of the probability of achieving technical success $\left(P_{T}\right)$ for meeting needed cost/performance requirements, times the probability of achieving commercial success $\left(P_{c}\right)$ through mobilization and effective management of the skills and resources required.

$$
I_{M}=P_{T} \times P_{C}
$$

Historically, a 5 to 10 imes improvement in cost/performance over exising technology, serving a market need, has been required for a new market entry to profitably capture market share. This degree of improvement then establishes the parameters for technical success desired, and if the operational capabilities required also are present then a staged technical program can be justified, which sets out critical cosiperformance milestones that must be met before proceeding. Failure to meet a milestone terminates the program thereby eliminating unnecessary and usually accelerating expenditures.

Regression analysis has identified a dozen factors which are crivical for success. However, these are separated into (I) "Intrinsic Business Artactiveness" factors, and (II) 
"Business Fit" factors. The two are separared intentionally since inuinsic factors are not easily modified, but fit factors can be stengthened where necessary, through joint ventures. acquisitions, licensing arrangements, and other forms of strategic alliance.

A decision tee results (Figure 1)

Figure 1

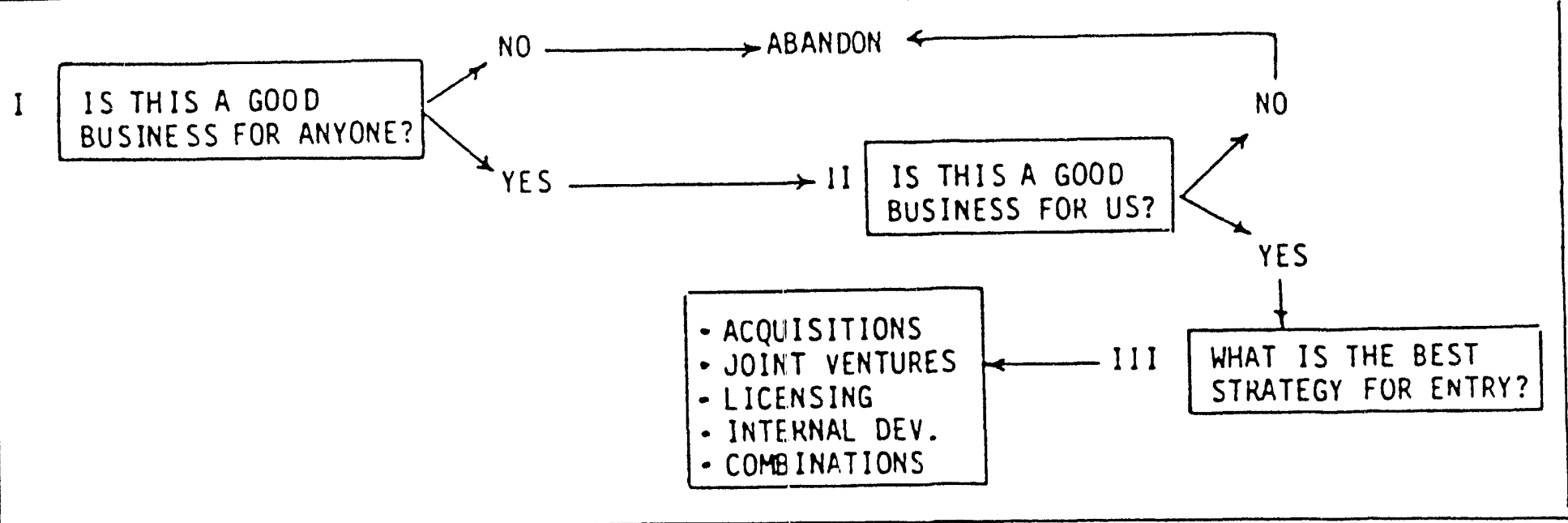

Six critical factors define each of the two categories, and each factor is rated on a scale of 0 to 10 , resulting in a maximum of 60 points for each category. A score card (Figure 2)) results, on which scores are ploted on each axis and their intersection circled in the grid as an additive score. For example, if a giver project rates 40 points out of 60 on the Business Value side, and 45 points on the Fit Factor side, the total of 85 , result (A), is plotted as shown. If the two scores are 25 and 30 respectively, the result will be (B). Staristically, opportunicies that have scores of 80 points or more, usually are successful $80 \%$ to $90 \%$ of the time. Below 70 points, success ratios are $10 \%$ to $20 \%$. 
This methodology is equally useful in assessing the values of existing operations centers. and in determining what strategy to follow (growh. cash cow operation, or divestment). A brief description of each factor follows.

Figure 2

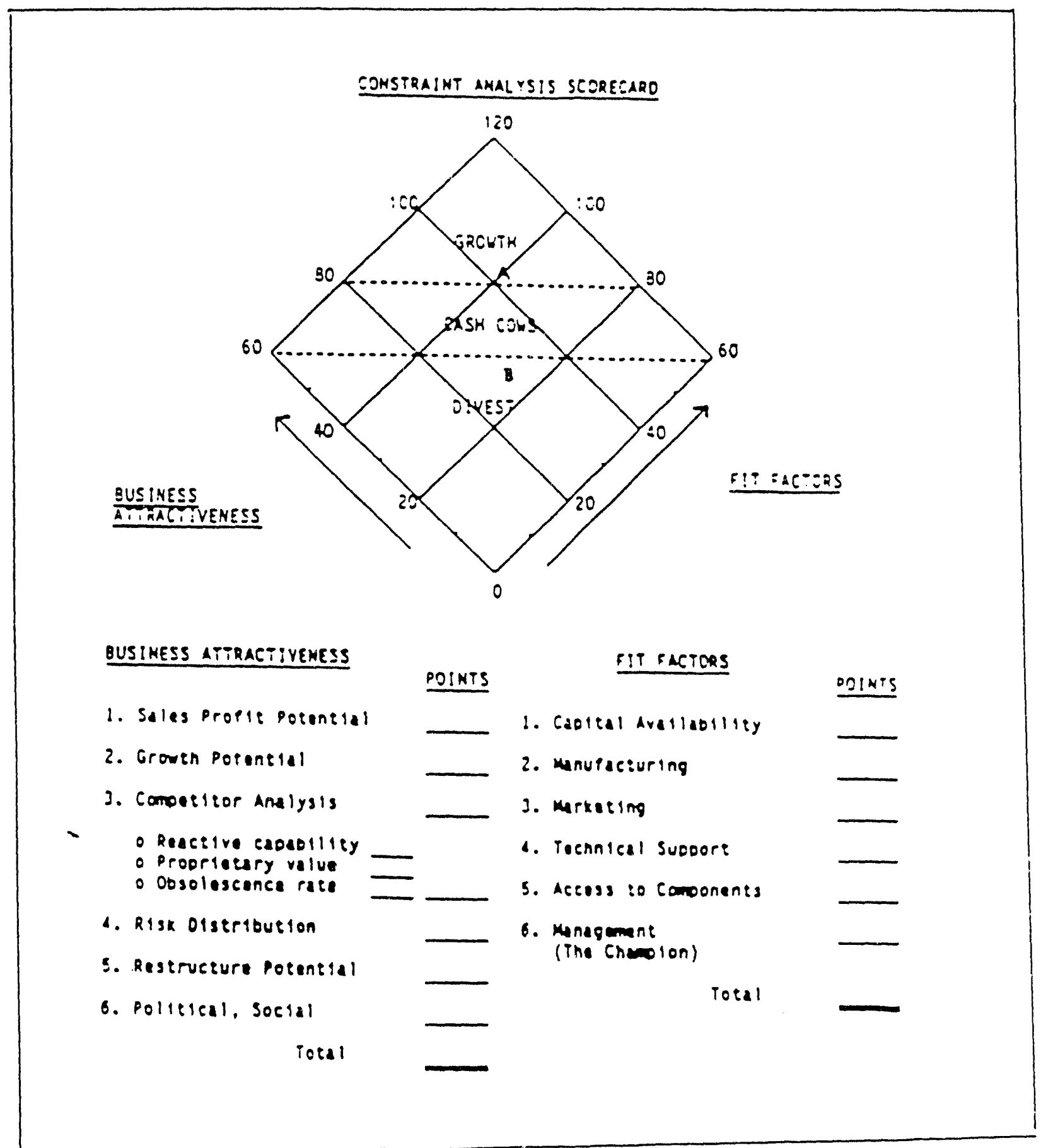




\section{DESCRIPTION OF FACTORS}

\section{Business Attractiveness Factors}

A. Sales/Profit Potential (Score on a scale of 0 to 10)

The potential market to be addressed should not be seen only as one which involves the sales volume for a given product, process, or service, but one which meets a basic human need, and currently may be parly satisfied in a number of different ways. For a competitor already serving a market need, in a given business, continual incremental improvements in costperformance of $5 \%$ to $10 \%$ per year likely will be needed to maintain short-term comperitiveness.

However, rarely will only marginal improvements allow a new compector to enter an existing market and capture market share and be profitable. Historically, a 5 to 10 imes greater improvement in cost/performance has been required for a new entry. Also, a similar magnirude of improvement will be required for an existing comperitor to sustain a longer-term competitive advantage. Major investments of this type must be carefully screened for real potential. 
$-5$.

1. Measurement of Sales Potential (Score on a scale of 0 to 5)

Statistically, every doubling in sales volume results in reduced costs of $15 \%$ to $25 \%$, as economies of scale are realized. However, regression analyses (see Figures 21 and 22) show that indices of merit for this (and other factors that follow) are not linear with changes in the factor involved, but are exponential. In this case, the constraint score is shown to be exponential with sales volume, but actually with a dip between about $\$ 100$ million and $\$ 500$ million in sales volume. At about $\$ 100$ million, what has been essentally a niche market, somewhat protected from visibility, and therefore, from competition, begins to become atractive to very large companies, interested in follow-on technology (Figure 3) However, as the market continues to expand, multiple smaller segments involving multiple applications usually emerge. These again provide more protected niche markets for both suppliers and entrepreneurs to participate in the new technology. 
Figure 3

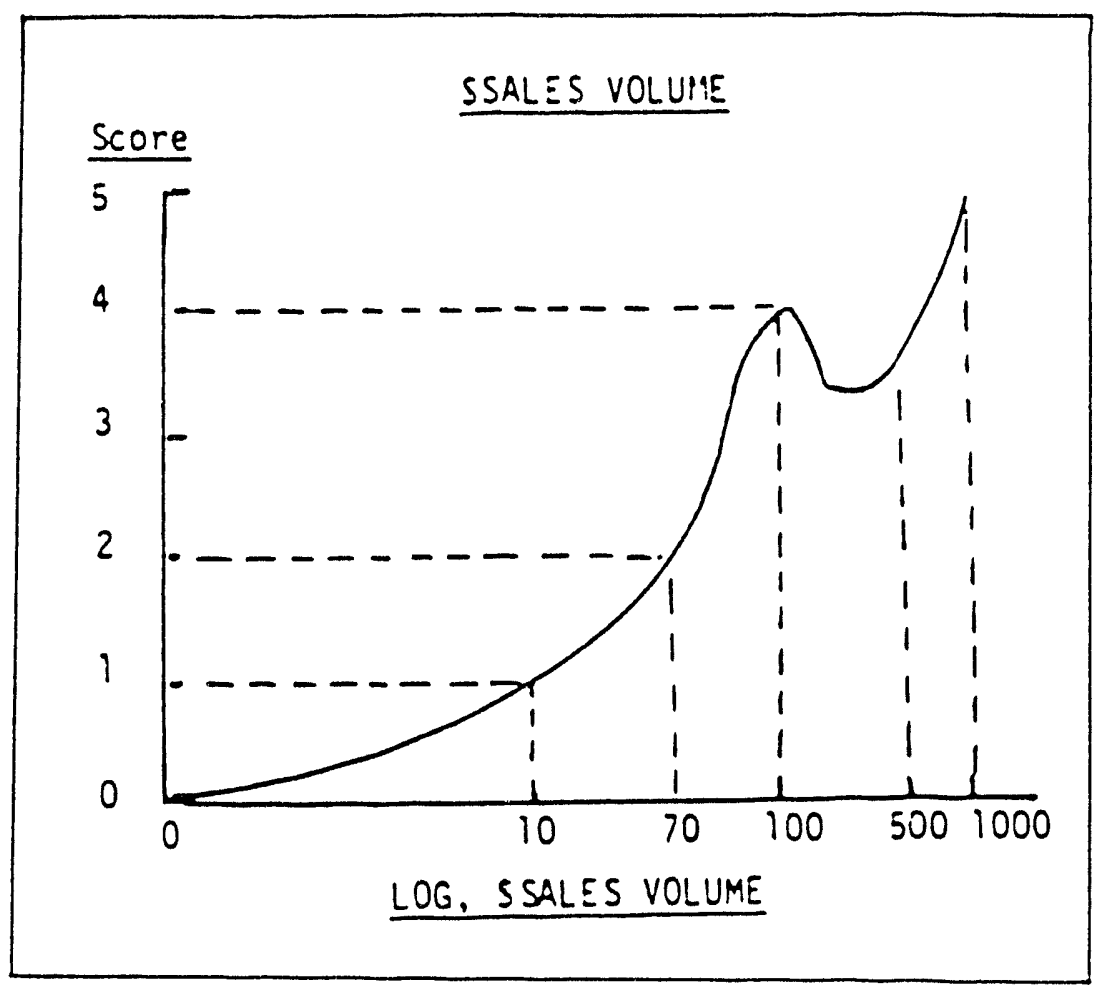

2. Profit Potential (Score on a scale of 0 to 5)

Sales volume without profits do not merit investment. An instanteous "snapshot" of current profitability can be provided by a discounted cash flow return on investment (DCF-ROI) which corrects for inflation, and also discounts for alternative risk-free investment of capicil. for example, in Govemment securities. A DCF-ROI rating of 20\% or higher would score $5 \%$ as illustrated in Figure 4.

The sum of the scores for sales and profit potentiai provides the total constraint analysis sfore for this factor. 
Figure 4

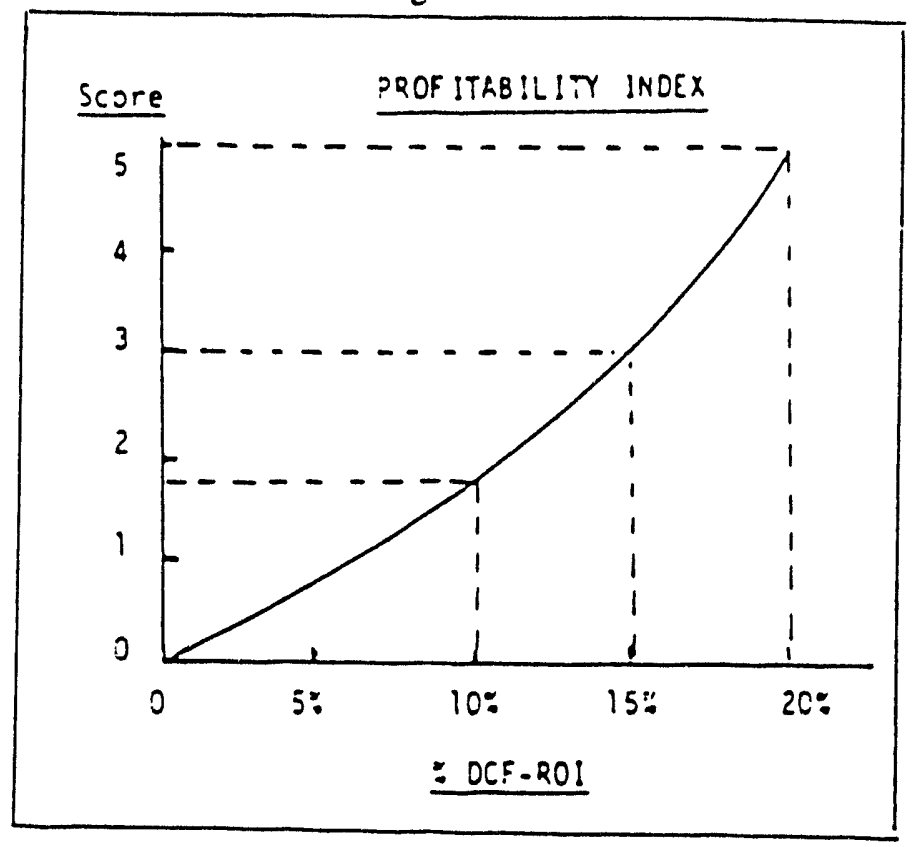

B.. Growth Potential (Score on a scale of 0 to 10)

"A rising tide raises all the boats, even the leaky ones". Therefore, an important factor involves the potential growth rate of the market need being served, and the relative degree to which it is being effectively served. For example, a slow-growing or static market also can provide rapid growth down the learning curve for a major innovarion that is sufficiendly costbenefit superior that it captures the market from less effoctive technology.

In both cases, a first mover advantage can be critical in esiablishing a "dominant design" and commanding economies of scale, before a compeditor can react In the past companies such as Timex. Xerox, Kodak, and IBM have established dominant positions, 
Figure $S$

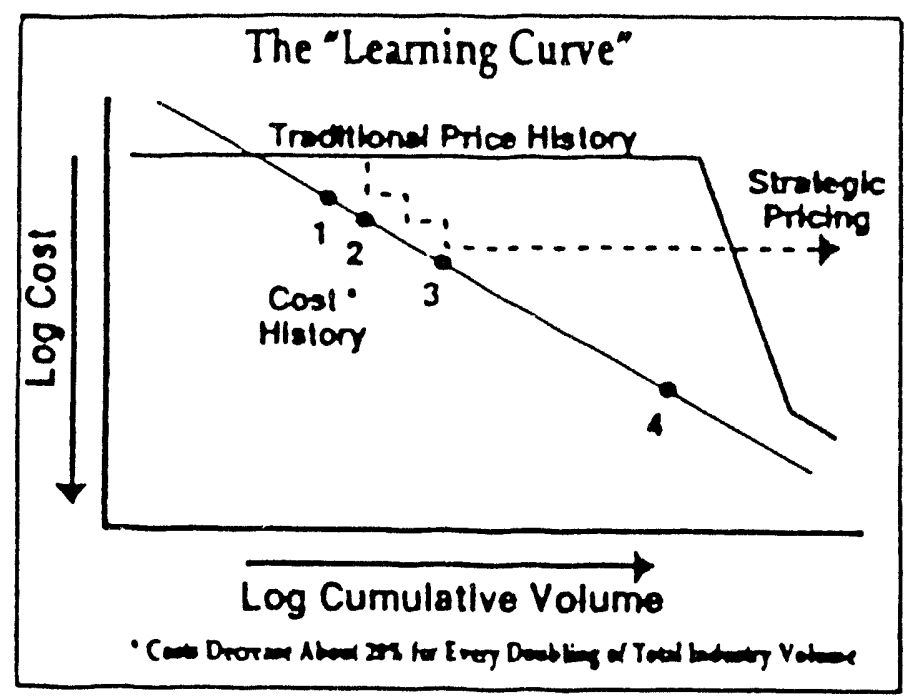

and prospered enormously, for a time. The slope of the leaming curve reflects the rate at which advancing technology may be betuer serving a growing human need (Figure 5). Therefore, if product, process or service costs are decteasing $20 \%$ or more with each cumulative doubling in sales volume, the indication is that both economies of scale and improving performance will continue to drive accelerated market growth. Score 10 for a $20 \%$ rate of dectease. Altimarively, use available literature date for market growth trends. Score 10 for $20 \%$ on higher annual grounth (Figure 6). 


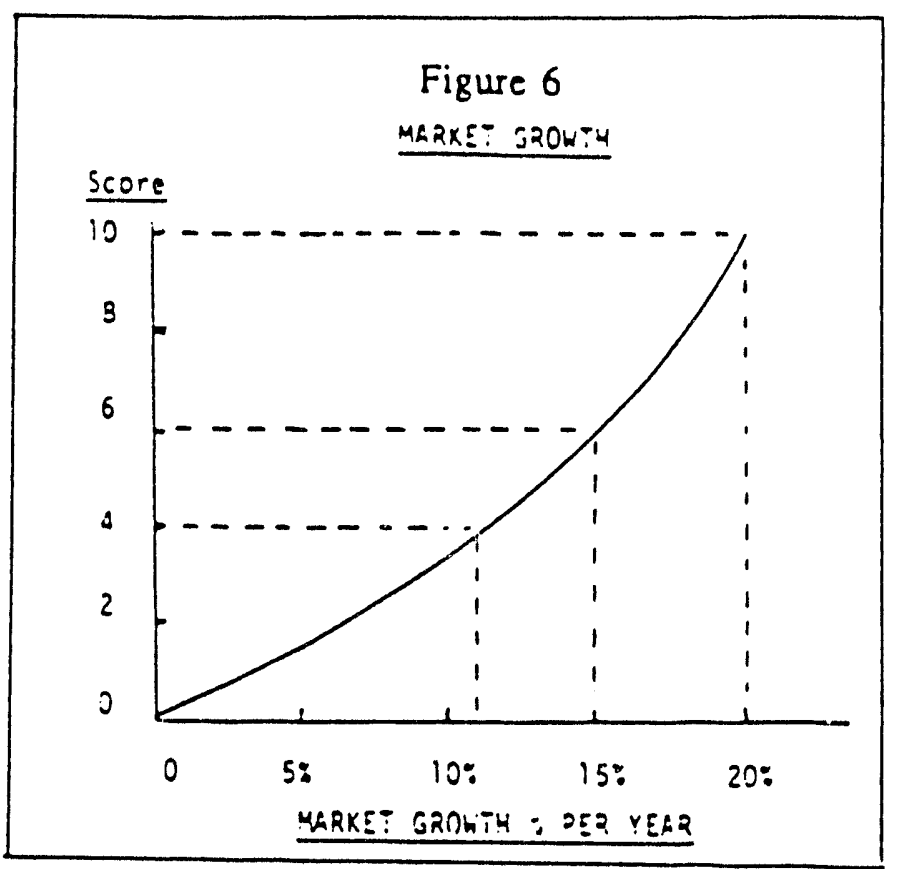

C. Comperitor Reactivity (Score on a scale of 0 to 10)

This factor is measured in three different ways. One of these involves the ability of a dominant competitor to respond quickly to a loss of profitability or market share to a new entrant. A second involves the degree of proprietary character of an innovarion, that protects it from immediate reaction or duplication. The third involves the rate at which even more effective solutions to the market need could obsolete current operations before the ir useful lives can be realized.

1. Dominant Comperitive Reactivity (Score on a scale of 0 to 4) An entrenched competitor with a dominant share of a market must react when threarened by a new entrant. The first defensive move ur dally involves price reductions to slow the loss of market share at the expense of proficability, with the hope of buying time 
to be a "fast follower" ..- later overwhelming the new entrant with superior marketing, distribution, production, and access to capital for rapid expansion. This Figure 7 strategy no longer may be effective, as life cycles collapse 10 just a few years (Figure 7)). For example, when Apple commercialized the Xerox Palo Alto Research Laboratory personal computer, and

STAGES IN THE S CURVE COSTIPERFORMANCE

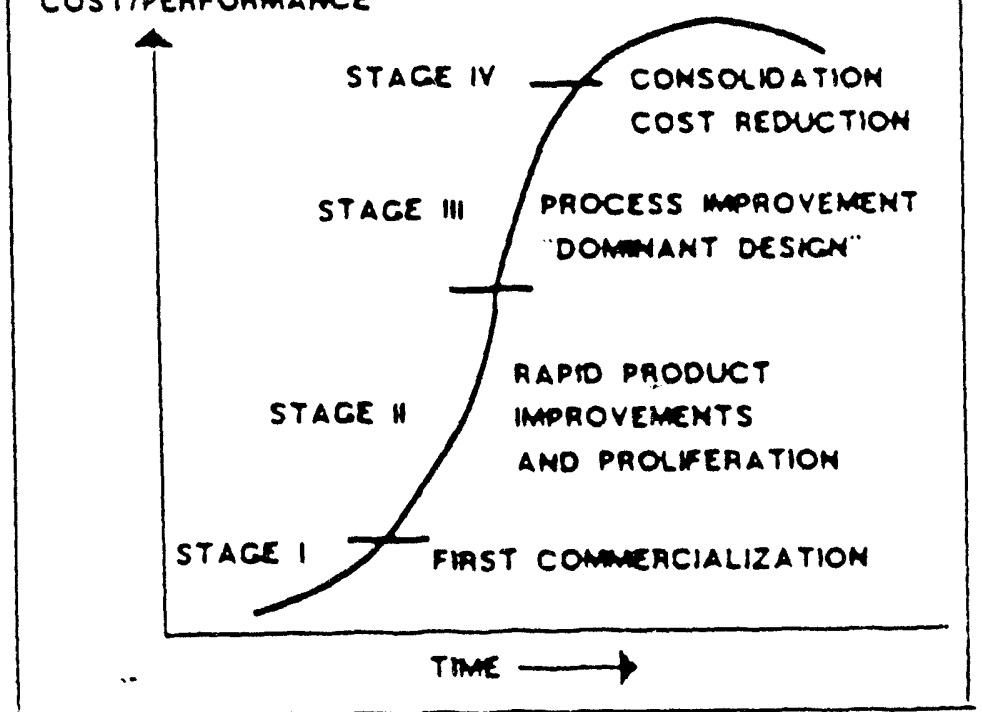

Microsoft commercialized the Xerox precursor to "Windows". IBM reacted with its open architecrure PC and funded instead of capruring Mictosoft However, the rapid grownh in Stage II and ready availability of microchips allowed many comperitors to enter, and DBM which had captured about one third of the market failed to establish a dominant position, and lost much of its market share.

In the past, the s-curve syndrome has passed through four stages. the fust being the introduction of an innovation, the second being a period of dynamic new development as many compecitors enter. the third teing 
a period when a dominant design appears, discouraging radical changes, and the market begins to consolidate to a few larger competitors, and the fourh beginning a period of decline, when next-generation systems may emerge. Figure 8 illustrates the Arthur D. Little "Life Cycle Marrix" describing this phenomenon.'

Figure 8

A. D. Linle Life Crele Marrix

\begin{tabular}{lcccc} 
Characteristic & $\frac{\text { Stage I }}{\text { (Introduction) }}$ & $\frac{\text { Stage II }}{\text { (Rapid Growth) }}$ & $\frac{\text { Stage III }}{\text { (Maturity) }}$ & $\begin{array}{c}\text { Stage IV } \\
\text { (Decline) }\end{array}$ \\
Sales Volume & Low & Rising & Peaked & Declining \\
Profitability & Negative & Positive & High & Fallina \\
Growth Rate & Slow & Rapid & Leveled & Declining \\
Operating Costs & High & Falling & Low & Low \\
Product Line & Limited & Divestifying & Diverse & Shrinking \\
Pricing & Cost-Plus & Penetration & Competitive & Cut-lhroat \\
No Competitors & Few & Many & Consolidating & Few \\
\hline
\end{tabular}

Less frequendy, however, will life cycles see Stages III and IV as new tochnology supercedes older systems at an increasing rate. The risk of reaction to a new market entrant is soll real. It is lowest in a badly fragmented market with many small comperitors. However, for an innovation which is penetaring 
an existing market dominated by a major comperitor. an index of reactivity can be measured by the percent of market share held (Figure 9). The existence of no dominant competitor rates a score of 4 .

Figure 9

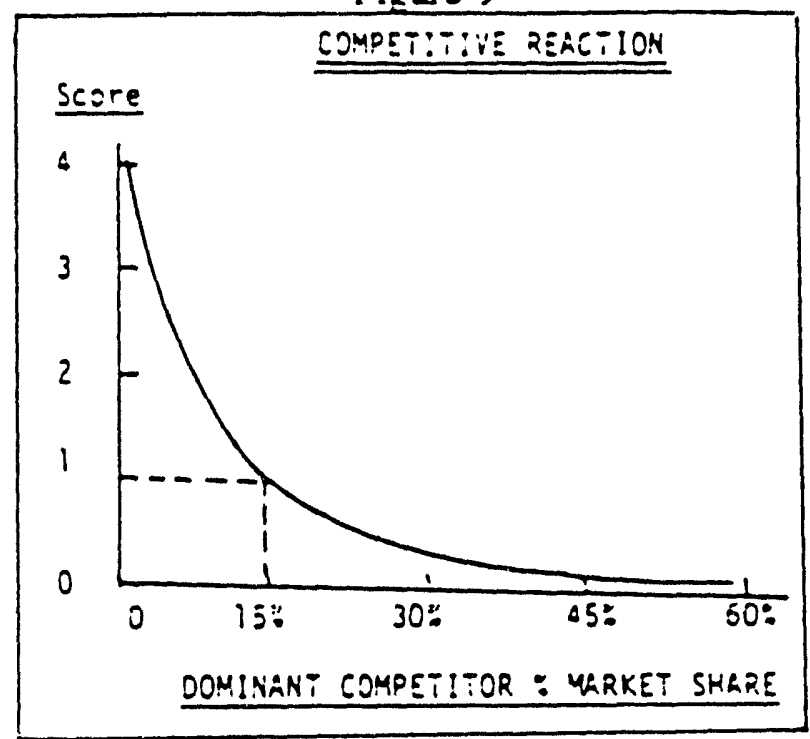

2. Proprietarv Character of the Operation (Score on a scale of 0 to 3)

A patent or copyright provides a constimional right to a legal monopoly for a projected operation. The stronger the patent or copyright the greater is the protection from early competitor reaction. Pharmaceuricals and specialty chemicals ofuen are based on unique "composition of maner" patents which can provide extended protection. When further stengthened by a porfolio of suppor patents (process and construction), and by muliple picket patents (use and application), the protection can be impenetrable. Some countries still have not adopted the Intemational Patent and Trademark Convention. so 
Figure 10

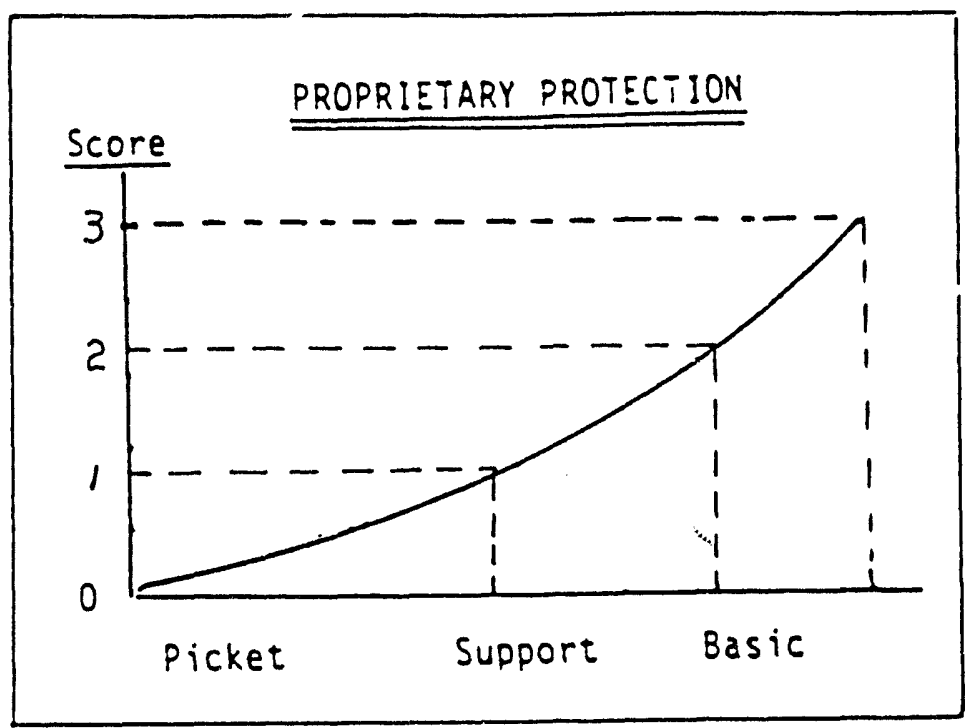

universal coverage is not possible. However, it is imporant to obtain whatever protection is possible and is economically justified, based on the potential value of the technology. Score this sub-factor as illustrated in Figure 10.

3. Rate of Toshnical Obsolescence (Score on a scale of 0 to 3) About $90 \%$ of all scientific knowledge has been generated in the last 30 years by about 9090 of all scientists and engineers who have ever lived, and now are living and working. ${ }^{2}$ As a result product and process life cycles now have collapsed to just a few years in many industries, obsolecing equipment and facilities long before their useful lives can be realized. 
As life cycles continue to collapse, a sustainable comperitive advantage will require both continual improvements in existing operations Figure 11

for near-lerm survival, as well as simultareous development of "nextgeneration" systems for longer term comperitiveness. Also needed, will be time-critical access to flexible manufacruring

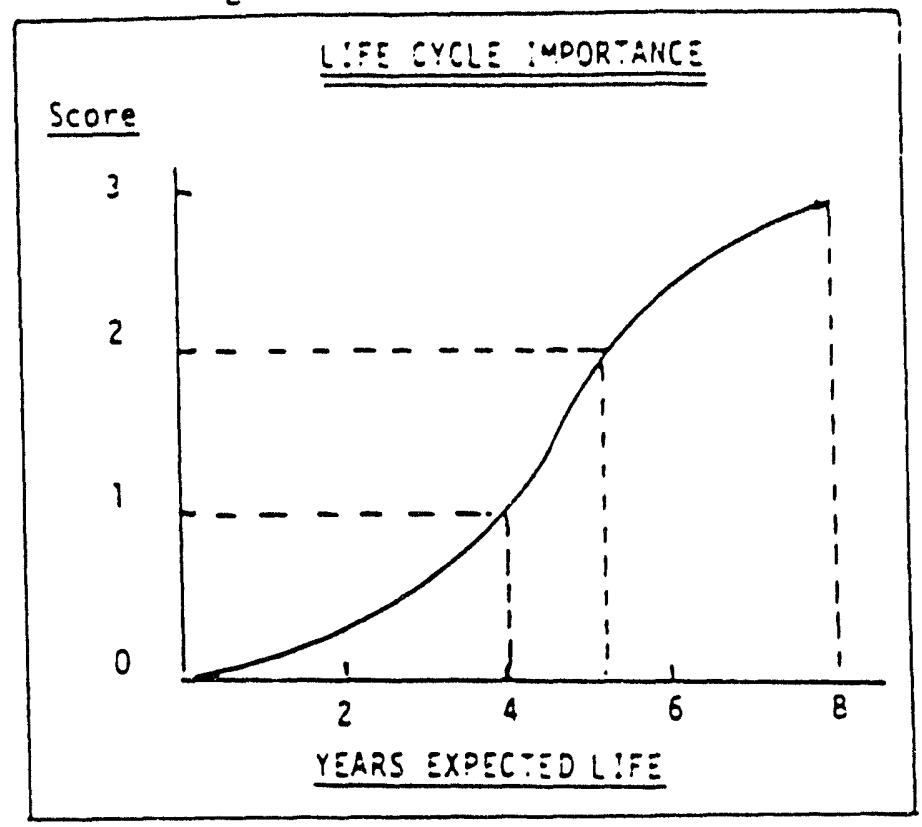
and global marketing and distribution, either through in-house capabilites or through stategic alliances. The risk of obsolescence associated with rapidly advancing technology can be measured in terms of expected life cycles. Score this "obsolescence factor" as illustrated in Figure 11.

The sum of the "reaction" factor, the "intellectual property" factor and the "obsolescence" factor constitute a measure of the global climate of comperitor reacrion to an innovation. 
D. Risk Discribution (Score on a scale of 0 to 10)

Survival increasingly will depend upon a degree of product line diversity, since the risk of sudden collapse is much greater "when all the eggs are in one basket". An operation which is focused in one segment of a market can be disadvantaged when an unexpected event or a new innovation intervenes. The risk must be distributed over a number of areas sufficiently differentiated from each so that if one is lost, all are not lost.

Figure 12

\section{A comprehensive}

literamure search can

surface potential dif-

ferential segments of

a market that can still

build upon core com-

petencies. Careful seg-

mentation and subsequent

exploitation of priority

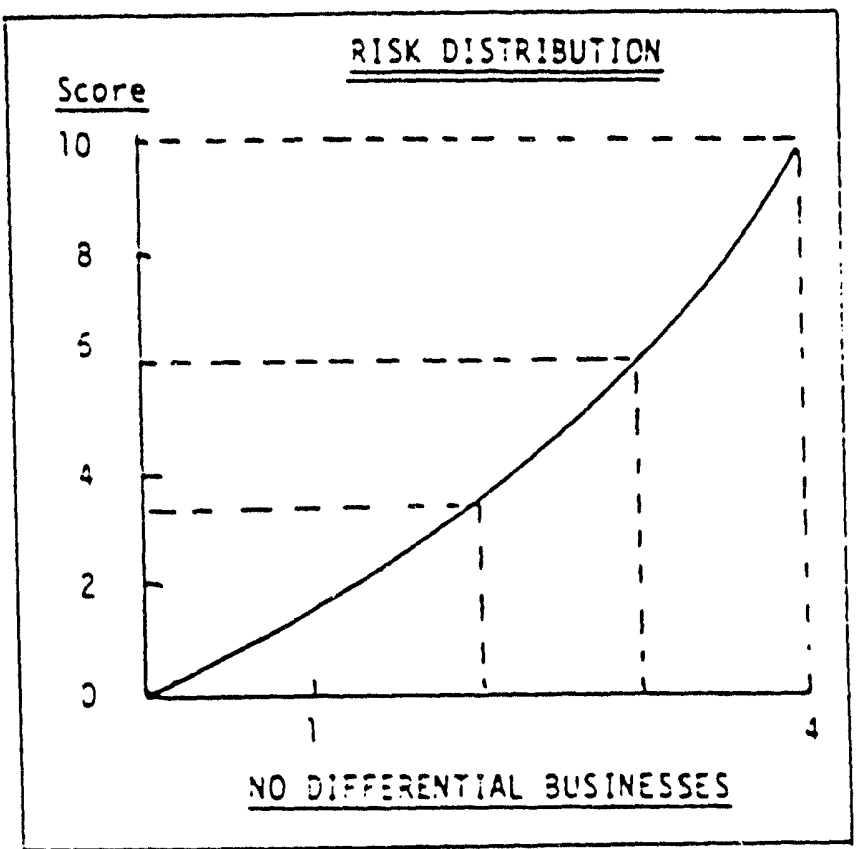

opportunities can be critical for sustained comperiviveness. Score risk .

distribution as illustrated in Figure 12. 
E. The Polential for Industrv Restructure (Score on a scale of 0 to 10) An innovation that provides a 5 to 10 imes improvement in costbenefits over existing market solution, can resructure an entire industry or at least segments of the indusuy. Significant leverage is possible for such a development. These can take the form of exclusive field of use (or territorial) licenses with leading edge companies, together with an equity participation in a new joint venture that builds on mutual strengths. plus an up-front payment, a royalty on sales of the final product, and a transfer price for the component or material involved. Seminal discoveries such as the transistor, high temperature superconductivity, a break-through in electrical energy storage, or a method for sequencing the human genome, can restucture one or more entire industries and create new ones not previously feasible.

Altemative possibilities for exploiting such a major discovery may not be recognized at first, and therefore a systemaric search of world literature can be important in surfacing these altematives. Also, realization of the full potential for a major new development requires simultaneous market penetration of all segments, since life cycles can be shor. The strategic alliance approach can make this possible, and intemational alliances can multiply the eventual return. Score this factor as illustrated in Figure 13. 
Figure 13

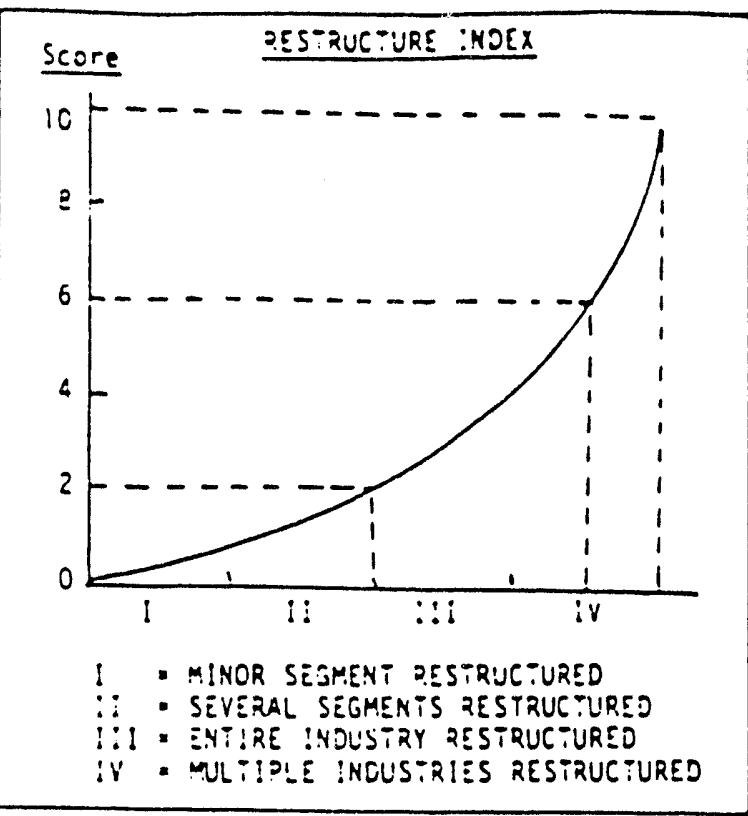

F. Political and Social Constraints (Score on a scale of 0 to 10)

The hyper-compedive global village with vanishing borders, in which we now live. still is beset with a bewildering aray of changing tariffs, non-tariff restrictions, as well as culural and language barriers, over which a company may have little control. Foreign nations not only raise protecive tariffs, but often create standards requirements, por of entry restrictions, and other "creative" barriers to impors. The U.S. has tariffs, quotas, and expor conuols (for national security-sensitive products), all of which impede the free flow and access to materials and components.

Also domestically. U.S. regulatory agencies require approvals for building and construction, for sale of pharmaceuticals, agricultural chemicals, meat and dairy products, and for emission of toxic air and water effluents. Compliance standards exist for sale of securities, and for broadcast and communications operations. Liability laws currendy result in industry payments of over $\$ 200$ 
billion each year resulting from class action and other forms of punitive litigation. Dozens of local codes and restrictions also must be complied with. when relevant, which add costs, result in delays, and can seriously reduce the attractiveness of an oppormunity.

Finally, an incoherent combination of monetary, fiscal and regulatory policies which have existed in the U.S. and other countries, have produced repecitive recessions and concommitant budget deficits. Four year "boom and bust" cycles introduce unceraintes for sustained isvestment that are destructive, but must be anticipated by management strategies. The multiplicities of these exogenous factors, make difficult their quantification, and different types of operation are paricularly sensitive to cerain types of political/social

Figure 14

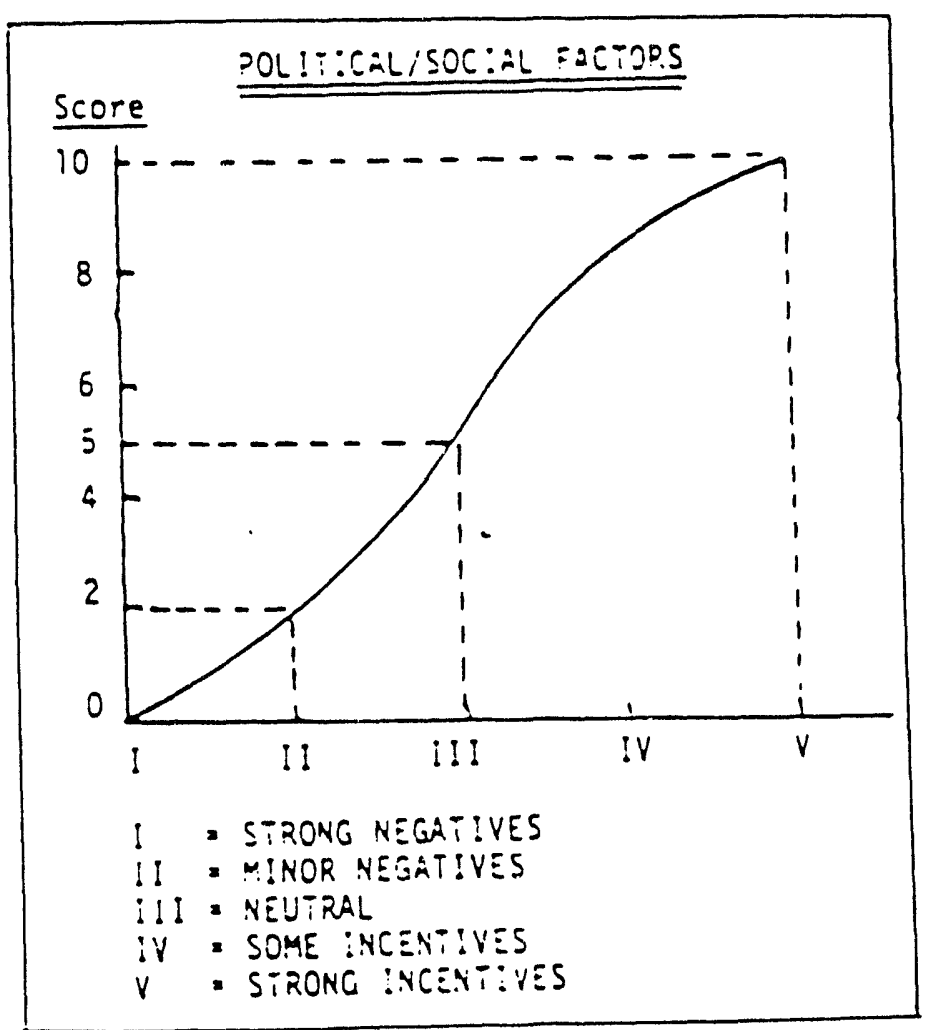


intervention. For example, impor-export businesses will be especially affected by abrupt changes in exchange rates. Score this factor with a neutral sination rating 5 points, and positive or negative factors adding or subtracting as can be best estimated (Figure 14). Obviously, an activity that is illegal or unethical requires a "no-go" decision for the project.

\section{Business Fit Factors}

The "Inurinsic Business Attactiveness" factors identified above are not easily modified. This is not tue of the "Fit Factors," since weaknesses here often can be corrected by pooling of skills and resources through strategic alliances. In particular, few companies alone either now can hold captive all the skills and resources needed to develop and commercialize a basic discovery, which may have multiple applications, or alternatively, can justify the long negative cash flow's required. Therefore, fit factor weaknesses need careful analysis for successful results to be obtained.

A. Capital Availabilitv (Score on a scale of 0 to 10)

A discounied cash flow rerurn on investment (DCF-ROD) of $20 \%$ establishes a high hurdle rate for a vailability of capital. Large companies with heavy cash flows might choose to ignore this hurdle. but not advisably. Also, an undercapitalized company may not have access to funds at any rate. For start-up businesses, lack of capital usually 
results in major dilutions of equity for the entrepreneurs involved, as a result of multiple rounds of financing. "Cash rescue" in distess usually results in loss of management control as well. Therefore, affordable levels of capital must be available as needed from a combination of equity and debr financing. Also, once commercial operation begins, the generation of sustained cash flow should be sufficient to finance further measured growth (hedged for negative surprises), or at least sufficient to create options for additional leverage.

Figure 15

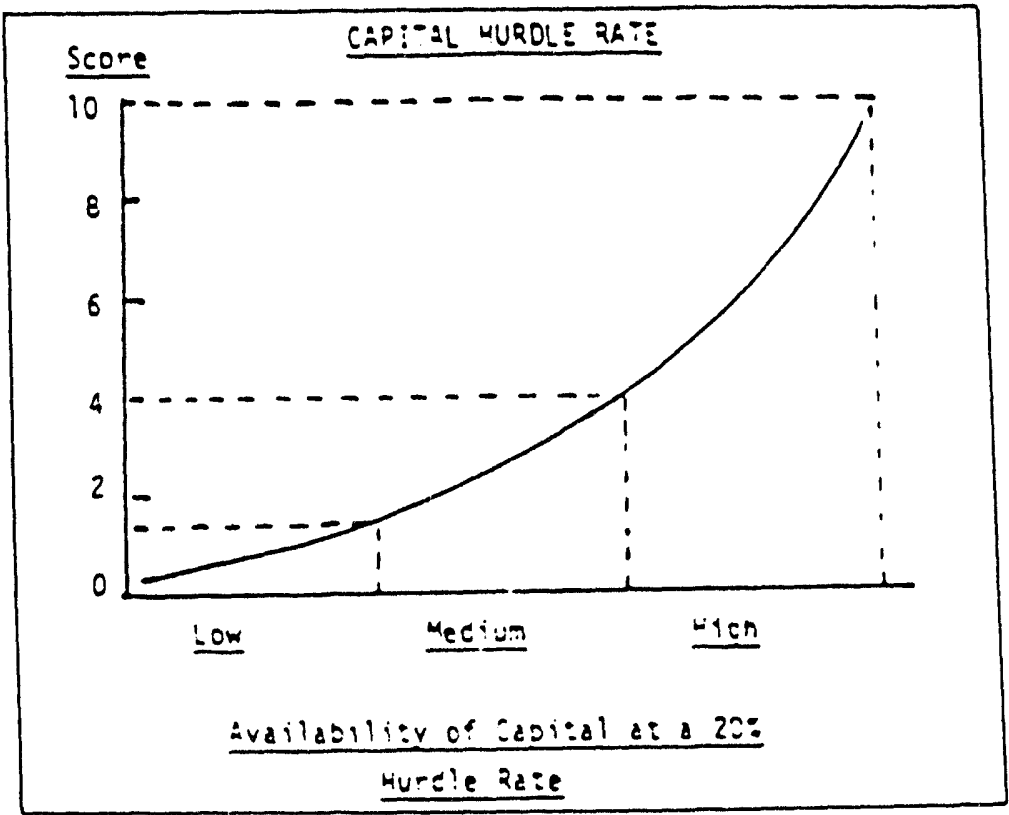

Capital needs usually are underestimated by a factor of at least two. and negarive surprise factors can muluply the requirements. Therefore. contingency plans for rapid reduction of overhead and other direct costs should be worked out in advance. The rule of thumb is that cash flow 
requirements for manufacturing marketing and distribution can exceed the cost of inicial development by a factor of 10 . Services, software and light manufacturing businesses tend to be low capital-intensive, and shared flexible computer integrated manufacturing facilities, now being developed, can mitigate some of the initial entry costs, and accelerate prototyping. Dedicated facilities making a single product often can be obsolescent now before repayment of their investment.

In the U.S. the cost of capital has averaged 5 to 7 times greater than Japan and other countries. Incoherent fiscal and monetary policies largely have been responsible. As a result, the hurdle rate for risk investments has been too high for venture capitalists, or when investing in opportunities still in development, they require large proporions of the equity.

Other limited sources of capital have included Small Business Innovation Research (SBIR) grants from U.S. Government laboratories, which provide $\$ 50.000$ Phase I, and $\$ 500.000$ Phase II grants. However, only about one in 100 applications is funded. The Commerce Department's Advanced Technology Program (ATP) has a growing budget, but one which also does not meet the demand. Finally Advanced Research Projects Agency, ARPA (formerly DARPA) funds promising dual-use developments that have both military and commercial potential. Friends and individual investors can be another limited source of funds. However, reliance on such funding cannot be 
advisable, and the ime-critical availability of funding is an imporant constraint Score as illustrated in Figure 15.

B. Marketine and Distribution (Score on a scale of 0 to 10)

Early entry and rapid peneration of global markets is critical in maximizing the retum on any investment. Moreover, time-critical access to global markets often will require formation of strategic alliances. (It is bener to have $50 \%$ of something than $100 \%$ of nothing.) Alliances must be properly structured and the individuals Figure 16

involved surongly incentivized to produce results. Separate arrangements may be required for different market segments, but the degree of differences in skills and capabilines needed can provide both risk distribution and barriers to entry for \begin{tabular}{|l} 
SCORE MARKETING/DISTRIBUTION \\
105
\end{tabular} comperitors. 
The U.S. Department of Commerce has set up a number of joint venture arangements with developing countries to facilitate formation of alliances. Contacts can be made through the Office of Tectinology Administration and through foreign commercial officers at many U.S. embassies. Score this factor as illustrated in Figure 16.

\section{Manufacruring Compelence (Score on a scale of 0 to 10)}

This factor is measured in terms of the ability to rapidly prototype a new developrnent, and provide easly market entry with sustainable and reproducible precision producion. Elements involved include bench scale and pilot plant facilities which are flexible and computer integrated. and can provide interim production at reasonable costs while gauging the need for and rate of capacity increases. Figure 17

Flexible computer integrated manufacturing. (FCDM) modules now are being developed which can be share-owned and ame critically accessed. for rapid protoryping and early market entry. These modules involve metal machining, plastics forming and molding, ceramics

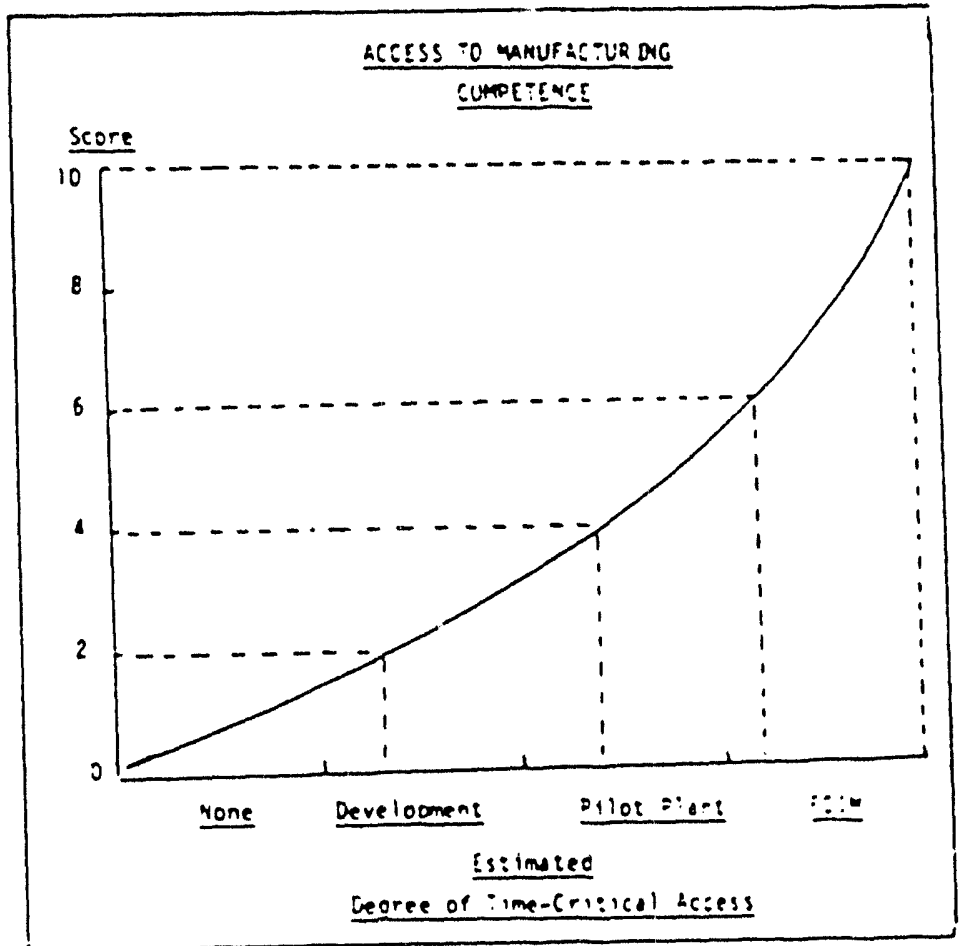


processing, and mechano-electronic assembly systems. Effective use of these facilities requires designing for production at the earliest stages of development.

Opportunities that do not require sophisticated production capabilities such as software and many services automatically rate scores of 10 . For others, score as illustrated in Exhibit 17.

D. Technical Support Capabilitv (Score on a scale of 0 to 10) Rapidly advancing technology now is the primary engine driving all economies. Therefore, an effective technical competence increasingly will be essential for industrial competitiveness. This function involves a number of imporant capabilities which include 1) a strong sales service function. 2) an ability to make continuous incremental improvements in existing operations, and 3) the experise to develop next-generation systems, deliberately designed to obsolete current operations before a compecitor does so.

1. Technical Services to Sales (Score on a scale of 0 to 3 )

Support of sales in the field can be vital for sustained customer satisfaction and repeat business. This is a specialized skill function. but often does not require a sophisticated technical background. Therefore, it must be supported on demand in a ime-critical fashion by more sophisticated skills whenever needed. 
2. Incremental Improvements (Score on a scale of 0 to 4)

Near-term competiviveness

Figure 18

and sustained cash flows

increasingly will depend

upon making $5 \%$ to $10 \%$

annual improvements in

cost/performance for most

businesses. This process

requires concurrent

engineering skills needed

from the laboratory bench

to commercial demonstration.

iECHNICAL COMPETEMICE

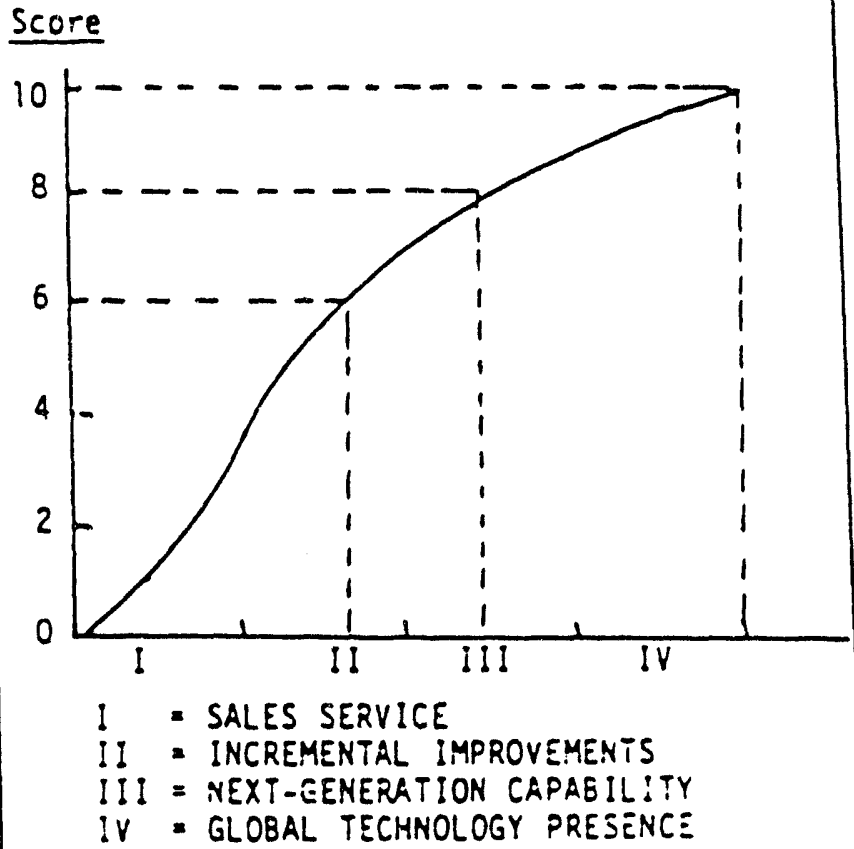

In addition, it requires a professionally staffed computer-aided literature search funcrion, since important developments can surface anywhere.

"A good idea doesn't care who has it." This very imponant "world scan" capability must be designed to identify both new discoveries that might synergize with existing operabions, as well as to provide early waming of next-generation developments that might obsolete existing systems.

3. Next-Generation Sustems (Score on a scale of 0 to 3)

The U.S. currendly spends some $\$ 25$ billion each year for basic reseasin. 
The United Kingdom is next with about $10 \%$ of that amount. All other nations spend less. Moreover, it is this unique (and unmatchable) capability that now generates most of the Nobel Prizes and has produced about two dozen "critical technologies" that will restructure almost every industry over the next two decades, and dominate the 21 st century. No U.S. or other industrial nation company, from now on. can expect to maintain profitability in any commodity business, unless it is protected by quotas or tariffs. Survival will depend upon making significant investments in these next-generation technologies with the deliberate intent to obsolete current operations as soon as possible.

This requires a high level and broad spectrum of technical capabilities which few companies alone can hold capative. Yet survival in the longer term depends upon the ability to access such capabilities. Often this will require collaboration in vertically integrated consortia ... a management style not easily accepted by a fiercely independent corporate culture.

The sum of these three scores constiutes the figure of merit for this technical support capability (Figure 18).

E. Access to Critical Materials and Components (Score on a scale of 0 to 10 ) A time-critical assured supply of raw materials or components is essential for 
sustained proficable operation.

Even a temporary shorage

Figure 19

or intertuption of a vital inter.

mediate. raw material, an

essential microchip, a circuit

board, or a testing service can

push a small business into

Chapter 11. or make a larger

company vulnerable to take

over if its stock price falls

below book value. Dependency

upon impors from politically

unstable countries is unwise, and

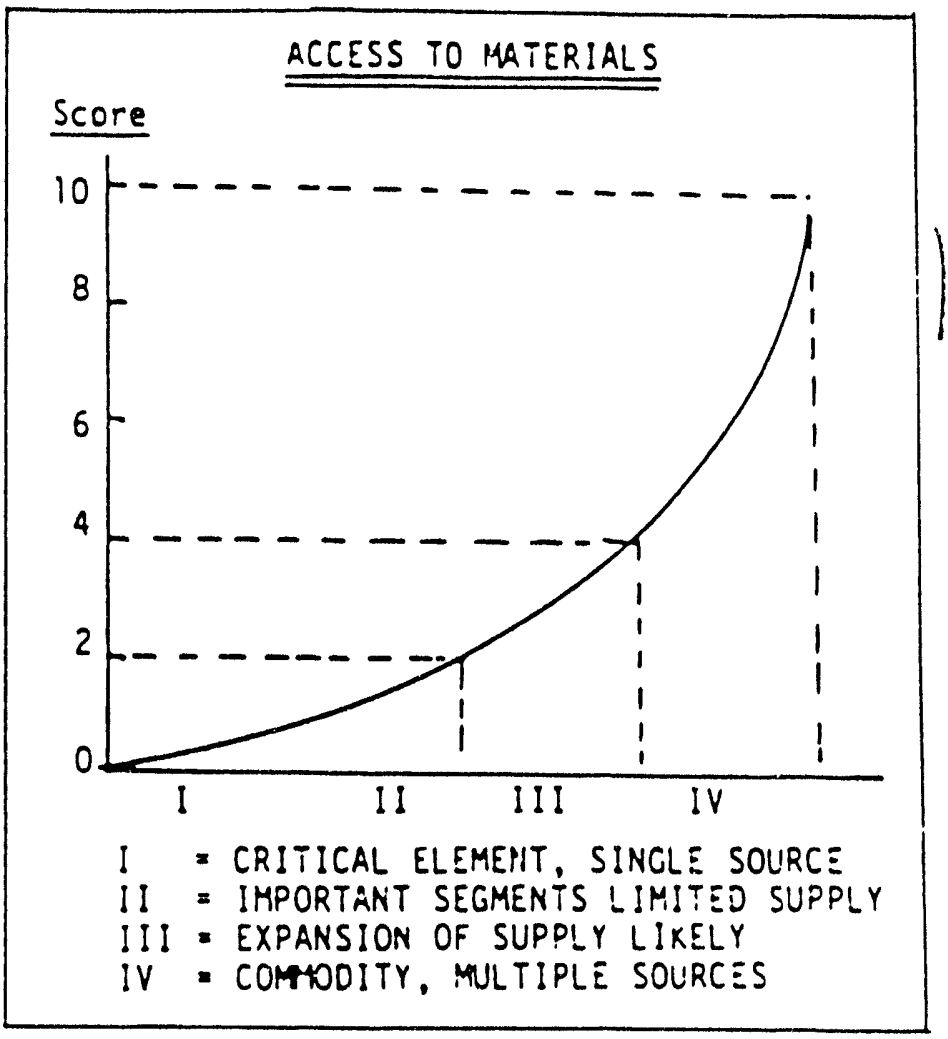

contingency plans that include reserve supplies are imporant Sole source procurement also can result in shrinking profit margins as the supplier takes advantage of the control possessed to raise prices. Rate the sensitivity to disrupuion as illustrated in Figure 19.

F. Management (Score on a scale of 0 to 10 )

Hemando deSoto, a Peruvian, has written a book based on a seven year siudy of Latin American companies, in which he points out that the definition of an underdeveloped country is one where the entepreneurial funcrion has been 
made illegal. This is true, of course, of all the Maxist-Socialist economies, but also, it is tue in par in many large companies where bureaucratic layers of managers have seriously impeded the intrapreneurial function. The furst requirement for successful entepreneurial and intapreneurial activities is a dedicated "champion" determined to succeed. In a large company a second requirement for success is the need for active top management support. Finally a third element that is required for all operacions is a flexible organization and strucrure that allows ime-critical access to all the skills and resources needed.

- Top management commitment means intervention at all levels of the organization to assure that skills and resources are available when needed, and that the fledging innovation is protected from existing entenched profit centers, competing for the same resoruces.

- The champion must be both technically competent and have had management experience. High levels of energy, good communication skills, and ability to relate easily to all types of people, and enormous persistence, also are needed.

- A concurrent engineering (task force) or matrix form of organization is essential to allow time-critical access to needed 
skills and resources. Also, increasingly, various forms of strategic alliance structures will be requried to pool skills and resources, share risk, and accelerate development times for early commercialization, and an all-imporant "first-mover" advantage.

The Limited Parmership scrucrure is parcicularly useful for both funding and managing a major innovation. which may be beyond the skill capabilities and risk threshold for an individual company. Score this factor as illustrated in Figure 20.

Figure 20

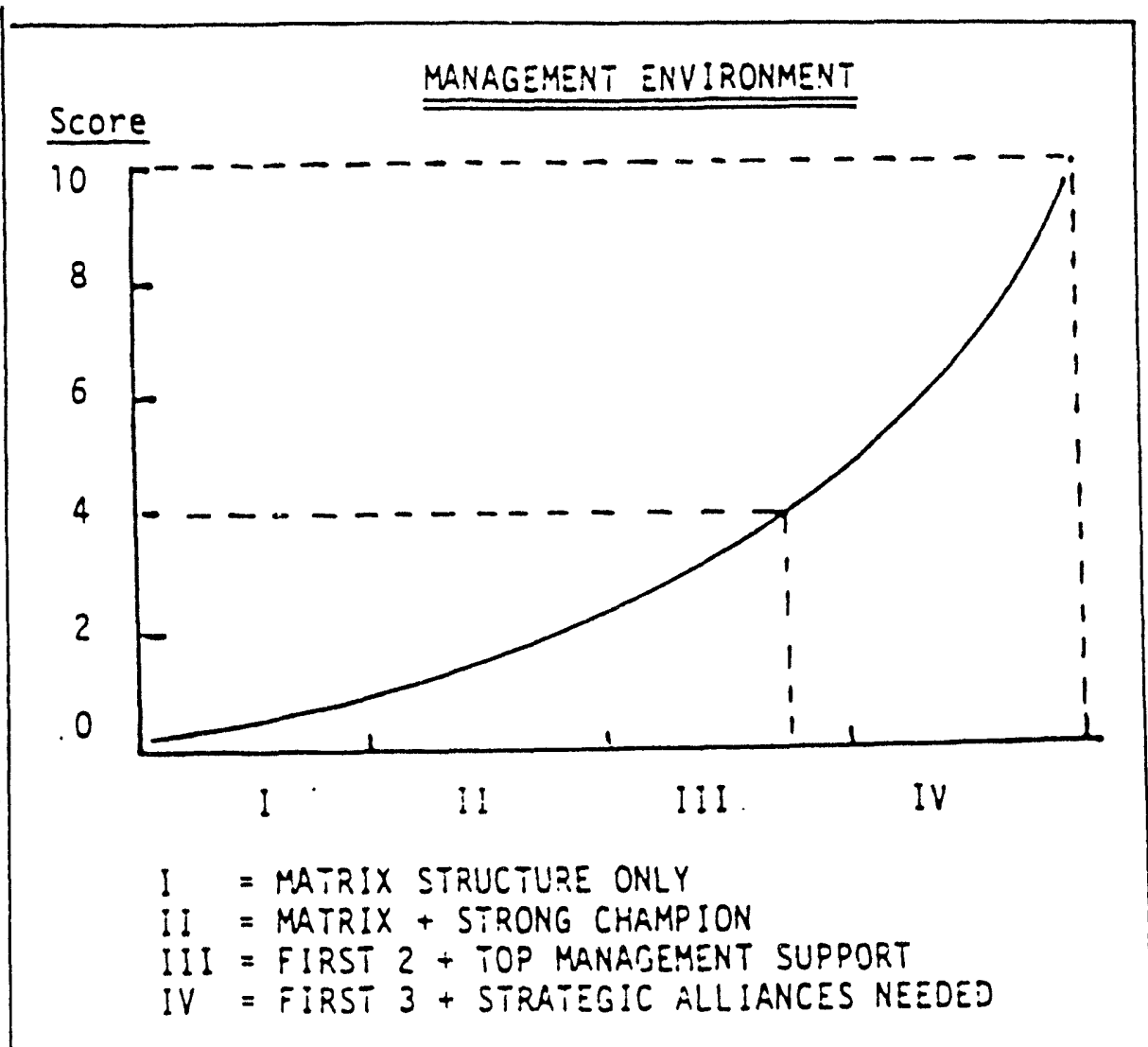


Regression Analysis

Figure 21 tabulates several dozen projects. some of which in retrospect should never have been underaken. and others resulted in varying degrees of success as measured by a discounted cash flow rerum on investment. Regression analysis ${ }^{3}$ produced a correlation factor ( $r$ ) of 0.91 , with a coefficient of determination of 0.82 , and the coefficient of nondetermination of 0.17 . The $T$ value (14.45) also is very high, indicating that the possibility of zero correlation within the population is unlikely (less than 5\%), and that a $95 \%$ confidence exists for the correlations postulated.

Figure 22 also plots the correlation between \% ROI and the constaint scores. Rerum on investment rises exponentially with the constraint score. The author was intimately involved in these projects over several decades, commencing in an earlier "more naive" time. Commiting the ime. energy and enthusiasm of a young researcher to projects that have minimal hope of commercial success, can be dispiriting ... and was the origin of the consuaint analysis. The analysis developed over a number of years, and much berer results were obtained, as the oppormunity for management control over investment oppormuities occured.

The analysis was picked up by $T$. Ohed. in Japan. when resident at the Wharon Scthool of Business. He carried out a study of some 38 comporate diversification ventures, involving 18 major Japanese corporations. $80 \%$ of the ventures were manufacturing and $20 \%$ service businesses. Regression analysis showed a strong correlation with the "Fit Factors", and 4 of the 6 "Business Atractiveness" factors (Figure 23). 
Project Analysis

Business Attractiveness

rit ractors

Results

Project

Specialty Polymer

Ure Flotation Agent

Rocket Fuel

Specialty Polyester

Zinc/Chloride Battery

lligh Temp Polymer

IIF From Phosphates

Vulcanization Agent

(juiet Ride lime

Ziegler Catalyst

Retort Pouch

Synthetic [thaverine

Polystyrene Cup

Specialty Phenolic

Scale Inhibitor

tmulsion Butadiene

Phenolic Uye

Chlorine Membrane Cell

Edible Sausage Casing

Barrier Plastic (CO)

rire Retardant.

Dipolar Chlorine Cell

Instant Corrosion Meter

Corrosion Inhibitor

specially Emulsifier

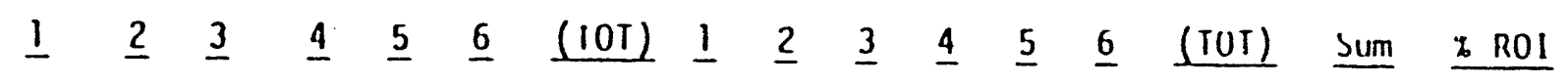

$\begin{array}{llllllllllllllll}5 & 5 & 4 & 2 & 0 & 5 & (21) & 8 & 3 & 4 & 7 & 9 & 5 & (36) & 57 & 0 \%\end{array}$

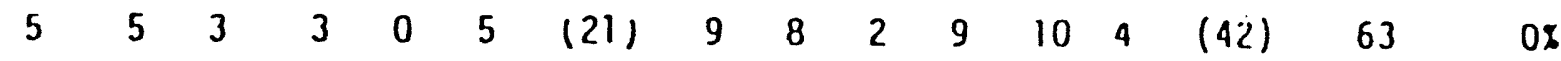

$\begin{array}{llllllllllllllll}7 & 5 & 2 & 1 & 4 & 6 & (25) & 7 & 7 & 2 & 9 & 10 & 5 & (40) & 65 & 0 \%\end{array}$

$\begin{array}{llllllllllllllll}7 & 7 & 5 & 4 & 0 & 5 & (28) & 8 & 7 & 8 & 8 & 0 & 7 & 138) & 66 & \text { Ux }\end{array}$

$\begin{array}{llllllllllllllll}5 & 5 & 2 & 5 & 5 & 5 & (27) & 4 & 4 & 3 & 7 & 10 & 5 & (33) & 60 & 0 x\end{array}$

$\begin{array}{llllllllllllllll}7 & 5 & 4 & 6 & 0 & 5 & (27) & 6 & 5 & 3 & 7 & 10 & 6 & (39) & 66 & 0 x\end{array}$

$\begin{array}{llllllllllllllll}6 & 5 & 5 & 7 & 0 & 7 & (30) & 5 & 7 & 4 & 6 & 10 & 5 & (37) & 67 & 0 x\end{array}$

$\begin{array}{llllllllllllllll}5 & 4 & 4 & 3 & 2 & 5 & (23) & 8 & 8 & 7 & 8 & 9 & 5 & (45) & 68 & 0 x\end{array}$

$\begin{array}{llllllllllllllll}5 & 4 & 4 & 2 & 2 & 6 & (23) & 8 & 8 & 7 & 8 & 10 & 5 & (46) & 69 & 08\end{array}$

$\begin{array}{llllllllllllllll}7 & 8 & 2 & 2 & 4 & 5 & (28) & 8 & 6 & 5 & 8 & 10 & 5 & (42) & 10 & 56\end{array}$

$\begin{array}{llllllllllllllll}6 & 5 & 3 & 4 & 4 & 6 & (28) & 7 & 1 & 7 & 5 & 10 & 6 & (42) & 10 & 46\end{array}$

$\begin{array}{llllllllllllllll}5 & 4 & 5 & 2 & 0 & 6 & (22) & 9 & 8 & 8 & \text { y } & 10 & 7 & \text { (b1) } & 73 & 11 x\end{array}$

$\begin{array}{llllllllllllllll}7 & 6 & 3 & 7 & 0 & 6 & (29) & 6 & 6 & 7 & 8 & 10 & 7 & 144) & 73 & 12 x\end{array}$

$\begin{array}{llllllllllllllll}5 & 4 & 2 & 5 & 0 & 5 & (21) & 7 & 10 & 10 & 7 & 10 & 7 & (51) & 72 & 9 x\end{array}$

$\begin{array}{llllllllllllllll}5 & 6 & 3 & 3 & 0 & 5 & (22) & 9 & 8 & 9 & 9 & 10 & 5 & (30) & 72 & 12 x\end{array}$

$\begin{array}{llllllllllllllll}6 & 6 & 4 & 3 & 3 & 5 & (29) & 7 & 9 & 7 & 8 & 10 & 5 & (46) & 75 & 13 \%\end{array}$

$\begin{array}{llllllllllllllll}5 & 4 & 7 & 4 & 2 & 5 & (27) & 8 & 9 & 9 & 7 & 10 & 5 & (48) & 15 & 12 x\end{array}$

$\begin{array}{llllllllllllllll}7 & 6 & 4 & 3 & 3 & 5 & (30) & 8 & 7 & 8 & 7 & 10 & 7 & (47) & 77 & 15 \%\end{array}$

$\begin{array}{llllllllllllllll}8 & 8 & 4 & 4 & 5 & 7 & (36) & 8 & 4 & 7 & 5 & 10 & 7 & (41) & 77 & 15 x\end{array}$

$\begin{array}{llllllllllllllll}8 & 7 & 5 & 7 & 3 & 5 & (27) & 7 & 6 & 3 & 8 & 10 & 6 & (42) & 77 & 11 \%\end{array}$

$\begin{array}{lllllllllllllll}6 & 8 & 3 & 7 & 0 & 7 & (31) & 8 & 9 & 8 & 6 & 10 & 6 & (47) & 18\end{array}$

$\begin{array}{llllllllllllllll}6 & 6 & 5 & 4 & 3 & 5 & (29) & 8 & 9 & y & 8 & 10 & 7 & \text { (31) } & 80 & 16 \%\end{array}$

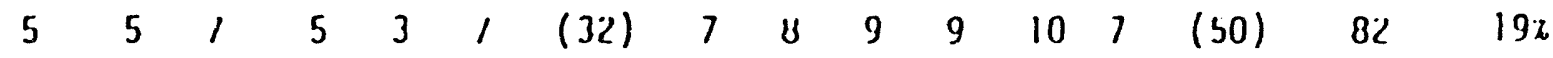

$\begin{array}{llllllllllllllll}8 & 6 & 5 & 7 & 2 & 6 & (34) & 8 & 8 & 9 & 9 & 5 & 9 & (18) & 82 & 23 \%\end{array}$

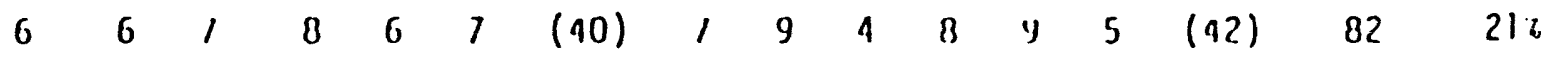


Project Analysis

\begin{tabular}{|c|c|c|c|c|c|c|c|c|c|c|c|c|c|c|c|c|}
\hline \multirow[b]{2}{*}{ Project } & \multicolumn{7}{|c|}{ Business Altractiveness } & \multicolumn{6}{|c|}{ rit ractors } & \multicolumn{3}{|c|}{ Resulis } \\
\hline & 1 & 2 & $\underline{3}$ & 1 & $\underline{5}$ & $\underline{6}$ & (TOT) & 1 & $\underline{2}$ & $\underline{3}$ & $\underline{4}$ & $\underline{5}$ & $\underline{6}$ & (TUT) & $\underline{\text { Sum }}$ & $\underline{x}$ HOI \\
\hline High Impact PVC & 10 & 8 & 6 & 10 & 3 & 5 & $(12)$ & 7 & 8 & 3 & 7 & 10 & 5 & $(40)$ & 82 & 426 \\
\hline Fine Particle PvC & 8 & 7 & 7 & 7 & 1 & 5 & $(35)$ & 8 & $y$ & 5 & 9 & 10 & 7 & $(48)$ & 83 & $39 x$ \\
\hline$\angle$ inc Cerrophos Corrosion & 8 & 6 & 7 & 5 & 1 & 5 & $(35)$ & 9 & 9 & 6 & 8 & 10 & 7 & (49) & 84 & $32 \%$ \\
\hline Plastic Beverage Bottle & 8 & 8 & 5 & 3 & 3 & 6 & $(35)$ & 8 & ४ & 9 & 7 & 10 & 7 & $(49)$ & 84 & $24 \%$ \\
\hline Pour Point Uepressant & 8 & 8 & 5 & 5 & 3 & 7 & $(36)$ & 9 & ४ & 7 & 9 & 10 & 6 & $(49)$ & 85 & $24 x$ \\
\hline Uimension stable Anode & 9 & u & 5 & 4 & 6 & 6 & $(38)$ & 9 & 8 & 9 & 6 & 10 & b & $(48)$ & 86 & $32 x$ \\
\hline Synthetic Wax & 9 & 1 & 6 & 5 & 3 & 5 & $(35)$ & $\hat{y}$ & 8 & 7 & $y$ & 10 & 1 & $(51)$ & 86 & $42 \%$ \\
\hline Rubber Accelerant & 8 & 6 & 4 & 7 & 5 & 5 & $(35)$ & 9 & 9 & 9 & b & 10 & 7 & $(52)$ & 87 & $26 x$ \\
\hline Uil Field Bacteridstat & 8 & 8 & 6 & 6 & 3 & 7 & $(35)$ & $y$ & 8 & 9 & 8 & 10 & 7 & (51) & 89 & $37 \%$ \\
\hline Rubber Antidegradent & 9 & ४ & 6 & 7 & 6 & 9 & $(15)$ & 7 & 9 & 3 & 9 & 10 & 8 & $(46)$ & 91 & $46 x$ \\
\hline Iligh Impact Polystyrene & 9 & 8 & 6 & 7 & 5 & 5 & $(40)$ & 9 & 10 & 1 & 9 & 10 & 6 & $(51)$ & yi & $42 x$ \\
\hline Agriculture Herbicide & 9 & 9 & 7 & 7 & 4 & 6 & $(42)$ & 8 & 9 & 9 & 9 & 10 & 7 & $(52)$ & 92 & $43 \%$ \\
\hline
\end{tabular}

Correlation of Constraint Score Sum With $\approx$ ROI

0.924

Coefficient of Determination

$0.85 \mathrm{~J}$

Coefficient of Non-Ueternination

0.147

$\pi$ Value

14.951

Correlation of ROI Wilh

Business Altractiveness

0.8

ric ractors

0.6 
FIGUPE 22

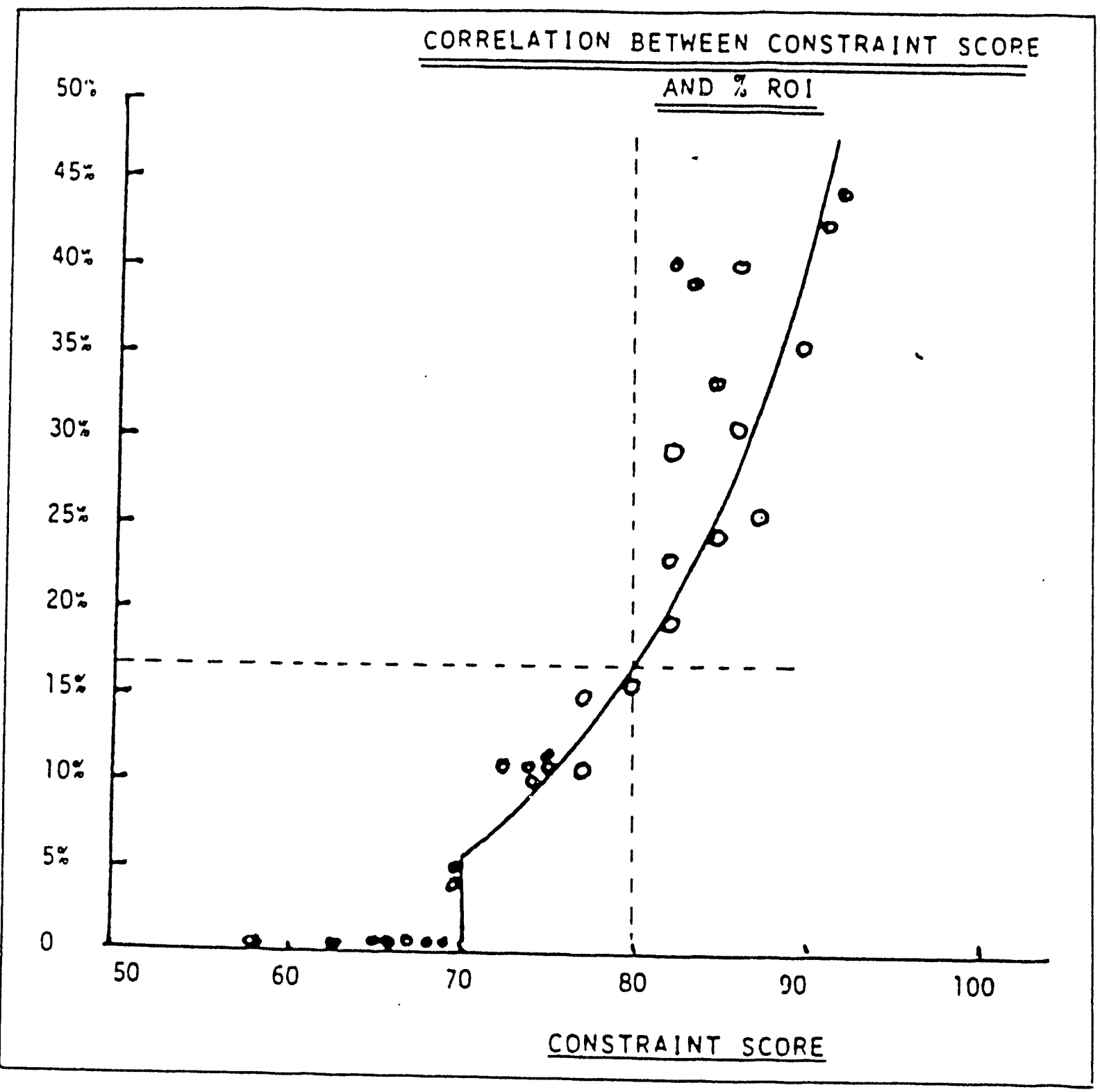


Figure 23

\begin{tabular}{|c|c|c|c|}
\hline \multicolumn{2}{|c|}{ Business Attractiveness } & \multicolumn{2}{|l|}{ Fit Factors } \\
\hline $\begin{array}{l}\text { 1. Sales/Profit Potential } \\
\text { ROI } \\
\text { Market Size } \\
\text { 2. Growth Potential } \\
\text { 3. Competitor Analysis } \\
\text { Product Life } \\
\text { Competition } \\
\text { Patent Protection } \\
\text { 4. Risk Distribution } \\
\text { 5. Restructuring } \\
\text { 6. Political/Social }\end{array}$ & $\begin{array}{r}0.255 \\
0.237 \\
0.331 \\
0.115 \\
0.345 \\
0.321 \\
0.287 \\
-0.021 \\
0.489 \\
-0.249 \\
-0.170\end{array}$ & $\begin{array}{l}\text { 1. Capital Availability } \\
\text { 2. Manufacturing } \\
\text { 3. Marketing, Distribution } \\
\text { 4. Technology Capability } \\
\text { 5. Component Availability } \\
\text { 6. Management } \\
\text { Top Mgmt. Support } \\
\text { Champion }\end{array}$ & $\begin{array}{l}0.215 \\
0.258 \\
0.215 \\
0.257 \\
0.305 \\
0.615 \\
0.561 \\
0.291\end{array}$ \\
\hline Sub Total & 0.216 & Sub Total & 0.506 \\
\hline
\end{tabular}

Lack of correlation with Nos. 5 and 6 in the Business Artactiveness category and with the need for patent protection reflect the fact that the projects selected were not based on new $R \& D$, but were diversifications into existing businesses with limited proprietary character. Also, the regulatory climate in Japan has been more benign than in the U.S. $(80,000$ new U.S. regulations were legislated between 1980 and 1990.) The study was underiaken because the acrive diversification effors by large companies in Japan, had met with limited successs. Those that were successful had constraint scores of 80 points or more (Figure 24). 
Figure 24

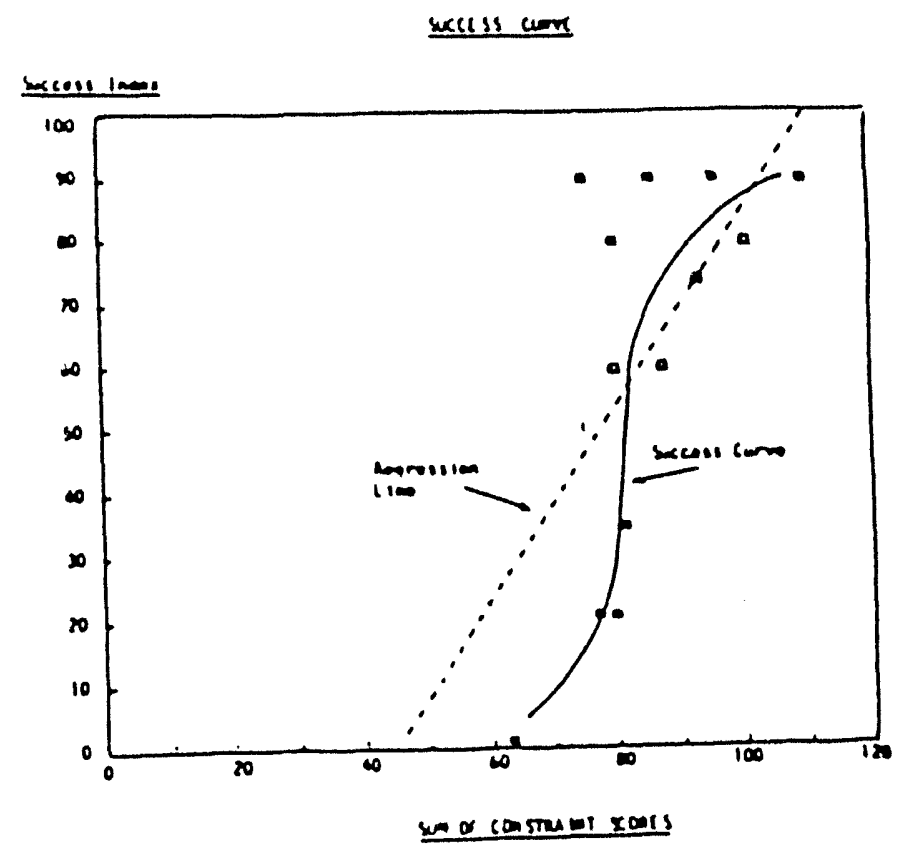

Ohe defines commercial success as illustrated in Figure 25.

Figure 25

STATUS OF BUSINESS

A "Going Concern"

B Planning For Expansion

C Planning For Cutback

D Sales Performance On Plan

E Profit Perfomance on Plan

F Cash flow status.

$G$ Operational Profit Status

$H$ Accumulative Profit Status

1 Profit Compared To Ma in Business

$J$ Revenue as : Of Total Company

$K$ Status of Invisible assets

$L$ Reputation of Venture in Company
SUCCESS

FAILURE

No

No

Yes

No

Exceeds

Yes

Exceeds

Below

Below

Positive

Profitable

Negative

Loss

Loss

Worse

Better

Less ihan ::

Over 1:

Decreased

success

Failure 
Summary

Regression analyses have identified a dozen performance factors that are imporant for profitable operation of an existing business, or for successful development of a new business.

Each factor is scored on a scale of 0 to 10, and the sum of the individual scores provides a global benchmark of the operation. Statistically, total scores of 80 points or more define growth businesses, and predict 8 or 9 out of 10 commercial successes for new business investments. 
References

1. Kotler. P. Marketing Management. Analvsis, Planning and Control, Sth ed. Prentice Hall 1984, Chapter 11.

2. National Science Foundation Science and Technology Data Book (1992).

3. Analysis carried out by R. Merrifield for Masters Degree Thesis in parual fulfillment of MBA requirements (1993) University of Phoenix. Phoenix. Arizona.

4. Ohe, T., Honjo, S., Merrifield, D.B., J. Bus. Venturing, Vol. 7. No. 3 May 1992.

5. Nikei Business, 1987 Nov. 23, 6, 24 (A Survey of Corporate Ventures of Large Japanese Firms). 


\author{
APPENDIX 3 \\ PROTECH OVERVIEW
}




\section{PROTECH OVERVIEW}

ProTech is an interactive computer-based tool developed by Battelle Pacific Northwest Laboratory for DOE-OTD to provide stakeholders with top level (limited detail) information on "technologies being used to assess, monitor, and clean up the environmental damage at Department of Energy (DOE) facilities." ProTech prr vides technical information, but does not provide guidance for comparing or evaluating.

The ProTech data base is designed to provide information for comparison of candidate "new" technologies, as well as, comparing the "new" technologies to attributes of current "off-the-shelf" technologies. As illustrated in Figure A.3-1, the technology profiles in ProTech include information organized is provided in according to 40 individual comparison criteria that have been grouped into the following four categories:

- Effectiveness;

- Envirnnment, Safety, and Health;

- Socio-Political Interests; and

- Regulatory Objectives.

ProTech provides technical information that supports, in varying degrees, each of the three evaluation and screening areas: Technical, Stakeholder, and Industrial. It is up to the evaluator to determine the degree of usefulness to each assessment type and how to use this information in the assessment. The ProTech criteria correlate strongly with Technical and Stakeholder evaluations, and to a lesser degree with Industrial (commercial success) evaluations. As examples relating to Commercial Success assessments, technology data provided under the ProTech "Socio-Political Interests" criteria, supports the evaluation of the "Political and Social Constraints" success criterion of the Quantitative Commercial Success Constraint Analysis; and data from all of the ProTech criteria support the assessment of the Quality of Technology success factor of the Qualitative Commercialization Success Factor Assessment .

Other environmental technology information sources exist in various stages of development throughout the DOE complex.

ProTech criteria descriptions and data input questions are provided in Table A.3-1. 
Figure A.3-1.

ProTech Technology Evaluation Criteria

Effectiveness Criteria (Performance, Cost, \& Time)
Environmental Safety \& Health Criteria

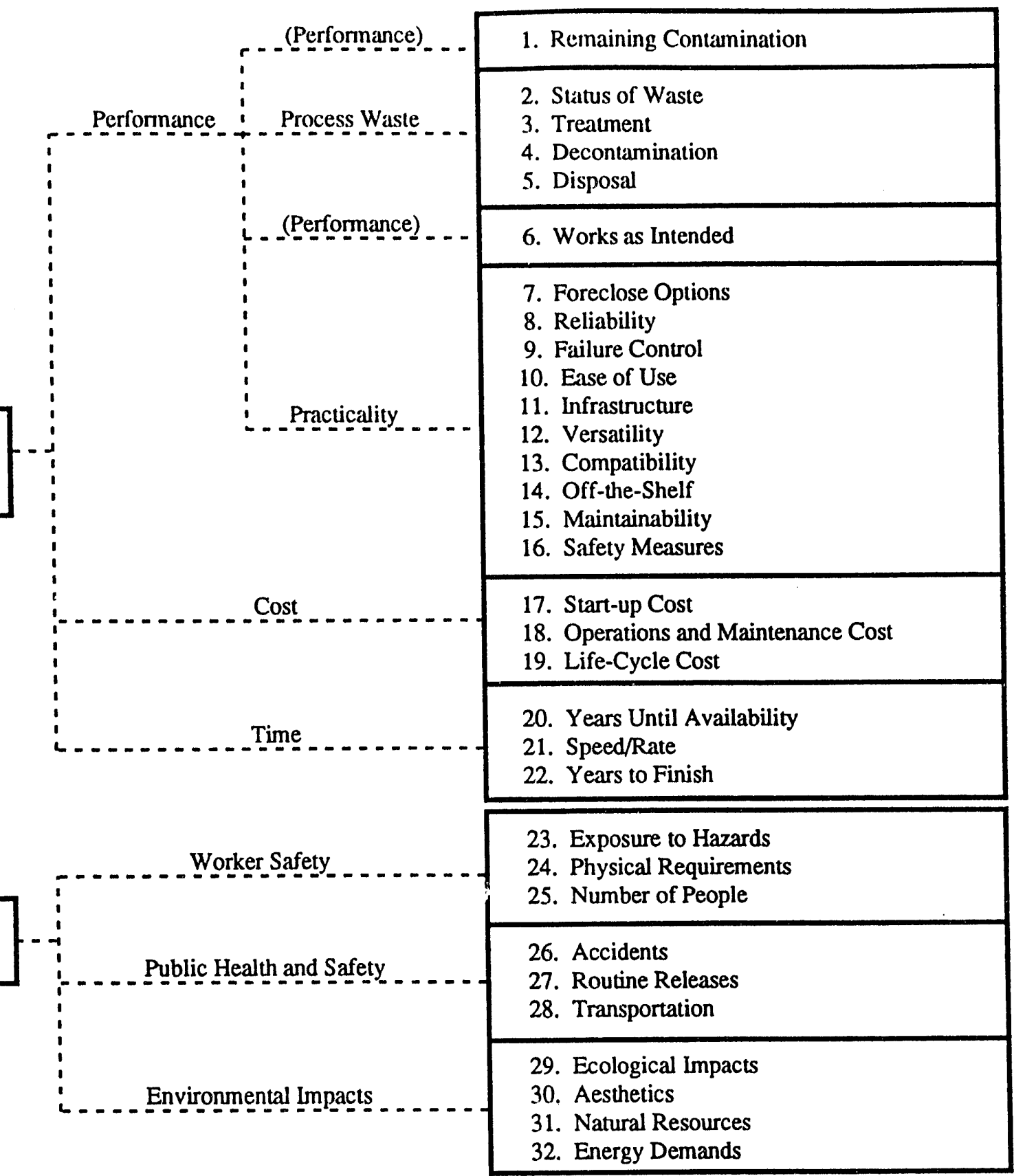

33. Proponent Reputation

34. Familiarity/Understanding

35. Capacity for Unrestricted Use

36. Economic Impacts

37. Labor Force Demands

38. Compatibility with Clean-up Milestones

39. Regulatory Infrastructure/Track Record

40. Regulatory Compliance
Regulatory

Objectives Criteria 


\begin{tabular}{|c|c|}
\hline $\begin{array}{l}\text { Remaining } \\
\text { Contamination }\end{array}$ & $\begin{array}{l}\text { This criterion refers to conlaminants remaining after the technology has } \\
\text { been applied (e.g.. the } 1 \text { percent remaining after a } 99 \text { percent-effective } \\
\text { groundwater treatment technique is completed). The remaining } \\
\text { contamination is to be measured according to how much contaminant } \\
\text { mobility, volume, and toxicity are reduced by the lechnology. }\end{array}$ \\
\hline & $\begin{array}{l}\text { What contamination will remain after the technology is } \\
\text { applied? Will the mobility of the contamination be reduced? } \\
\text { Will the volume be reduced? Will the contaminant be less } \\
\text { toxic? (This criterion applies primarily to retrieval } \\
\text { treatment technologies.) }\end{array}$ \\
\hline
\end{tabular}

2. Status of Waste The status of the waste can be assessed. including consideration of waste mobility, volume, degree of hazard represented by the character of the waste, and recycle potential. The ability to characterize the waste, handle it safely, and transport it with minimal risk. are also important.

What process waste (secondary waste) dues the technology produce? Is the secondary waste mobile? What is its volume? What hazards are associated with the secondary waste? Can it be recycled?

3. Treatment Waste treatment requirements needed 10 address a given technology's residuals can be assessed, and the availability of the needed treatment technology defined.

What types of treatment or storage are needed for the secondary waste? What is the availability of this treatment or storage? 4. Decontamination Requirements for decontamination and decommissioning of a technology.
and the resulting waste, can be evaluated.

What are the requirements of decontamination or decommissioning of equipment?

5. Disposal the technology can also he evaluated according to the need for waste
disposal, and whether such disposal capacity is available. The nature of
available disposal (e.g., landfill versus more progressive disposal method)
should also be considered.
How must the secondary waste be disposed or? Is disposal
available?

Works as
Intended

A sy'stems analysis perspective on the technology will evaluate whether the technology is compatible with the other elements of the remediation system. The ability to procure the technology "off the shelf," with the simplest possible development approach, is another criterion. How easy the technology is to routinely maintain. and how often maintenance is requised. should be considered. Also, the safely measures required in protect workers and the public can be evaluated. Finally. determining whether a technology actuaily works as intended is also a consideration.

What is the technology's ability to function as intended? Does the lechnology work as intended? If not, what are the functional problems? What are the scale-up issues and how are they being addressed? 


\begin{tabular}{|c|c|}
\hline $\begin{array}{l}\text { 7. Forecluse } \\
\text { Options }\end{array}$ & $\begin{array}{l}\text { Practicality is defined hy several criteria. It assesses whether use of a given } \\
\text { lechnology will preclude or foreclose future cleanup options. Il evaluates } \\
\text { whether a lechnolngy is reliable, and can be expected in coperate with } \\
\text { minimal operational problems and production downtime. If the lechnology } \\
\text { fails. it should he possible to control the effects of that failure easily and } \\
\text { rapidly. Other criteria include whether the technolegy is easy to use and } \\
\text { capable of operating with the existing facility infrastructure (e.g.. buildings, } \\
\text { power sources, persennel). Versatility of the lechnology to address other } \\
\text { types of contamination, in other media, or at other locations, can also be } \\
\text { assessed. }\end{array}$ \\
\hline & $\begin{array}{l}\text { What future cleanup options are precluded by this } \\
\text { lechnology? }\end{array}$ \\
\hline
\end{tabular}

\begin{tabular}{ll}
\hline 8. Reliability & See Criterion 7 \\
& How reliable is the technology (potential breakdowns, \\
& effectiveness, and sensitivity to operating conditions)?
\end{tabular}

9. Failure Control See Criterion 7
If the technology fails, how are the effects of the failure
controlled?

\begin{tabular}{ll} 
10. Ease of Use & See Criterion 7 \\
& $\begin{array}{l}\text { How easy is the technology to use? What level of skills and } \\
\text { training are required to use the technology? }\end{array}$ \\
\hline 11. Infrastructure & See Criterion 7 \\
& $\begin{array}{l}\text { What infrastructure (buildings, power source, personnel) is } \\
\text { needed to support the technology? }\end{array}$
\end{tabular}

12. Versatility See Criterion 7

How versatile is the technology? Can it be applied to other types of contamination, in other media, or at other locations?

A systems analysis perspective on the technology will evaluate whether the technology is compatible with the other elements of the remediation system. The ability to procure the technology "off the shelf," with the simplest possible development approach, is another criterion. How easy the technology is to routinely maintain, and how often maintenance is required, should he considered. Also, the safery measures required to protect workers and the public can be evaluated. Finally', determining whether a technolngy actually works as intended is also a consideration.

How is the technology compatible with other elements of the system? What is the nature of the system that the technolugy is part of?

\section{Off-the-Shelf See Criterion 13}

Can the technology be procured "off-the-shelr?" Is it an innovative use of an existing technology? Which components are available and which must be developed? 


\section{Maintainability Sec Criterion 13}

How difficult is the technology equipment to maintain? What are the maintenance frequencies? What tevel of still or training is required to maintain the technology.

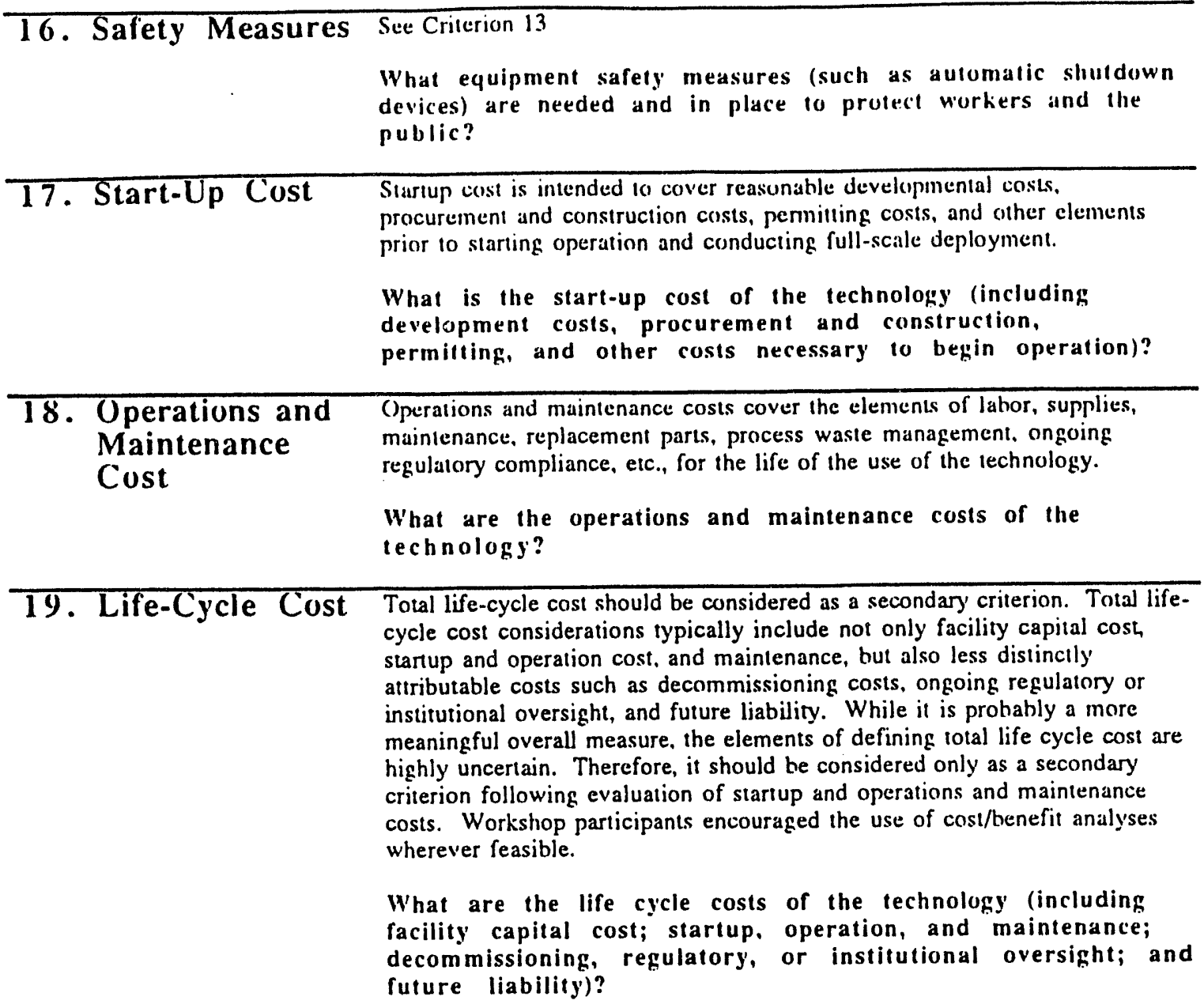

\section{Years Until} Available
Years until available, while an estimate, is directly comparable between and among technologies.

When will the technology be available for commercial use or use at other sites?
Speed or rate is measured differently for different categories of technologies (e.g.. feet per hour for a drilling technology, pounds per day for an extraction technology), but is a useful measure of comparison of technologies within a category.

What is the speed or rate of the technolugy?

\section{Years to Finish \\ Years to finish measures the total time required for setup and removal, as well as the total length of time needed for a given technology or combination of technologies to achieve the given objective(s).}

What is the total time required for the technology to achieve its objectives at the speed or rate identified? 


2.3. Exposure to
Hazards

The crileria for evaluating a technology according 10 us worker safety aspects include the level of exposure of workers to hazardous materials or other hazards resulting from use of the lechnology, the physical requirements of developing and operating the technology, and the number of workers required. Factors to evaluale worker safety may include the number of days Inst due to accidents or exposure, the concentration of contaminants in the workplace, or operational considerations such as the need for protective clothing or equipment. Technologies using remote handling techniques are preferred.

What potential is there for workers to be exposed to hazardous materials and lor other hazards? What are those malerials and hazards?

24. Physical
Requirements

See Critcrion 23

What are the physical requirements for workers?

25. Number of
People Required

26. Accidents Public healith and safety aspects of a given technology can he evaluated based on the number, type and severity of accidents postulated to nccur related to that technology's development. operation, and decommissioning.

What is the technology's history of accidents? Has there been a history of accidents and if so, what was the nature of the accidents?

\begin{tabular}{ll}
\hline 27. Routine & Routine releases to air, ground, or water pathways from a technology can he \\
Releases & $\begin{array}{l}\text { samples, wastes, or other materials associated with the technology. Careful } \\
\text { consideration needs to be given as to whether the risks from transporting } \\
\text { contaminants offsite are offset by the risks of disposing of them onsite. }\end{array}$ \\
Does this technology produce routine releases of \\
contaminants?
\end{tabular}




\begin{tabular}{|c|c|}
\hline $\begin{array}{l}\text { 31. Natural } \\
\text { Resources }\end{array}$ & $\begin{array}{l}\text { See Criterion } 29 \\
\text { What natural resources are used in the rechnology's } \\
\text { development, manufacture, or operation? }\end{array}$ \\
\hline 32. Energy Demands & Sec Criterion 29 \\
\hline & What are the technology's energy requirements? \\
\hline $\begin{array}{l}\text { 33. Proponent } \\
\text { Reputation }\end{array}$ & $\begin{array}{l}\text { The reputation of the proponent of a technology, whether the technology } \\
\text { developer or deployer, affects puhlic perception of that technology. This } \\
\text { may apply to a government agency, national lahoratory, academic } \\
\text { institution, contractor firm, or private industry partner. } \\
\text { What is the reputation of the technology's developer and/or } \\
\text { user? }\end{array}$ \\
\hline $\begin{array}{l}\text { 34. Familiarity } \\
\text { Understanding }\end{array}$ & $\begin{array}{l}\text { The degree of familiarity of a technology and its use is a key factor affecting } \\
\text { public perception of a given technology. Information needed for decision } \\
\text { making (e.g., cost projections) is often unavailabic or unreliable, thus } \\
\text { causing public concerns. The ability to explain the technology in } \\
\text { understandable terms is important to public acceptability. Involvement of } \\
\text { the public in decisions about the use of different technologies is a key } \\
\text { element of public acceptability of those technologies. Other factors that } \\
\text { have been addressed elsewhere also affect public perception, including } \\
\text { elements such as related employment, and the overall benefit a person } \\
\text { perceives that would result from deployment of the technology. In addition, } \\
\text { generalized public fear and dread of hazards, high technology solutions, and } \\
\text { government actions may be factors affecting acceptability of some } \\
\text { technologies. }\end{array}$ \\
\hline & $\begin{array}{l}\text { How familiar is the technology to the public? How easy is } \\
\text { the technology to explain to the public? }\end{array}$ \\
\hline
\end{tabular}

35. Capacity for
Unrestricted
Use

Native American values related to the land and its uses offer criteria for evaluating alternative cleanup technologies. In addition to the affected tribes, many other groups and individuals have interests in future uses of currently-contaminated land. The return of the land to a pristine state is a major goal. Capacity for future unrestricted use of the contaminated areas, including both terrestrial and aquatic uses, is a key criterion. This relates to spiritual values as well as traditional uses (e.g., hunting, fishing, recreation, living areas). To the degree possible, the physical nature of the land itself should not be changed (e.g., not vitrifying large solid blocks of earth in place).

How will the technology affect future unrestricted use of land and water?

36. Economic
Impacts

Effects of a technology or suitc of lecthnulogies on the economic bise of the community should be considered, including fiscal as well as less tangible impacts. Impacts may include local infrastruciure requirements (c.g., sewer. fire protection, etc.), labor force lurnover (if new or different capabilities are needed), housing values, or other factors. Availability of the required labor force can be evaluated for different technologies, including the need for personnel training.

What are the potential economic impacts of this technology? What are the effects on the economic base of the community? Are there infrastructure requirements? 


\begin{tabular}{ll}
\hline 37. Labor Force & $\begin{array}{l}\text { Sec Criterion 36 } \\
\text { Demands }\end{array}$ \\
How will the technology affect labor force demands?
\end{tabular}


APPENDIX 4

VALLEY OF DEATH

SCIE-COM 190-94 


\section{Valley of Death}

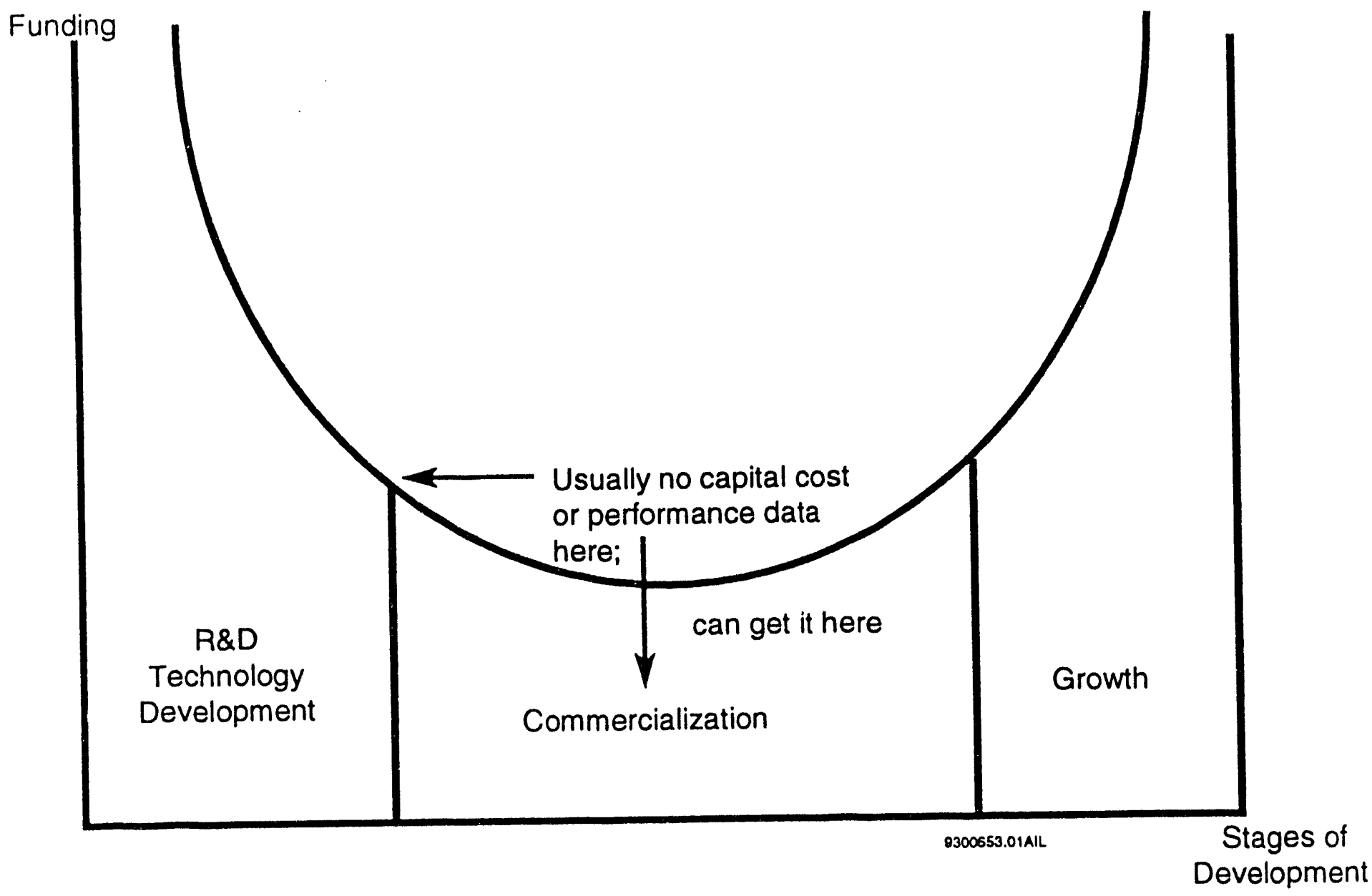

- A lot of investment here; e.g., government, small business, venture capitalists (assume venture capital requirements are worst case)

- $\quad$ Some jobs created
- Abandoned by everyone, including corporate partners; no one wants to invest

- $\quad$ No defined market

- Could get hung up

- Usually costs $\geq \mathrm{R} \& \mathrm{D}$ phase

- Not much return on investment

- This is where Japan and Germany jump in
- Real job creation here

- $\quad$ Can get funds from banks, private sources, initial public offering and other investors 


\section{Environmental Technology Market}

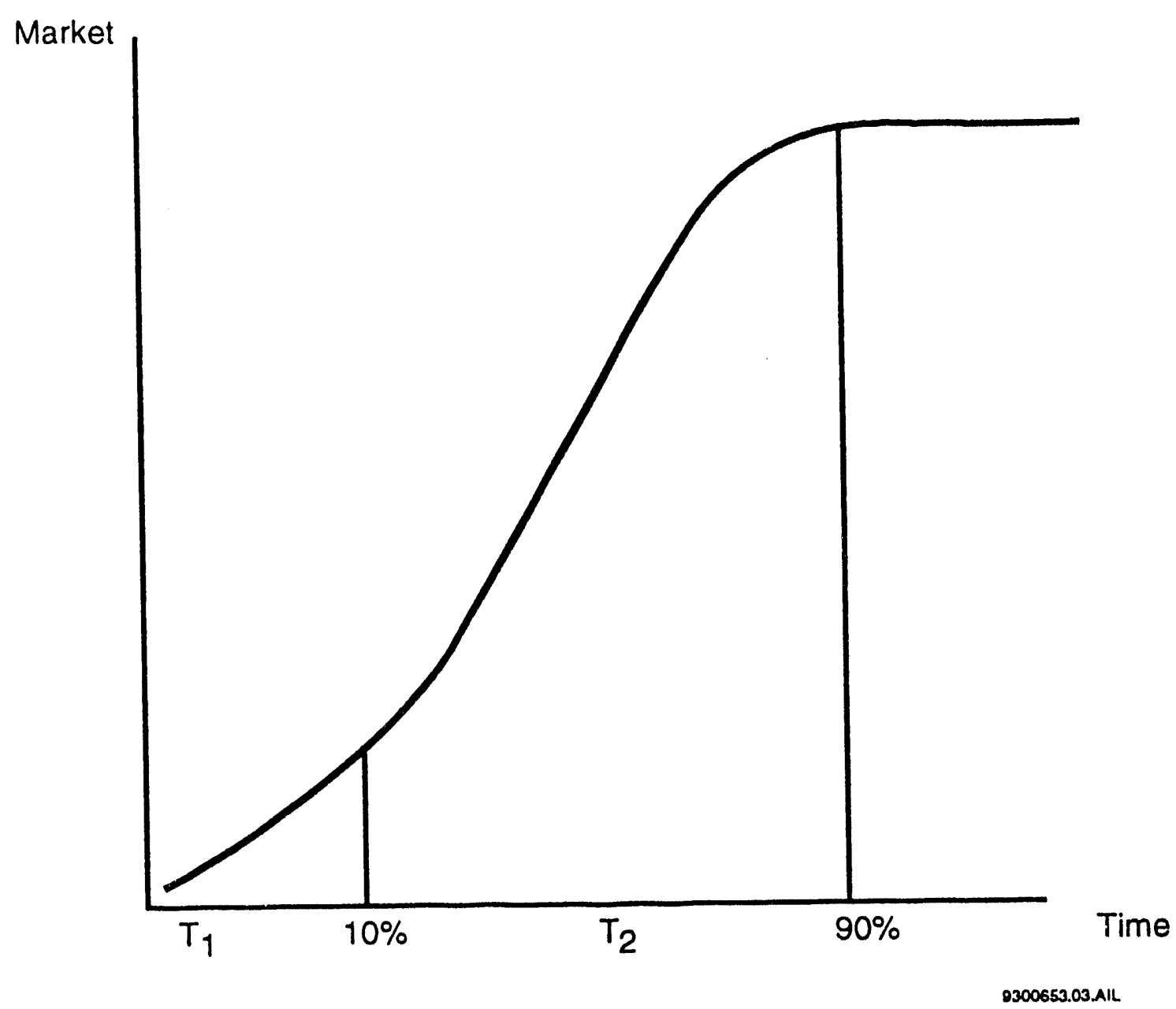

$T_{1}=T_{2}$ (takes as long to develop $10 \%$ as $\sim 80 \%$ )

- In the environmental industry, if it gets hung up in $T_{1}$ for various reasons, then other companies catch up and there is no market advantage

- Most environmental technology is more technique than technology

- Profitability declining in the environmental industry because the number of suppliers is increasing

- $\quad$ Sales + Earnings = Reality

No Sales + Earnings $=$ You Can Dream 

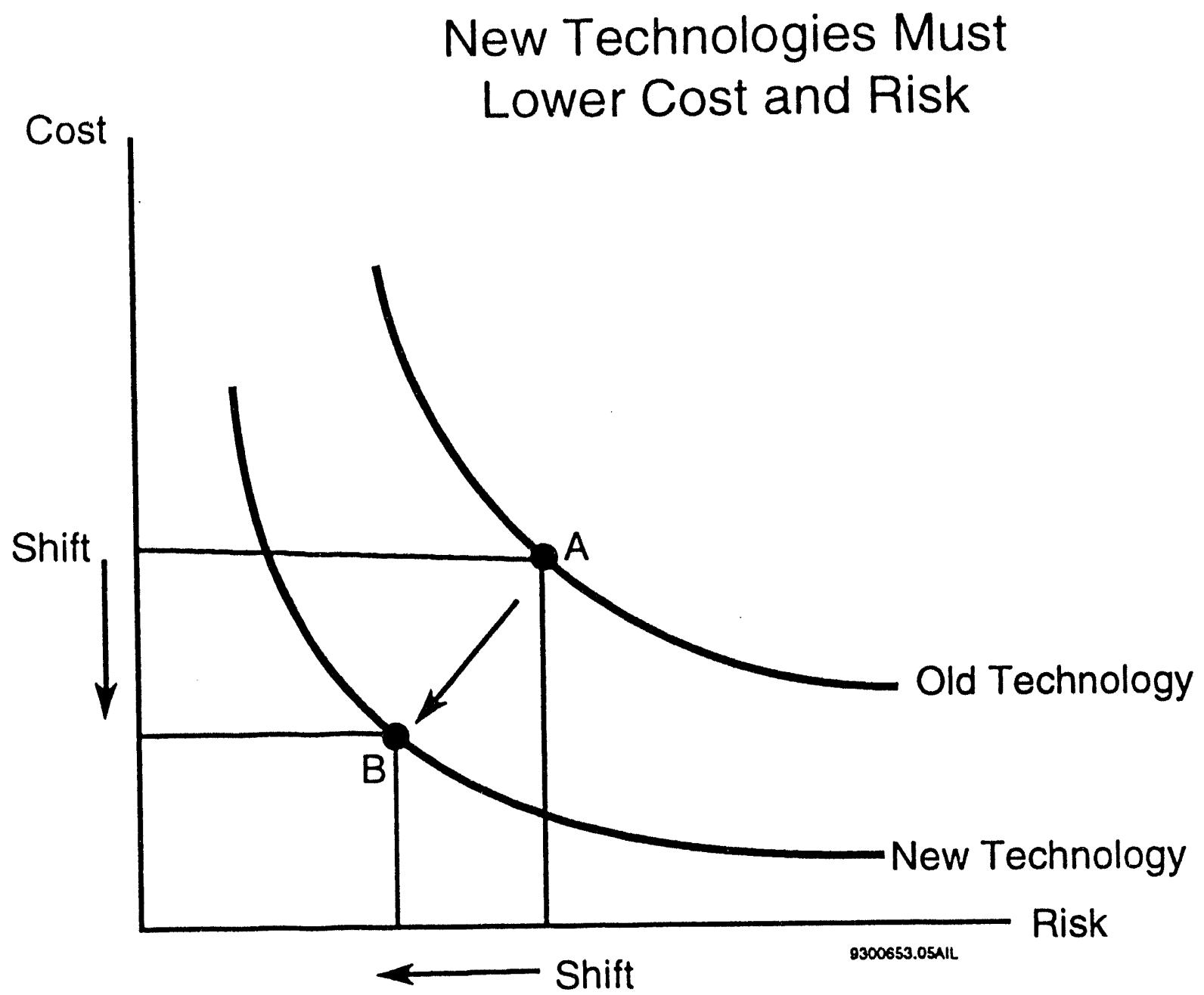

- Cost of failure on curve shift is very expensive so big companies do it internally - Only way for a company to move down risk curve was to increase costs per above curve

- Curve shift cannot be accomplished by tweaking a technology

- A look at solutions getting permitted and what is successful is especially important to small business 


$$
\overline{\underline{Y}}
$$




\section{The Opportunity}

Value/Risk

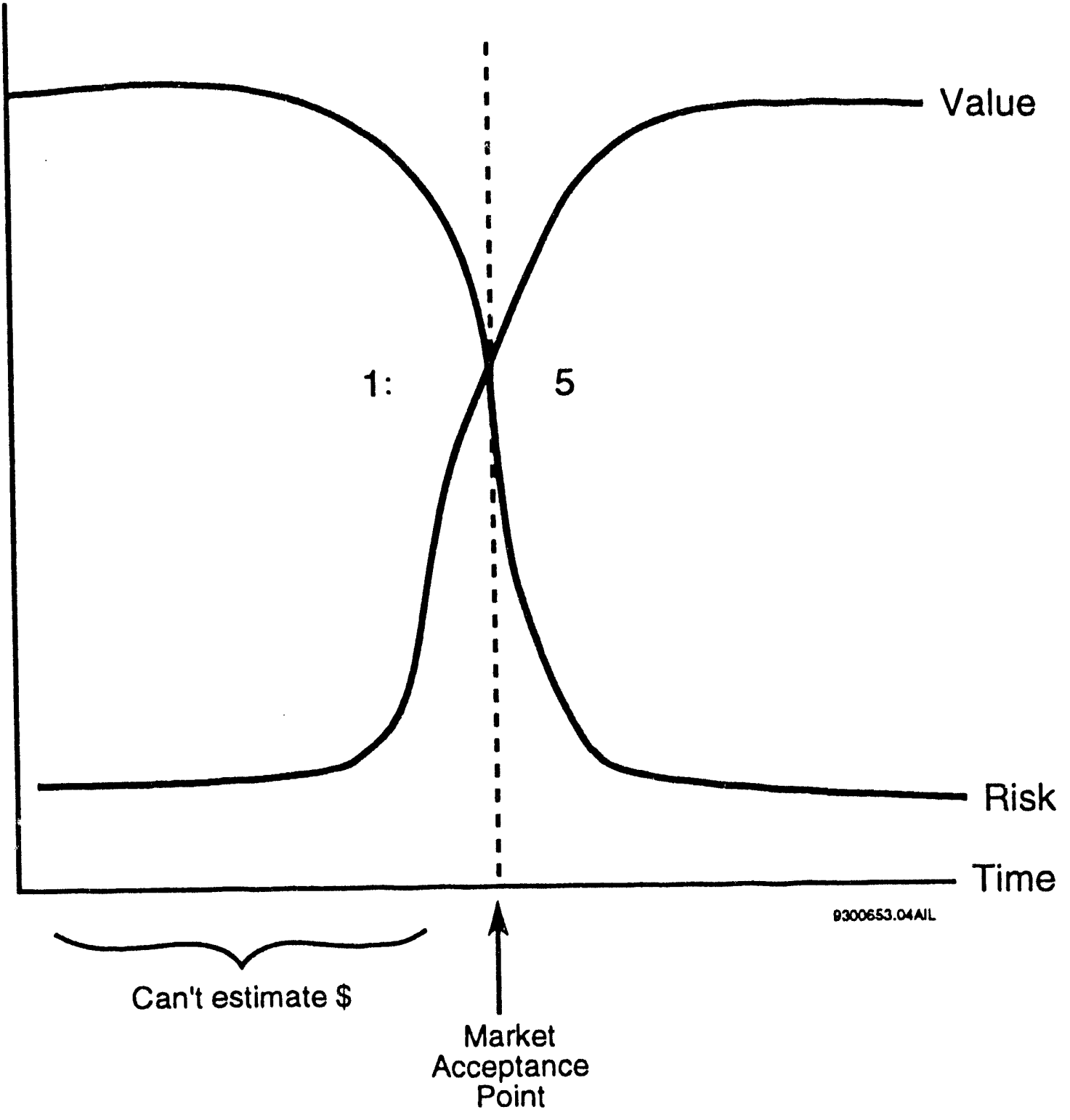

- Food and Drug Administration (FDA) (provides acceptance and others use it)

- If the risk is high, the value will be low and vice versa

- Capitalize on low valuations

- $\quad$ Lower risks; accelerate growth

- About $85 \%$ dies before reaching the market or is sold to foreign countries

- In environmental technology, if you set your standard at $90 \%$ and get $80 \%$, you lose 
APPENDIX 5

PUBLISHED EXCERPTS 
APPENDLX 5

SPEECH AND BOOK EXCERPTS

\section{The Secretary of Energy's strategic plan for DOE. "Partnerships for Gilobal Competitiveness":}

The economic imperative facing the nation requires the Department to redirect resources-particularly at its Laboratories--toward partnerships that contribute to American industrial competitiveness while maintaining a strong science and technology base.

More appropriate for today's environment is the concept of technology partnerships--which recognizes the mutuality of interest essential for success.

Technology partnerships must become integral to the way we do our business--all our business. From the earliest stages of program planning to the final steps in meeting our mission responsibilities, we must fully consider opportunities for establishing partnerships which leverage departmental resources to maximize their contributions to society.

Every dollar spent in the Department must be examined for its potential to be leveraged toward a mutual benefit with industry, academia, or other agencies.

We will increase our focus on achieving dual-use benefits from our mission-oriented work, where dual-use means accomplishing goals that serve both the public missions of the Department and commercialization interests of the private sector.

We must ensure that our technology transfer process and technology development programs are guided by market-pull, actively seeking industry involvement to provide market context at all stages of DOE programs, including the conceptual stages of new initiatives.

We must make it easier for industry to access DOE technology, resources and facilities. We need to help industry learn about the specific resources of DOE.

We must develop with industry and others integrated program plans, which will require increased collaboration.

We must optimize our technology partnership processes, streamline existing technology partnership mechanisms and create new mechanisms that are responsive, reliable, and consistent.

DOE must change its culture: this will require integration of technology partnerships into every mission of DOE, continual reinforcement of customer focus as a core value, and continual measurement of performance. 


\section{Bresident Clinton and Vice President Gore's. "Technology for America's Economic Growth. A New Direction to Build Economic Strength":}

American technology must move in a new direction to build economic strength and spur economic growth by:

- creating a business environment where technical innovation can flourish and where investment is attracted to new ideas

- forging a closer working partnership among industry, federal and state governments, workers, and universities

- ensuring the coordinated management of technology all across the government

.... with new criteria for:

- accelerating the development of technologies critical for long-term economic growth, but not receiving adequate support from private firms because the returns are too distant or the level of funding is too great for individual firms to bear.

- accelerating the development of technologies that could increase productivity while reducing the burden of economic activity on the local, regional, or global environment.

Agencies should:

--invest in and procure advanced technologies, where it is economically feasible, in order to facilitate their commercialization.

--experiment with a portion of their procurement budget to allow them to procure innovative products and services incorporating leading-edge technologies.

--evaluate bids based on their ability to minimize life-cycle costs rather than acquisition cost, including environmental, health and safety costs borne by the public.

--obtain rights in technologies developed under government contracts only to the extent necessary to meet agencies' needs, leaving contractors with the rights necessary to encourage private sector investment in the development of commercial applications.

--use performance-based contracting strategies that give contractors the design freedom and financial incentive to be innovative and efficient.

Government purchases or government-contracted development should give priority to commercial specifications and products.

Technology is the engine of economic growth."

\section{From the book, "Reinventing Government" by D.Osbourne and T.Gaebler:}

This is a condensation of methods used to leverage limited resources so that the organization is still meeting the needs of its customers, but more efficiently and effectively. It gives many enlightening examples, such as the US interstate highway system costs twice as much as French highways per mile. The French let contracts where specifications require contractors to guarantee roads for 20 years, not just awarding contracts to the lowest bidder.

The principles:

- Proactive customer involvement, continuous listening to customer/public needs.

- Results-oriented culture--look for outcome and reward that.

- Market-oriented culture--know what the customer wants.

- Decentralize the organizational structure and keep it flat and spread authority.

- Mission-driven culture vs. rules-driven culture.

- Incorporate performance measurement tools--what you count counts.

There are 10 steps to a more effective and efficient governance--

1. Steer more than you row.

2. Empower those in need; don't merely deliver services. 
3. Foster as much competition as you can; don't settle for monopolies.

4. Be driven by missions, not by rules.

5. Fund outcomes, not inputs.

6. Meet the needs of customers, not those delivering services (bureaucracy).

7. Concentrate on earning, not just spending.

8. Invest in prevention to minimize future demands not quick fixes.

9. Decentralize authority, move it as close as possible to those in need.

10. Leverage the marketplace rather than simply creating programs.

\section{Erom the book, "Searching for the Soirit of Enterprise: Dismantling the} Twentieth-Century Corporation" by L.Farrell:

Any set of statistics today will tell you that the real growth in all major economies is coming from smaller, more entrepreneurial companies.

The need for downsizing has forced entrepreneurial basics to become the no-frills version of corporate strategy and culture.

The 2 most fundamental concepts in a successful enterprise are Customer and Product, to make products that make customers happy and want more.

High-speed innovation is the entrepreneur's ultimate weapon and the freedom to act quickly.

In the current global war for competitive advantage, size and weight will no longer get you into the winner's circle. Fast-moving, customer-driven entrepreneurship will. We've got to learn to do less, not more; keep it small, personal, and simple. 
COMMERCIALIZATION MUST ATTRACT PRIVATE CAPITAL TO SUCCEED

\section{by Andrew Palerson, RIM'Tech}

NTherefore art thou Successful Commercialization? Alas, it depends on who you ask. National labs point to technical meetings with industry, CRADAs, licensing. Government contractors yearn for large scopes of work and lots of technology demonstrations. Entrepreneurial technology companies seek development contracts and eventually sales. Regulators want to see public hazards reduced, sites cleaned up. Governors and Congress push for exports, jobs. Manufacturers are moving to curtail liability, cut costs.

However, commercialization is $\mathrm{ul}$ timately measured by investment return. Private investors and industry measure commercial success by profitable bookings and repeat sales that generate a payback on investment. Investors do not fund technologies per se; they fund growth businesses with competitive products and systems that sieze market share.

Environmental deals have attracted less than $2 \%$ of the $\$ 35$ billion in venture capital invested since 1980 . Why? Capital seeks high growth and profit; so, most has been invested in computer, telecommunications, and biotechnology ventures.

Federal programs, then, play a critical role in advancing technology applications, because they have the problems and provide a primary funding source. But, only $3.4 \%$ of the $\$ 10$ billion spent each year by DOE, DOD and EPA actually winds up in innovative technology conıpanies. Most of it is absorbed by the bulky contracting establishment-and Superfund lawyers.

In a recently completed study for U.S. EPA on private investment patterns and mechanisms conducted by RIMTech and NETAC, five major barriers to private investment and conmercialization were clearly prioritized: 1) uncertain pathway to market, including procurement, 2) lack of seasoned entrepreneurial management, 3 ) inconsistent multilevel permitting, 4) perceived liability exposure, and 5) illdefined performance/cost data.

A Roundtable on Commercialization convened last Aligust by the Western Governors Assn. (WGA, Denver) with investors, industry and federal progran managers confirmed that: "Market development is more important than technology development." And, investors usually rate management alsove technology. The following niches appealed to active investors most (in order): Water treatment, Air pollution control, Alternative energy, Resource recovery, Prevention, Instrumentation... not low-profit government cleanups.

\section{SHIFT TO DUAL-USE}

Energy Secretary Hazel O'Ieary warned in Feloniary that, DOE's $\$ 6$ billion annual Environnental Management budget will be flat until taxpayers and Congress see more bang for the buck: real cleanup, more market inipact. So, federal agencies, particularly DOE and DOD, are trying to shift their environmental programs to "dual-use". Air force and naval bases scheduled for closure are dressing themselves up as testbeds: unexploded ordnance, metals, fuels and solvents in soil and groundwater. With the Cold War in remission (nuclear proliferation remains the ultimate environmental threat), the well min Defense Advanced Research Projects Agency (DARPA) is now just "ARPA."

DOE is striving to catalyze commercial applications by shifting funds to new Focus Areas: rapid characterization and contaminant plumes, mixed waste processing and storage, decomnissioning. And, there may be opportunities to leverage funding with some utilities, who face similar problems, including radioactive waste. However, labs and contractors are oriented toward fulfilling federal nuissions first, rather than being truly responsive to the commercial marketplace and investors. And the major flaw with CRADAs is that any DOE lab or university research group is accountable most to its primary paymaster: a politically-driven bureaucracy. ARPA's recent billion dollar Technology Reinvestment Program is a start in the right direction, if nore of the funding actually flows to high growth innovative companies. So was expansion last year of the SBIR grant program by Congress.

A number of environmental technology companies made successful public stock offerings in 1993-Molten M/ctal. Ensys, Catalyuca, Purus. This is im. portant, just as Apple Computer and Genentech started the technology company investment boom in the 1980s. But not enough have achieved profitable sales yet that would attract more capital into the industry.

New mechanisms: DOE and DOD demo funding should focus on products and systems. When a demo is technically successful, cost-effective, and competitive, then a performance contract should be executed. Too many federal agencies, the EPA-SITE program and DOD testbeds just kick up dust with no pathway to paydirt-real sales. No revenues, no commercialization.

Regional initiatives, such as "DOIT" with the WGA, as well as the interstate waste management programs spearheaded by the Southern States Energy Board (SSEB, Atlanta), could augment commercialization substantially by implementing regulatory streamlining: e.g., technology certification and tiered permitting such as recently announced by California EPA, common performance data formats, and then interstate permitting reciprocity. With stakeholders on board, these measures-more than "demo mania" - will help foster larger markets to attract investment, and can be linked to federal contracts, industryled consortia or utility deregulation.

Federal CRADAs can be directed instead by the industry partners to drive development toward the marketplace. All CRADAs should sunset or spinoff after 2-3 years; half should wind down on a rolling basis to ensure that only the most narket-driven thrive.

Engineering firms in turn can be incentivised to employ innovative technologies via performance contract provisions, and by allowing them to use small business set-asides to boost their award fee, such as in ERMCs and TERCs (more risk, more reward). Liability can be capped for demos, also, like in the EPA-SITE program.

Federal spending comprises the largest pool of funds for environmental technology, but it is not very productively invested, nor leveraged with private capital. In fact, no equity investment can be made in a national lab. Investors are attracted instead to profitable growth companies with a well-defined customer base. There shall thee find successful commercialization.

Andrew Palerson is President of RIMTech (Pasndena, Calif.), which develops publicl private investment partnerships in lechnology commercinlization. 

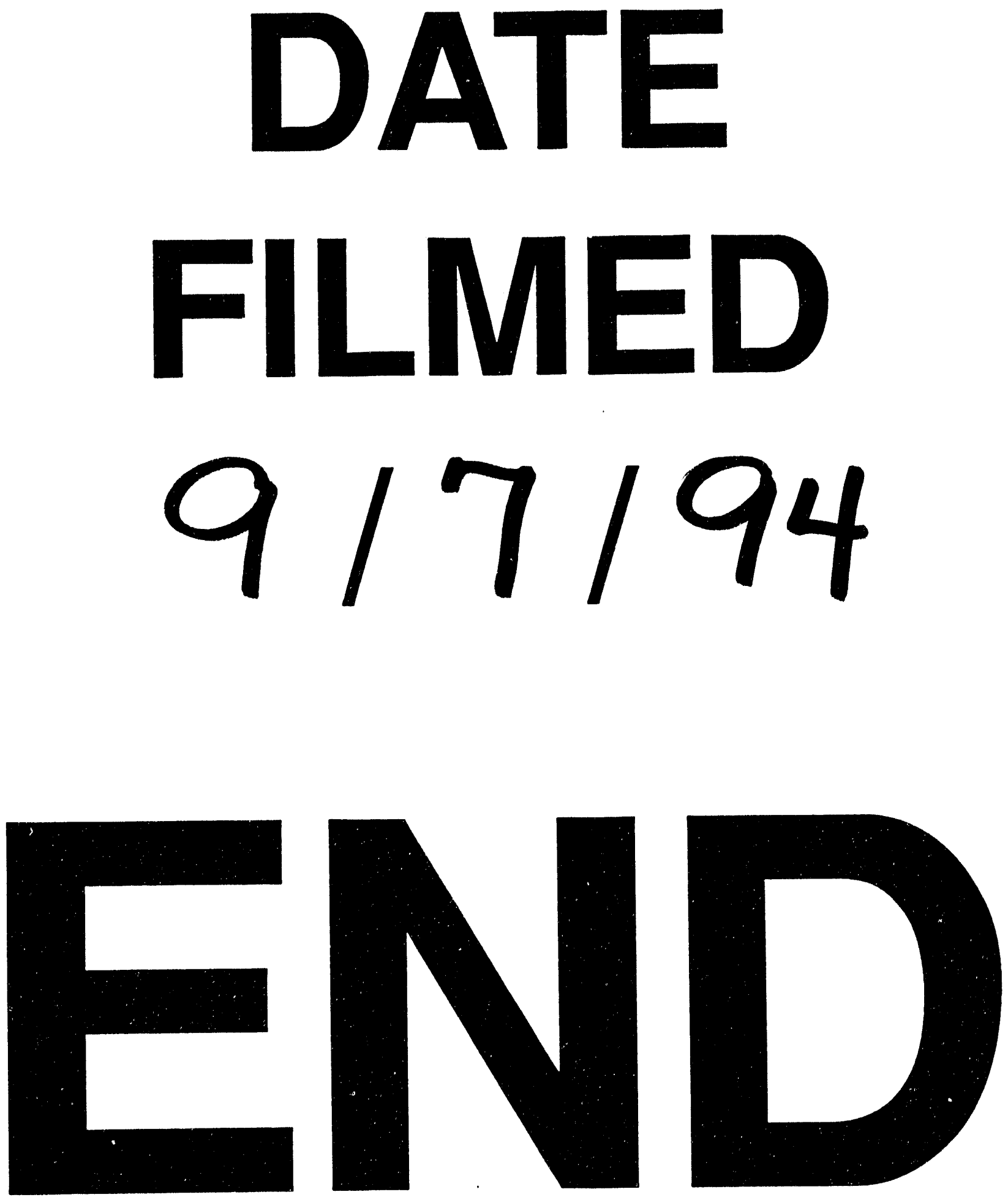


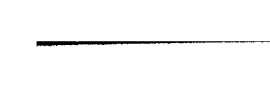

